UNIVERSIDADE DE SÃO PAULO

ESCOLA DE ENGENHARIA DE SÃO CARLOS

BRENO PADOVEZI ROCHA

\title{
EMPREGO DO ENSAIO SPT SÍSMICO NA INVESTIGAÇÃO DE SOLOS TROPICAIS
}

São Carlos

2013 


\author{
UNIVERSIDADE DE SÃO PAULO \\ ESCOLA DE ENGENHARIA DE SÃO CARLOS \\ PROGRAMA DE PÓS-GRADUAÇÃO EM GEOTECNIA
}

\title{
EMPREGO DO ENSAIO SPT SÍSMICO NA INVESTIGAÇÃO DE SOLOS TROPICAIS
}

\author{
BRENO PADOVEZI ROCHA
}

Dissertação apresentada à Escola de Engenharia de São Carlos, da Universidade de São Paulo, como parte dos requisitos para obtenção do título de Mestre em Ciências, Programa de Pós Graduação em Geotecnia.

Versão Corrigida

Original se encontra disponível na Unidade que aloja o Programa

ORIENTADOR: PROF. DR. HERALDO LUIZ GIACHETI

São Carlos-SP

2013 
AUTORIZO A REPRODUÇÃO TOTAL OU PARCIAL DESTE TRABALHO, POR QUALQUER MEIO CONVENCIONAL OU ELETRÔNICO, PARA FINS DE ESTUDO E PESQUISA, DESDE QUE CITADA A FONTE.

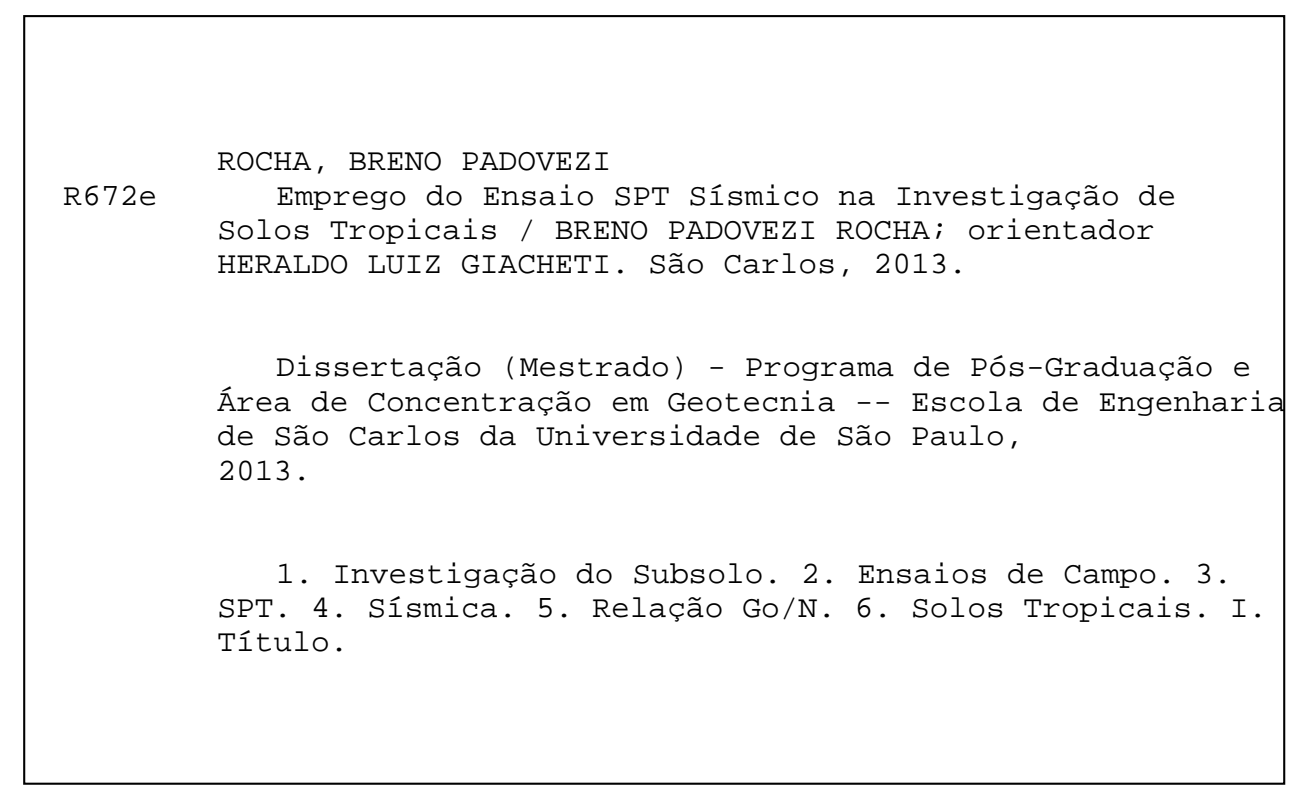



A Mariana, pelo amor e apoio. Aos meus pais, Maderly e José e ao meu irmão Rodrigo. 
Primeiramente a Deus. Sem ele nada é ou será possível.

Ao apoio incondicional de meus familiares, minha mãe Maderly, meu pai José, meu irmão Rodrigo e minha namorada Mariana.

Ao Professor Heraldo Luiz Giacheti, orientador e amigo. Pelo auxílio no trabalho, desde o início.

Aos Professores Paulo José Rocha de Albuquerque e David de Carvalho da Universidade Estadual de Campinas, pela colaboração na campanha de ensaios realizados no campo experimental da Faculdade de Engenharia Agrícola (FEAGRI).

Aos técnicos Sergio e Gustavo da UNESP de Bauru, pelo auxílio na realização dos ensaios e esclarecimento de dúvidas sobre a operação dos equipamentos.

Aos Professores e Funcionários do Departamento de Geotecnia da EESC-USP.

Aos meus colegas de mestrado: Liz Abreu, Felipe Loch, Vanessa Almeida, Gian Napa, Bruno Canoza, Bianca Munhoz, Loana Sanchez, pela ótima convivência.

A CAPES pela concessão da bolsa de estudos. 


\section{RESUMO}

ROCHA, B. R. Emprego do Ensaio SPT Sísmico na Investigação de Solos Tropicais. 116 p. Dissertação de Mestrado. Escola de Engenharia de São Carlos, Universidade de São Paulo, São Carlos, 2013.

O principal objetivo deste trabalho é avaliar a aplicação da técnica híbrida de SPT Sísmico (SSPT), ou seja, a realização da sísmica up-hole em conjunto com a sondagem de simples reconhecimento com medida de SPT, para uma melhor caracterização de solos tropicais. O ensaio híbrido mais empregado para determinação de parâmetros dos solos, inclusive o módulo de cisalhamento máximo $\left(G_{o}\right)$ é o de cone sísmico (SCPT). No entanto, sua realização exige equipamentos especiais e de custo elevado. A possibilidade de medir a velocidade de propagação da onda $\mathrm{S}\left(\mathrm{V}_{\mathrm{S}}\right)$ em conjunto com o ensaio SPT empregando o a técnica up-hole é uma alternativa interessante. Essa técnica combinada, pouco empregada no Brasil, foi recentemente desenvolvida e testada. Neste trabalho, a determinação ao mesmo tempo e no mesmo furo dos valores de $\mathrm{N}$ do SPT e velocidade de onda S (Vs) permitiu calcular o módulo de cisalhamento máximo $\left(\mathrm{G}_{\mathrm{o}}\right)$ e avaliar as vantagens de se obter a relação $\mathrm{G}_{\mathrm{o}} / N$, similar a relação entre $G o / q_{c}$, para investigação de solos tropicais colapsíveis. As áreas de estudo são os campos experimentais da UNESP-Bauru, USP-São Carlos e UNICAMP-Campinas, onde ensaios S-SPT foram realizados. Os resultados desses ensaios foram comparados com valores de $\mathrm{V}_{\mathrm{S}}$ referência, determinados através de ensaios sísmicos cross-hole, down-hole e SCPT. A diferença entre os valores de $\mathrm{V}_{\mathrm{S}}$ foram, em média, 8,5, 9,0\% e 16,0\% respectivamente para os campos experimentais da UNESP-Bauru, USP-São Carlos e UNICAMP-Campinas. Considera-se que a técnica híbrida do S-SPT pode ser empregada para obter o perfil de $\mathrm{G}_{\mathrm{o}}$, em conjunto com o ensaio SPT, rapidamente e a um custo relativamente baixo. Constatou-se que a relação $G_{\delta} / N$ é maior na camada de solo laterítico, e que ela diminui quanto menos evoluído é o perfil do subsolo. Observou-se essa a mesma tendência nos ensaios S-SPT, porém com menor nitidez. Este fato pode estar associado a maior dificuldade de interpretar os registros de ondas sísmicas pela técnica up-hole bem como pela variabilidade do perfil dos subsolos.

Palavras-chave: Investigação do subsolo, Ensaios de campo, SPT, Sísmica, Relação Go/N, solos tropicais. 
ROCHA, B. R. The Use of Seismic SPT Test for Site Investigation of Tropical Soils. 116 p. Master Dissertation. School of Engineering at São Carlos, University of São Paulo, São Carlos, 2013.

The main objective of this work is to assess the applicability of the hybrid test, the Seismic SPT (S-SPT), i.e. the up-hole seismic test carried out together with SPT test, in order to achieve a better site characterization of tropical soils. The most used hybrid test to determine the soil parameters, including the maximum shear modulus $\left(\mathrm{G}_{\mathrm{o}}\right)$, is the seismic cone test (SCPT). The possibility of measuring the $\mathrm{S}$ wave velocity together with the SPT test using the up-hole technique is an interesting alternative. This combined technique was scarcely used in Brazil and it has been recently developed and tested. In this work, the concomitant measuring of the SPT N value together with the $S$ wave velocity in the same test allowed calculating the maximum shear modulus $\left(\mathrm{G}_{\mathrm{o}}\right)$ and assessing the advantages of obtaining the $G_{o} / N$ ratio, similar to the $G_{o} / q_{c}$ ratio, for the site characterization of tropical collapsible soils. The research areas are the experimental sites of UNESP-Bauru, USP-São Carlos and UNICAMPCampinas, where SPT tests were carried out. The results of these tests were compared with reference values $\mathrm{V}_{\mathrm{S}}$, which were determined via cross-hole, down-hole and SCPT tests. The differences between $\mathrm{V}_{\mathrm{S}}$ values were, in average, 8.5\%, 9.0\% and $16.0 \%$ respectively for UNESP-Bauru, USP-São Carlos and Campinas-UNICAMP research sites. The hybrid S-SPT test can be used to define the $\mathrm{G}_{\mathrm{o}}$ profile, together with the N SPT values, with a relatively low cost. It was found that the $G_{o} / N$ ratio is higher in the lateritic soil layer and it gets lower as the soil profile is less developed. The same tendency was observed with the S-SPT tests, however with less distinctness. This fact can be associated to a higher difficulty on the interpretation of seismic wave traces with the up-hole technique as well as to soil variability.

Keywords: Site investigation, In situ test, SPT, Seismic, $G_{o} / N$ Ratio, Tropical soils. 


\section{LISTA DE FIGURAS}

Figura 1: Desenho esquemático do ensaio SPT 10

Figura 2: Esquema do ensaio sísmico cross-hole 13

Figura 3: Registro típico de um ensaio cross-hole 14

Figura 4: Esquema do ensaio sísmico down-hole (a); Determinação do tempo de chegada da onda $S(b)$ 15

Figura 5: Esquema do ensaio sísmico up-hole 15

Figura 6: Curva típica tensão versus deformação de um material sólido 16

Figura 7: Ondas de corpo: (a) onda P, (b) onda S 17

Figura 8: Ondas de corpo: (c) onda R, (d) onda L 18

Figura 9: Direção de propagação da onda (refletido e refratado) 18

Figura 10: Carregamento de compressão 20

Figura 11: Problemas dinâmicos e seus respectivos níveis de deformação

Figura 12: Curva de degradação.

Figura 13: Relação entre o módulo de cisalhamento máximo e a resistência de ponta, considerando as variações da tensão efetiva. 25

Figura 14: Métodos de geração das ondas de deformação. (a) Impacto vertical, (b) Explosivos, (c) Impacto horizontal, e (d) Ondas de superfície. ...........................................26

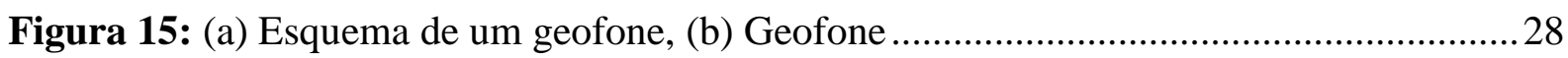

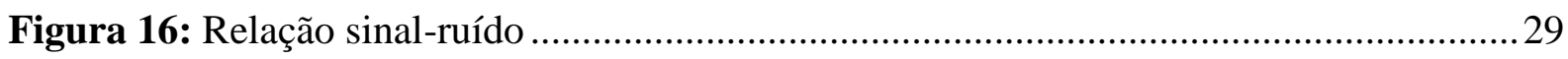

Figura 17: desenho esquemático da realização do ensaio SCPTU...................................... 31

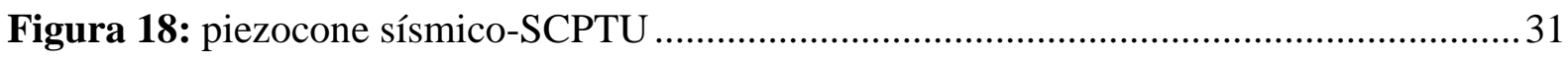


Figura 19: Esquema do método S-SPT.

Figura 20:(a)-Movimentação das partículas no solo gerada pela penetração do amostrador;(b)-Modelo numérico para análise de movimento das partículas. 33

Figura 21: Forma de propagação de ondas 33

Figura 22: Determinação do valor $\mathrm{V}_{\mathrm{S}}$ pelo método DTR 34

Figura 23: Determinação do valor $V_{S}$ na primeira e segunda camada pelo método convencional

Figura 24: Tela do programa de análise dos sinais. 39

Figura 25: Tela inicial do programa de aquisição de dados 40

Figura 26: Caixa para acondicionamento do equipamento de aquisição de dados e seus conectores.

Figura 27: Síntese da metodologia de execução desenvolvida 41

Figura 28: Síntese da metodologia de análise desenvolvida 42

Figura 29: Posição dos ensaios sísmicos realizados no campo experimental da UNESP-Bauru

Figura 30: Perfil típico de solos tropicais 45

Figura 31: Comparação entre valores de $\mathrm{G}_{\mathrm{o}}$ obtidos por coluna ressonante e cross-hole ...... 46

Figura 32: Comparação dos valores de $G_{o}$ medidos versus $G_{0}$ calculado

Figura 33: Relação $G_{o}$ (condição úmida) e Go (condição seca) versus o grau de saturação para uma areia em diferentes tensões de confinamento

Figura 34: Relação $\mathrm{G}_{\mathrm{o}}$ versus grau de saturação para um solo arenoso laterítico de Bauru... 48

Figura 35: Relação entre $G_{o}$ e $q_{c}$ para os solos de São Carlos, Bauru e Campinas no ábaco de Robertson et. al. (1995). 50 
Figura 36: Relação entre $G_{o}$ e $q_{c}$ para os solos de São Carlos, Bauru e Campinas segundo Schnaid, Fahey e Lehane, (2004) 50

Figura 37: Correlação entre $\mathrm{G}_{0}$ e $\mathrm{N}_{60}$ para solos residuais 51

Figura 38: Esquema do ensaio S-SPT (a); sistema de aquisição dos sinais (b). 53

Figura 39: Equipamentos utilizados nos ensaios SPT 54

Figura 40: Caixas e geofones utilizados na sísmica up-hole. 55

Figura 41: Barra de aço utilizado para aterramento do sistema de aquisição 56

Figura 42: Ativação do trigger e geração de ondas no ensaio S-SPT 56

Figura 43: Tela inicial do programa de aquisição e visualização dos sinais sísmicos 57

Figura 44: Programa de análise dos sinais e algumas das funções do programa. 58

Figura 45: Aplicação do filtro passa-baixo ou selecionar parte do sinal a ser analisado 59

Figura 46: Salvando e adicionado os sinais sísmicos 60

Figura 47: Parâmetros para plotagem dos perfis de onda 61

Figura 48: Escolha da onda a ser plotada 61

Figura 49: Procedimento para determinação do tempo de chegada das ondas $S$ 62

Figura 50: Preenchimento do tempo de chegada das ondas $\mathrm{S}$. 62

Figura 51: Exportação dos sinais para o aplicativo do Microsoft Excel 63

Figura 52: Módulo de cálculo de velocidades. 64

Figura 53: Perfis típicos e resultados de sondagens SPT realizados nos campos experimentais de (a) Bauru, (b) Campinas e (c) São Carlos 67

Figura 54: Ensaios sísmicos SCPT e Cross-hole executados no campo experimental da UNESP, Bauru 69 
Figura 55: Ensaios sísmicos SCPT e Cross-hole executados no campo experimental da EESC/USP, São Carlos

Figura 56: Ensaios sísmicos SCPT e Cross-hole executados no campo experimental da UNICAMP, Campinas

Figura 57: Comparação dos resultados dos ensaios S-SPT, SCPT e ponteira sísmica 76

Figura 58: Ensaio SPT, ensaios sísmicos e relação $\mathrm{G}_{0} / \mathrm{N}_{60}$ para o campo experimental da UNESP, Bauru

Figura 59: Relação entre $G_{0}$ e $N_{60}$ (ensaios anteriores) para o campo experimental da UNESP, Bauru 78

Figura 60: Resultados do ensaio S-SPT3 e a razão $G_{0} / N_{60}$ para o campo experimental da UNESP, Bauru 79

Figura 61: Relação entre $\mathrm{G}_{0}$ e $\mathrm{N}_{60}$ (ensaio S-SPT) para o campo experimental da UNESP, Bauru 80

Figura 62: Posição dos ensaios sísmicos realizados no campo experimental EESC/USP, em São Carlos/SP

Figura 63: Registros dos geofones horizontais a 10m (a), a $12 \mathrm{~m}$ (b) do furo de sondagem para o campo experimental da EESC-USP, São Carlos.

Figura 64: Espectros de frequências em diferentes profundidades do ensaio realizado no campo experimental da EESC/USP, São Carlos

Figura 65: Resultados obtidos pelo ensaio S-SPT1 realizado no campo experimental da EESC/USP, São Carlos

Figura 66: Ensaios SPT, sísmicos e relação $\mathrm{G}_{0} / \mathrm{N}_{60}$ para o campo experimental da EESC/USP, São Carlos 85

Figura 67: Relação entre $G_{0}$ e $N_{60}$ (ensaios anteriores) para o campo experimental da EESC/USP, São Carlos 
Figura 68: Resultados do ensaio S-SPT1 e a razão $G_{0} / N_{60}$ para o campo experimental da EESC/USP, São Carlos

Figura 69: Relação entre $\mathrm{G}_{\mathrm{o}}$ e $\mathrm{N}_{60}$ (ensaio S-SPT) para o campo experimental da EESC/USP, São Carlos

Figura 70: Posição dos ensaios sísmicos realizados no campo experimental da Unicamp, em Campinas 88

Figura 71: Registros obtidos pelo geofone horizontal a 10m (a), registro obtido pelo geofone horizontal a $12 \mathrm{~m}$ (b) do furo de sondagem

Figura 72: Espectros de frequências em diferentes profundidades do ensaio realizado no campo experimental da UNICAMP, Campinas

Figura 73: Resultados do ensaio S-SPT1 realizado no campo experimental da UNICAMP, Campinas 90

Figura 74: Resultados de ensaios SPT, sísmicos e relação $\mathrm{G}_{0} / \mathrm{N}_{60}$ do campo experimental da UNICAMP, Campinas 91

Figura 75: Relação entre $\mathrm{G}_{\mathrm{o}}$ e $\mathrm{N}_{60}$ (ensaios anteriores) para o campo experimental da UNICAMP, Campinas 92

Figura 76: Resultados do ensaio S-SPT1 e a razão $\mathrm{G}_{0} / \mathrm{N}_{60}$ para o campo experimental da UNICAMP, Campinas 93

Figura 77: Relação entre $\mathrm{G}_{\mathrm{o}}$ e $\mathrm{N}_{60}$ (ensaio S-SPT) para o campo experimental da UNICAMP, Campinas 94 


\section{LISTA DE TABELAS}

Tabela 1: Classificação dos solos (NBR 7250, 1982; NBR 6484, 2001) ............................... 11

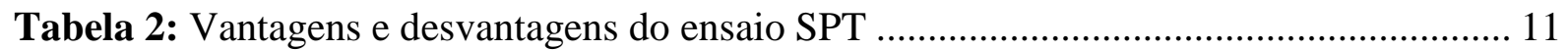

Tabela 3: Coeficiente k em função do IP do solo (GIACHETI, 1991)................................. 23

Tabela 4: Correlações entre N (SPT) e Vs (adaptado Hanumantharao e Ramana, 2008) ...... 24

Tabela 5: Requisitos técnicos e operacionais de uma fonte sísmica (Reynolds, 1997).......... 27

Tabela 6: Principais ensaios híbridos e parâmetros obtidos (Mayne, 2000)........................... 30 



\section{SUMÁRIO}

1. INTRODUÇÃO

1.1. Objetivos _ 6

1.2. Organização e Distribuição dos Assuntos _ـ 6

2. REVISÃO BIBLIOGRÁFICA _ 9

2.1. Sondagem de Simples Reconhecimento (SPT) _ 9

2.2. Ensaios Geofísicos

2.2.1. Considerações Iniciais ___ 11

2.2.2. Ensaios Sísmicos _ 12

2.2.2.1. Sísmica em Furo de Sondagem __ 12

2.3. Propagação das Ondas no Solo

2.3.1. Meio Elástico __ 15

2.3.2. Tipos de Onda __ 16

2.3.3. Lei de Snell _ـ 18

2.4. Parâmetros Geotécnicos a partir de Ensaios Geofísicos___ 19

2.4.1. Módulo de Elasticidade (E) __ 19

2.4.2. Coeficiente de Poisson (v) 20

2.4.3. Módulo de Cisalhamento Máximo $\left(\mathrm{G}_{\mathrm{o}}\right) \_21$

2.4.3.1. Estimativa de $\mathrm{G}_{\mathrm{o}}$ através de Correlações ___ 23

2.4.3.2. Estimativa de $\mathrm{G}_{\mathrm{o}}$ a partir de Ensaios SPT __ 24

2.4.3.3. Estimativa de $\mathrm{G}_{\mathrm{o}}$ a partir de Ensaios de Cone Sísmicos __ 25

2.5. Aquisição e Processamento de Dados Sísmicos _ 26

2.5.1. Fontes Sísmicas _ـ 26

2.5.2. Transdutores Sísmicos __ 27

2.5.3. Aplicação de Filtros _ 28

2.6. Ensaios Híbridos 29

2.6.1. Considerações Iniciais ___ 29

2.6.2. Piezocone Sísmico (SCPTU) ___ 29

2.7. Ensaio SPT com Sísmica Up-Hole (S-SPT) _ 31

2.7.1. Avaliações e determinação do perfil de $\mathrm{V}_{\mathrm{S}}$ 
2.8. Desenvolvimento do sistema para realização do ensaio S-SPT 38

2.8.1. Verificação e Validação do Equipamento Desenvolvido 42

2.9. Parâmetros Dinâmicos em Solos Tropicais 43

2.9.1. Solos Tropicais 43

2.9.1.1. Solos Lateríticos 44

2.9.1.2. Solos Saprolíticos 44

2.9.2. Módulo de Cisalhamento Máximo $\left(\mathrm{G}_{\mathrm{o}}\right)$ de Solos Tropicais 45

2.9.3. Cone Sísmico e a Relação $\mathrm{G}_{\mathrm{o}} / \mathrm{q}_{\mathrm{c}}$ na Investigação de Solos Tropicais 48

3. MATERIAIS E METÓDOS 53

3.1. Ensaio S-SPT 53

3.1.1. Sondagem de Simples Reconhecimento com medida de SPT 53

3.1.2. Geofones e aterramento 54

3.1.3. Fonte Sísmica e trigger 55

3.1.4. Programas Computacionais 57

3.1.4.1. Programa de aquisição 57

3.1.4.2. Programa de processamento e análise dos sinais 58

3.1.4.2.1. Modulo para cálculo da velocidade de onda S 63

4. ÁREAS EXPERIMENTAIS 67

4.1. Considerações iniciais 67

4.1.1. Campo Experimental da UNESP - Bauru 68

4.1.1.1. Aspectos Geológicos 68

4.1.1.2. Ensaios Sísmicos 68

4.1.2. Campo Experimental da EESC-USP-São Carlos 70

4.1.2.1. Aspectos Geológicos 70

4.1.2.2. Ensaios Sísmicos 70

4.1.3. Campo Experimental da UNICAMP - Campinas 72

4.1.3.1. Aspectos Geológicos 72

4.1.3.2. Ensaios Sísmicos 72

5. RESULTADOS E ANÁLISE 75

5.1. Campo Experimental da FEB/UNESP, Bauru 75

5.1.1. Determinação do perfil de velocidades de onda $S$ pelo ensaio S-SPT 75

5.1.2. Relação $\mathrm{G}_{0} / \mathrm{N}_{60}$ através de ensaios sísmicos e SPT anteriormente realizados. _ 76 
5.1.3. Razão $\mathrm{G}_{0} / \mathrm{N}_{60}$ através do ensaio S-SPT

5.2. Campo Experimental da EESC/USP, São Carlos 80

5.2.1. Determinação do perfil de velocidades de onda $S$ pelo ensaio S-SPT 80

5.2.2. Relação $\mathrm{G}_{0} / \mathrm{N}_{60}$ através de ensaios sísmicos e SPT anteriormente realizados 84

5.2.3. Relação $\mathrm{G}_{0} / \mathrm{N}_{60}$ através do ensaio S-SPT 86

5.3. Campo Experimental da UNICAMP, Campinas 87

5.3.1. Determinação do perfil de velocidades de onda S pelo ensaio S-SPT 87

5.3.2. Relação $\mathrm{G}_{0} / \mathrm{N}_{60}$ através de ensaios sísmicos e SPT anteriormente realizados 91

5.3.3. Relação $\mathrm{G}_{0} / \mathrm{N}_{60}$ através do ensaio $\mathrm{S}-\mathrm{SPT}$ 92

6. CONCLUSÃO E SUGESTÕES PARA CONTINUIDADe 95

6.1. Ensaio S-SPT 95

6.2. Relação $G_{0} / N_{60}$ 95

6.3. Sugestões para continuidade da pesquisa 96 97 


\section{INTRODUÇÃO}

O comportamento dos solos tropicais ultimamente tem chamado atenção da comunidade geotécnica. Nestes solos, a ação do intemperismo químico integrado as condições climáticas, leva a formação de depósitos não saturados. Tais solos, em função de seu processo de formação, apresentam ganho de resistência devido à cimentação das partículas e ao efeito da sucção. No território brasileiro, em sua grande maioria, os solos possuem tal comportamento, logo, uma grande quantidade de obras está assentada sobre eles, sendo necessário conhecer seu comportamento.

Para previsão adequada do comportamento de solos tropicais a primeira etapa é a investigação do subsolo. Nela deve-se determinar o perfil estratigráfico, a posição do lençol freático e os parâmetros mecânicos necessários ao projeto. No Brasil e na maioria dos países do mundo, o ensaio geotécnico mais utilizado para determinação de parâmetros e perfil estratigráfico é a sondagem de simples reconhecimento (SPT). No entanto este ensaio fornece um único índice para determinação de vários outros parâmetros, fato este questionado por Mayne (2000). Em função disso, nas últimas duas décadas foram desenvolvidos ensaios que permitem a determinação de mais parâmetros numa mesma técnica, denominados de ensaios híbridos. São exemplos desses ensaios: o SPT-T ( $\mathrm{N}_{\mathrm{SPT}}$ e a medida de torque), SCPTU (piezocone com medida de propagação de ondas), entre outros. O S-SPT, SPT com sísmica up-hole é, portanto, mais um desses ensaios, pois permite determinar as velocidades de propagação de ondas no solo $\left(\mathrm{V}_{\mathrm{S}} \mathrm{e} \mathrm{V}_{\mathrm{P}}\right)$ em conjunto com o $\mathrm{N}_{\mathrm{SPT}}$.

Alguns autores, como Bang e Kim (2007) tem mostrado que é possível incorporar a medida da velocidade de ondas S a partir do golpe de um ensaio SPT empregando o a técnica up-hole, recurso antigo, que foi recentemente desenvolvido e aplicado por Pedrini (2012). No ensaio S-SPT as ondas S são geradas pelo golpe de um martelo de mão na cabeça de bater do ensaio SPT. Apresenta por isso, uma grande vantagem em relação ao SCPT (mais barato) e ao ensaio cross-hole (menos trabalhoso).

Schnaid, Consoli e Averbeck (1998) sugerem a utilização de ensaios com cone sísmico para avaliação do tipo de solo a partir da relação entre $G_{o} / q_{c}$. Segundo Giacheti (1999) a utilização de um parâmetro de rigidez $\left(G_{o}\right)$ relacionado a um parâmetro de resistência $\left(q_{c}\right)$ ou o índice de resistência do SPT $\left(\mathrm{N}_{\mathrm{SPT}}\right)$ pode vir a ser mais apropriada para o 
entendimento do comportamento do solo, contribuindo assim, para um desenvolvimento mais racional da engenharia de fundações em solos tropicais.

A possibilidade de se medir, ao mesmo tempo e no mesmo furo os valores de $\mathrm{N}$ do SPT e velocidade de onda $S\left(V_{S}\right)$, que permite calcular o módulo de cisalhamento máximo $\left(\mathrm{G}_{\mathrm{o}}\right)$, abre uma nova perspectiva para investigação de solos tropicais colapsíveis, a partir da relação $\mathrm{G}_{\mathrm{o}} / \mathrm{N}_{\mathrm{SPT}}$, similar a relação entre $G_{o} / q_{c}$.

\subsection{Objetivos}

O principal objetivo dessa pesquisa é avaliar a aplicação do ensaio híbrido S-SPT, que incorpora a geofísica a sondagem de simples reconhecimento, com medida do SPT, visando uma melhorar caracterização de perfis de solos tropicais. Os objetivos específicos são:

- Dar continuidade as pesquisas que vem sendo realizadas para uma melhor caracterização de solos tropicais, a partir da integração de ensaios geofísicos (sísmica up-hole) e ensaios geotécnicos de campo (sondagem SPT), especialmente em solos colapsíveis;

- Avaliar o desempenho de um sistema (hardware e software) para realização de sondagens SPT em conjunto com a medida de velocidade de ondas sísmicas pela técnica up-hole, recentemente desenvolvido por Pedrini (2012), para simplificar a determinação do módulo de cisalhamento máximo $\left(\mathrm{G}_{\mathrm{o}}\right)$;

- Estudar as vantagens do uso integrado de ensaios sísmicos e de penetração na caracterização de solos tropicais e como tais informações podem ser utilizadas para auxiliar na previsão do comportamento geomecânico de solos tropicais, a partir da relação $\mathrm{G}_{\mathrm{o}} / \mathrm{N}$.

\subsection{Organização e Distribuição dos Assuntos}

Esta dissertação está desenvolvida em seis capítulos, sendo o primeiro, "Introdução", que destaca a importância da pesquisa e seu objetivo; o segundo, "Revisão Bibliográfica", que aborda uma síntese dos trabalhos utilizados e consultados sobre o assunto; o terceiro, 
"Materiais e Métodos, que trata dos equipamentos e procedimentos utilizados para execução dos ensaios e interpretação dos dados; o quarto, Áreas Experimentais", que faz uma breve descrição de cada área e apresenta resultados de ensaios geotécnicos e sísmicos anteriormente realizados; o quinto, "Resultados e Análise" que apresenta os resultados obtidos com o sistema desenvolvido por Pedrini (2012) e da relação $\mathrm{G}_{0} / \mathrm{N}_{60}$ para solos tropicais; e o sexta, “Conclusão e Sugestões”, que apresenta as conclusões e sugestões para continuidade desta pesquisa. 


\section{REVISÃO BIBLIOGRÁFICA}

\subsection{Sondagem de Simples Reconhecimento (SPT)}

A sondagem de simples reconhecimento (com medida do SPT) é o ensaio mais utilizado na investigação geotécnica no Brasil. O ensaio permite a identificação da consistência de solos granulares, sendo também aplicado na identificação de solos coesivos e até em algumas rochas brandas. O ensaio SPT fornece um valor correspondente ao número de Golpes necessários para cravar no solo um amostrador-padrão, de diâmetro externo de $50 \mathrm{~mm}$ (SCHNAID, 2000).

O ensaio inicia pela perfuração de um furo de sondagem, sendo que esta perfuração é realizada através da utilização de trado helicoidal, ou circulação de água (VELLOSO; LOPES, 1996).

Através da sondagem obtém-se:

- Níveis d'água ou a posição do lençol freático, se existir água;

- Tipo de solo em função de retirada de amostras deformadas;

- Resistência $\left(\mathrm{N}_{\mathrm{SPT}}\right)$ oferecida pelo solo, em função da cravação do amostrador-padrão;

O ensaio foi inicialmente normalizado pela ASTM em 1958, sendo posteriormente padronizado por diversos países. Na América do Sul é utilizada a normalização norteamericana ASTM D 1.586-67. Já o Brasil apresenta norma própria, a ABNT NBR 6484, cuja última revisão foi realizada no ano de 2001. Entretanto, mesmo havendo inúmeras normas do ensaio, os procedimentos para sua realização são variáveis, chegando a casos de duas sondagens realizadas por empresas diferentes no mesmo furo de sondagens apresentam valores diferentes de resistência (SCHNAID, 2000).

A NBR 6484 (2001) trouxe inovações quanto às especificações relativas aos equipamentos, processos de perfuração, métodos de observação do nível do lençol freático e observações sobre a apresentação formal dos resultados. Além disso, permite classificar as camadas de solos em função dos valores de $\mathrm{N}_{\text {SPT }}$ e prevê a utilização de dois tipos de martelo: o cilíndrico vazado e o prismático dotado de pino-guia (NEVES, 2004).

O ensaio pode ser realizado com perfuração revestida ou não. A perfuração do solo é realizada com trado ou lavagem de água, sendo com um furo de aproximadamente $55 \mathrm{~cm}$ de 
diâmetro. Após a perfuração o amostrador-padrão é colocado no furo de escavação, e assim inicia-se o ensaio. $\mathrm{O}$ ensaio consiste na queda de um martelo de $65 \mathrm{Kg}$, de uma altura de 75 cm. Conta-se o número de golpes necessários para se cravar $15 \mathrm{~cm}$ dos $45 \mathrm{~cm}$ restantes, sendo o valor de $\mathrm{N}$, o número correspondente aos últimos $30 \mathrm{~cm}$ (SCHNAID, 2000). Na Figura 1 encontra-se um desenho esquemático de um ensaio SPT.

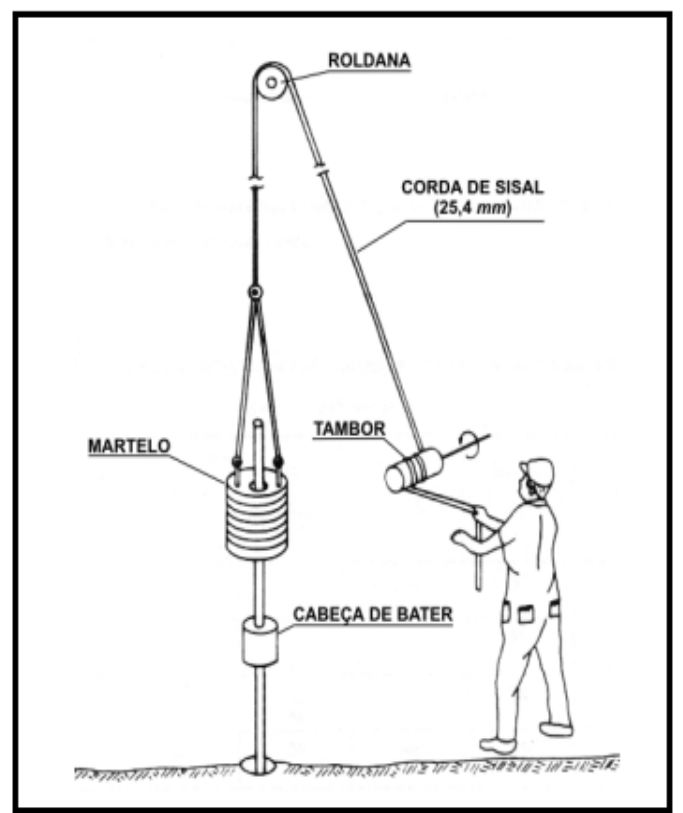

Figura 1: Desenho esquemático do ensaio SPT Fonte: Belincanta (1998)

Durante o ensaio, anotam-se as profundidades das transições das camadas detectadas por análise táctil-visual e da mudança de coloração dos materiais trazidos à boca do furo através do trado ou pela água de lavagem (ABNT/NBR 6484, 2001). A classificação das camadas de solo é realizada em função do índice de resistência à penetração $\left(\mathrm{N}_{\mathrm{SPT}}\right)$, tipo de solo, consistência ou compacidade (Tabela 1), cor, origem e pela presença ou não de materiais diversos na amostra.

A ABNT NBR 6484 (2001) também informa um critério de encerramento do ensaio:

- Quando, em $3 \mathrm{~m}$ sucessivos, se obter 30 golpes para penetração dos $15 \mathrm{~cm}$ iniciais do amostrador padrão.

- Quando, em $4 \mathrm{~m}$ sucessivos, se obter 50 golpes para penetração dos $30 \mathrm{~cm}$ iniciais do amostrador padrão.

- Quando, em $5 m$ sucessivos, se obter 50 golpes para penetração dos $45 \mathrm{~cm}$ iniciais do amostrador padrão. 
Tabela 1: Classificação dos solos (NBR 7250, 1982; NBR 6484, 2001)

\begin{tabular}{ccc}
\hline Solo & $\begin{array}{c}\text { Índice de resistência à } \\
\text { penetração }\left(\boldsymbol{N}_{\boldsymbol{S P T}}\right)\end{array}$ & Designação \\
\hline \multirow{2}{*}{ Areia e silte arenoso } & $\leq 4$ & Fofa (o) \\
& 5 a 8 & Pouco compacta (o) \\
& 9 a 18 & Mediamente compacta (0) \\
& 19 a 40 & Compacta (o) \\
Argila e silte argiloso & $>40$ & Muito compacta (o) \\
\hline & 3 a 5 & Muito mole \\
& 6 a 10 & Mole \\
& 11 a 19 & Média (o) \\
& $>19$ & Rija (o) \\
\end{tabular}

Na Tabela 2 é apresentada uma síntese das vantagens e desvantagens encontradas na literatura (SCHNAID, 2000 e Cavalcante, 2002, entre outros) na utilização do SPT como ferramenta de investigação geotécnica e ambiental.

Tabela 2: Vantagens e desvantagens do ensaio SPT

\begin{tabular}{cc}
\hline Vantagens & Desvantagens \\
\hline Simplicidade e rapidez na execução; & Diversos procedimentos de execução; \\
Coleta de amostras deformadas para caracterização; & $\begin{array}{c}\text { Grande número de empresas executoras, } \\
\text { Baixo custo financeiro; }\end{array}$ \\
$\begin{array}{c}\text { Informações suficientes para projetos de fundação } \\
\text { de obras correntes; }\end{array}$ & $\begin{array}{c}\text { não realizar a manutenção necessária no } \\
\text { equipamento utilizado; }\end{array}$ \\
$\begin{array}{c}\text { Permite a determinação direta do nível d'água do } \\
\text { subsolo; }\end{array}$ & $\begin{array}{c}\text { Análise e controle da energia transferida ao } \\
\text { amostrador padrão durante a execução do ensaio; }\end{array}$ \\
$\begin{array}{c}\text { Mundialmente utilizado, em função de muita } \\
\text { experiência acumulada no meio técnico e da ampla } \\
\text { utilização em correlações; }\end{array}$ & $\begin{array}{c}\text { Formação precária das equipes ocasionando vícios } \\
\text { na execução; }\end{array}$ \\
\hline
\end{tabular}

\subsection{Ensaios Geofísicos}

\subsubsection{Considerações Iniciais}

Os ensaios geofísicos são caracterizados como métodos não invasivos ou não destrutivos, devido ao fato de serem técnicas indiretas de investigação de alvos em subsuperfície através da aquisição e interpretação de dados instrumentais (CETESB, 1999).

Os ensaios geofísicos apresentam a possibilidade de avaliar as condições geológicas locais através dos contrastes das propriedades físicas dos materiais de subsuperfície, como por exemplo, a condutividade ou resistividade elétrica, magnetismo, permissividade dielétrica, 
sendo essas condições geológicas originadas por diferenciações litológicas e outras heterogeneidades naturais ou não (CETESB, 1999).

As técnicas geofísicas apresentam algumas vantagens em relação às técnicas convencionais de investigação. As principais vantagens são: rapidez na avaliação a baixo custo de grandes áreas além de fornecer perfis contínuos, que possibilitam uma identificação das variações laterais do maciço de solo, em função das mudanças litológicas, e da ocorrência ou não de contaminantes (MONDELLI, 2004).

Existe uma variedade de métodos geofísicos de superfície entre eles, destacam-se: o Geo-radar (GPR), os Eletromagnéticos (Indutivo - EM e Domínio do Tempo-TDEM), a Eletrorresistividade (ER), a Magnetometria, os Sísmicos (reflexão e refração), o Potencial Espontâneo (SP) e a Polarização Induzida (IP) (CETESB, 1999).

\subsubsection{Ensaios Sísmicos}

Os ensaios sísmicos utilizam a velocidade de propagação de ondas elásticas através do meio investigado. Existem inúmeras técnicas sísmicas, entre elas: sísmica de refração, de reflexão, sísmica em furos de sondagens, SASW, piezocone sísmico, sendo esse último uma técnica muito utilizada atualmente. Estes ensaios buscam avaliar parâmetros dinâmicos do solo, sendo que cada ensaio apresenta vantagens e desvantagens.

\subsubsection{Sísmica em Furo de Sondagem}

Os ensaios sísmicos em furos de sondagem possibilitam a determinação das velocidades das ondas de compressão $(\mathrm{P})$ e cisalhante $(\mathrm{S})$ e assim o cálculo dos parâmetros dinâmicos dos solos. Tais ensaios são denominados cross-hole, down-hole e up-hole, sendo função da posição das fontes no furo. Os ensaios em furos de sondagem são ensaios não destrutivos, apresentam rápida execução e abrangem grandes volumes do maciço de solo em análise (GIACHETI et. al, 2006a).

O ensaio cross-hole, normalizado pela ASTM (D 2845/ D 4428M), é considerado um dos mais eficazes para determinação dos parâmetros dinâmicos dos solos e consiste na colocação de uma fonte mecânica geradora de ondas elásticas num furo e no mínimo dois geofones em outros dois furos alinhados com o primeiro, todos no mesmo nível (Figura 2). A 
fonte mecânica gera ondas de compressão $(\mathrm{P})$ e cisalhantes $(\mathrm{S})$, e os geofones captam o momento da chegada das ondas. Com os registros obtidos nos ensaios, determinam-se os tempos de chegada das ondas e assim calculam-se as velocidades de propagação. Através das velocidades $\left(V_{P}\right.$ e $\left.V_{S}\right)$ e da massa específica do solo $(\rho)$ determinam os parâmetros dinâmicos do solo, entre eles os módulos de Young $(\mathrm{E})$, cisalhamento máximo $\left(\mathrm{G}_{\mathrm{o}}\right)$ e o coeficiente de Poisson dinâmico $(\boldsymbol{v})$, abordados anteriormente.

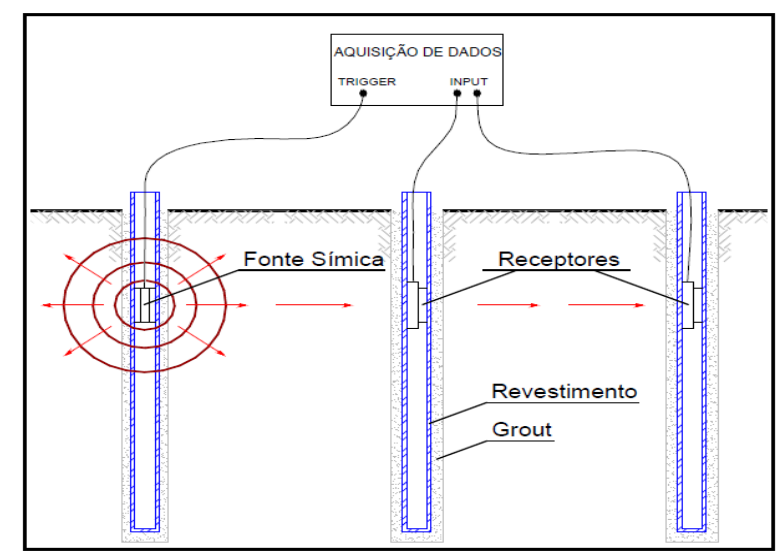

Figura 2: Esquema do ensaio sísmico cross-hole Fonte: Scheffer (2005)

Para realização do ensaio, é necessária uma preparação dos furos. A forma mais adequada consiste em revestir os furos de sondagem com tubos de PVC ou metálicos. Em relação aos equipamentos utilizados, são utilizados um sismógrafo, uma fonte sísmica e transdutores sísmicos. Através do ensaio e possível determinar diretamente a velocidade da onda em um ponto específico do maciço, porém apresenta como desvantagem o elevado custo, em função da preparação dos furos (GIACHETI et. al., 2006a).

Para determinação dos diferentes tipos de ondas são utilizados dois recursos. Para as ondas $\mathrm{P}$ é utilizado o recurso da soma dos sinais, já para a onda $\mathrm{S}$ é utilizado o recurso da inversão de polaridade, sabendo-se que a onda $\mathrm{P}$ é caracterizada sempre pela primeira deflexão do sinal e a onda $S$ é caracterizada pelo aumento na amplitude do sinal e também pelo fato da polarização, que corresponde ao fato de que se invertendo o sentido do golpe no ensaio de campo, todas as fases correspondentes às ondas cisalhantes aparecem de forma invertida. A Figura 3 apresenta a chegada das ondas $\mathrm{S}$ e $\mathrm{P}$ num típico ensaio cross-hole (GIACHETI, 2001). 


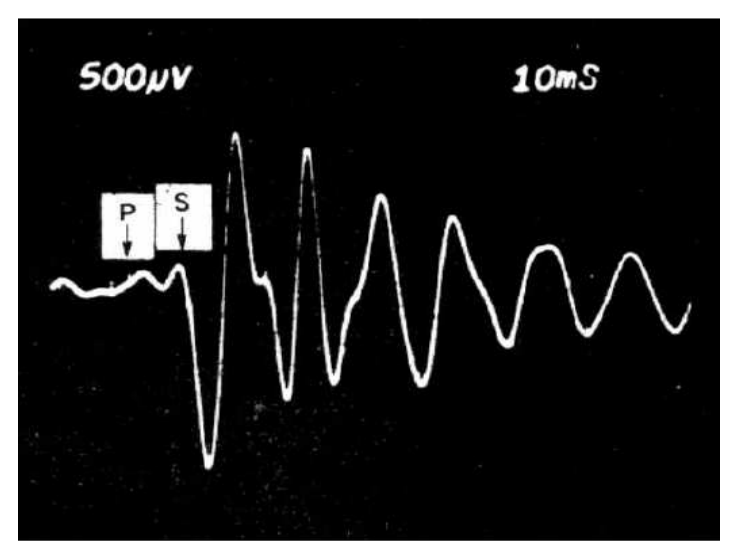

Figura 3: Registro típico de um ensaio cross-hole Fonte: Dourado (1984)

Para determinação da velocidade de propagação das ondas é utilizado à equação 1 , caracterizada pela relação entre o comprimento de trajeto da onda $(\Delta X)$ pelo tempo de propagação da onda $(\Delta \mathrm{T})$, sendo as distâncias determinadas pelas posições dos furos. Para se obter valores mais precisos das velocidades, é necessário um controle na medida das distâncias. Em função disso, é necessário utilizar inclinômetros para se ter uma medida mais precisa do trajeto percorrido pela onda (PEDRINI, 2012).

$$
V_{s} \text { ou } V_{p}=\frac{\Delta X}{\Delta T}
$$

$\mathrm{O}$ ensaio down-hole apresenta a vantagem de se usar apenas um furo de sondagem para medição das velocidades de ondas. Para realização do ensaio é utilizado um geofone ou um acelerômetro. Neste caso a fonte geradora encontra-se na superfície do terreno e os geofones dentro do furo de sondagem (Figura 4a). Além da vantagem da utilização de apenas um furo, o ensaio down-hole pode ser empregado juntamente com outros ensaios geotécnicos, tais como o CPT (ensaio de penetração do cone) e o DMT (dilatômetro de marchetti), originando os ensaios híbridos (união de duas ou mais técnicas de ensaio) SCPT e SDMT, respectivamente (GIAGHETI et. al., 2006a). Este ensaio é iniciado a partir do momento em que ocorre o golpe, e a fonte envia o sinal ao sismógrafo que inicia o registro das ondas captadas pelos geofones.

Segundo Robertson (1986) para determinação do tempo de chegada das ondas S, recomenda-se obter quatro registros de onda para cada profundidade, sendo dois golpes de cada lado da fonte, realizando assim o recurso de inversão de polaridade e consequentemente a superposição dos registros. Tal procedimento é ilustrado na Figura 4b (GIACHETI, 2001). 

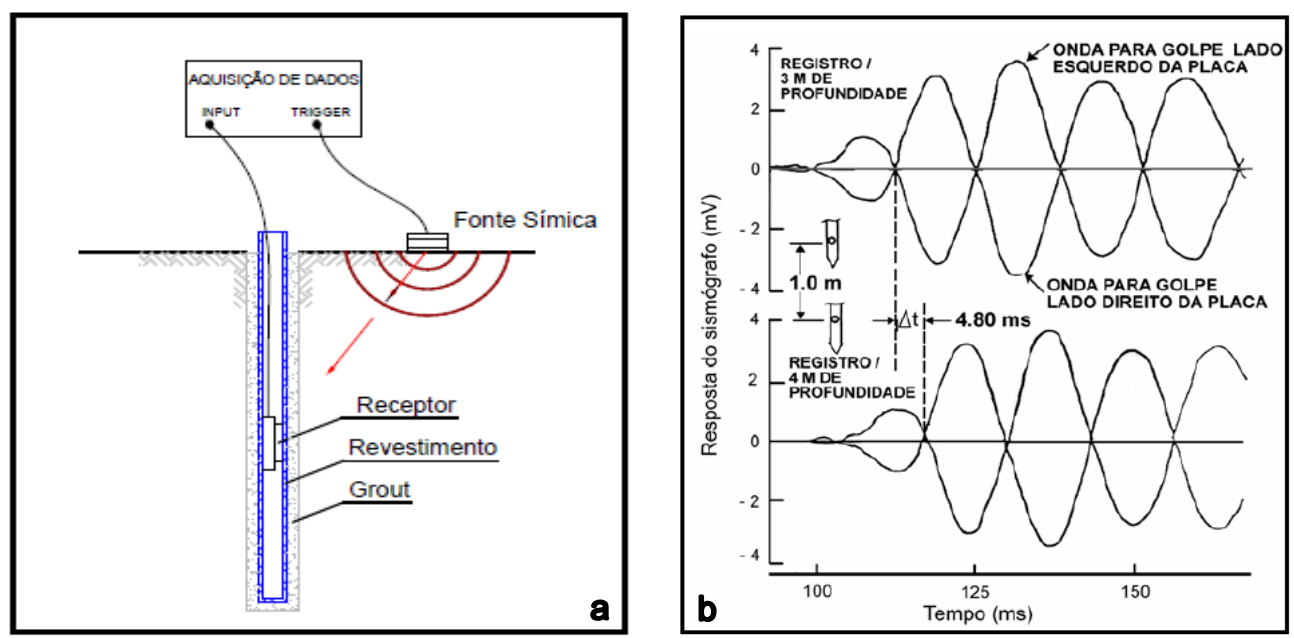

Figura 4: Esquema do ensaio sísmico down-hole (a); Determinação do tempo de chegada da onda $\mathrm{S}$ (b)

Fonte: Scheffer (2005)

$\mathrm{O}$ ensaio sísmico up-hole, semelhante ao ensaio down-hole, necessita de apenas um furo de sondagem. Nesse caso a fonte geradora de ondas encontra-se dentro do furo e o receptor na superfície do terreno, o oposto do que ocorre no ensaio down-hole, conforme demonstrado na Figura 5. O ensaio up-hole apresenta a dificuldade de gerar o tipo de onda desejado, em função da posição da fonte dentro do furo de sondagem, impossibilitando o direcionamento do golpe para geração das ondas (GIACHETI et. al., 2006a).

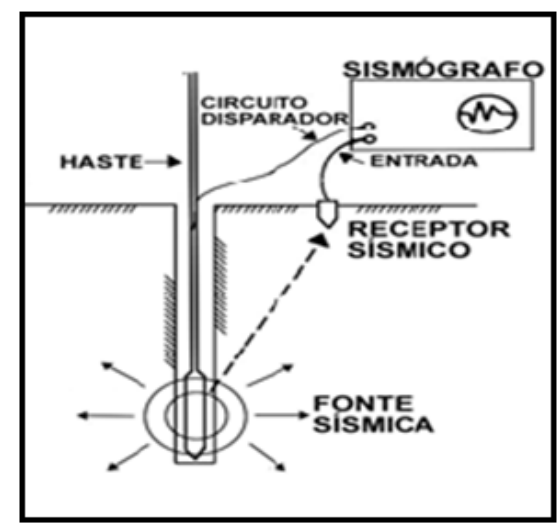

Figura 5: Esquema do ensaio sísmico up-hole Fonte: Giacheti et. al (2006a)

\subsection{Propagação das Ondas no Solo}

\subsubsection{Meio Elástico}


No estudo da propagação de ondas, é necessário se ter o conhecimento sobre o meio elástico e como ele se comporta em relação aos deslocamentos e os esforços gerados por tais ondas. Para tal análise, inicialmente é necessário conhecer algumas observações sobre a Lei de Hooke e definir alguns parâmetros que representam o comportamento dinâmico do solo.

Conforme Kearey (2009), qualquer material submetido a uma tensão (esforço/área) sofre uma variação de volume ou de forma, conhecida como deformação. Esta deformação apresenta um limite máximo, conhecido como limite elástico. Se o esforço aplicado gerar uma deformação até este limite, a deformação apresenta uma proporcionalidade com o esforço aplicado. O limite elástico apresenta a característica de que com a retirada do esforço, o material voltará às condições iniciais (deformação nula), sendo o trabalho no regime elástico do material.

No momento em que o material for submetido a um esforço acima do limite elástico, ocorrerá deformações permanentes ao material, causando a plastificação do mesmo, sendo denominado de campo dúctil. Neste campo o material passa do regime elástico para o regime plástico. Com o aumento do esforço aplicado, as deformações serão irrecuperáveis (irreversíveis) até o momento em que o material romperia.

A curva típica da relação esforço (tensão) versus deformação para qualquer material sólido é apresentado na Figura 6, caracterizando o campo elástico, campo dúctil e tensão máxima, esta última em relação à ruptura do material.

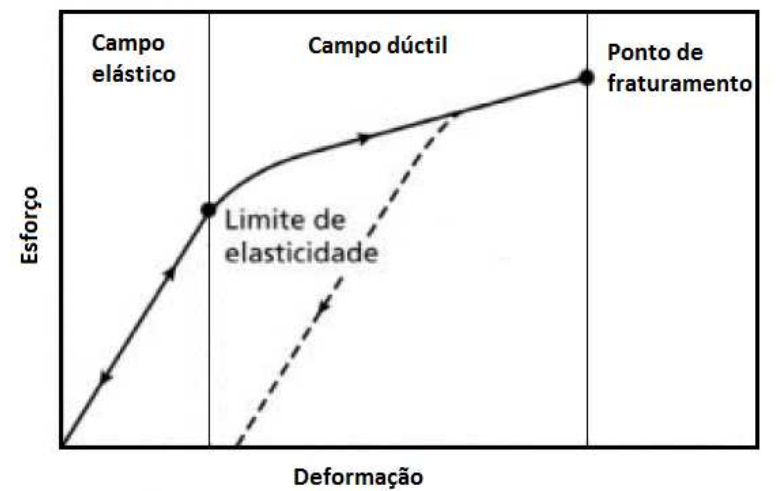

Figura 6: Curva típica tensão versus deformação de um material sólido Fonte: adaptado Kearey (2009)

\subsubsection{Tipos de Onda}

Uma perturbação gerada dentro ou na superfície do terreno é transmitida a Terra através de ondas sísmicas. Essas ondas dependem das propriedades elásticas do meio que irão 
transpor. As ondas sísmicas são divididas em dois grupos: as que se propagam pelo meio sólido da Terra (ondas internas) e as que se propagam pela crosta terrestre (ondas de superfície) (ROBERTSON, M., 1986).

Segundo Robertson, M. (1986) as ondas internas são divididas em:

- Ondas de compressão $(\mathrm{P})$, denominadas também de primárias ou longitudinais;

- Ondas de cisalhamento (S), denominadas também de transversal ou secundária;

As ondas P propagam-se por deformação uniaxial, apresentando movimentos rotativos de expansão e compressão no meio, na direção de propagação da onda. As ondas S propagamse através de um cisalhamento puro, em direção perpendicular à direção de propagação da onda, gerando esforços cisalhantes no meio sólido. Tais ondas são ilustradas na Figura 7.

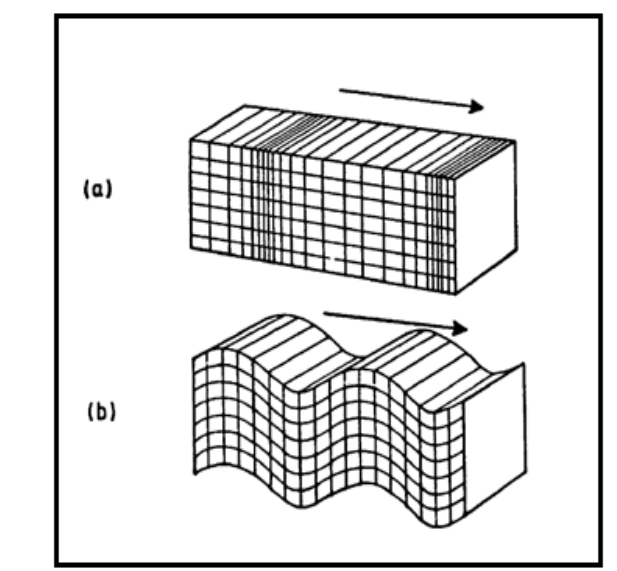

Figura 7: Ondas de corpo: (a) onda P, (b) onda S

Fonte: Robertson, M. (1986)

A principal diferença entre as ondas $\mathrm{P}$ e $\mathrm{S}$ é que as ondas $\mathrm{P}$ apresentam variação de volume sem a rotação das partículas do meio, já as ondas $\mathrm{S}$ apresentam rotação das partículas, mas sem alterar seu volume (ROBERTSON, M., 1986).

As ondas de superfície são divididas em:

- Ondas Rayleigh ou ondas R;

- $\quad$ Ondas Love ou ondas L;

As ondas $\mathrm{R}$ são caracterizadas por vibrar as partículas num plano que aponta na direção de propagação da onda em movimento elíptico horizontal e vertical simultaneamente, sendo seu movimento semelhante às ondas na superfície da água. As ondas L são caracterizadas pela vibração da partícula no sentido perpendicular à trajetória da onda, gerando um efeito cisalhante no meio sólido, similar às ondas $\mathrm{S}$, entretanto, no sentido horizontal. As ondas R e L são apresentadas na Figura 8 (ROBERTSON, M., 1986). 


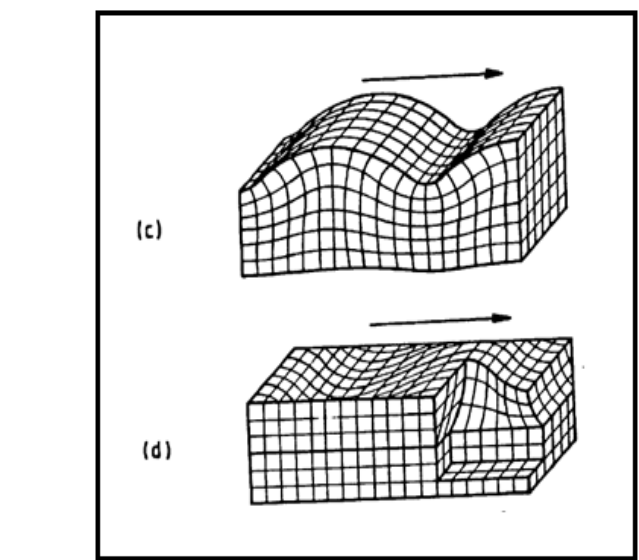

Figura 8: Ondas de corpo: (c) onda R, (d) onda L

Fonte: Robertson, M. (1986)

\subsubsection{Lei de Snell}

Os métodos sísmicos utilizam a premissa de que as ondas elásticas (ondas sísmicas) viajam com diferentes velocidades em diferentes tipos de materiais. A partir de um ensaio sísmico, determinando-se os tempos de chegada das ondas em diferentes pontos, é possível determinar uma distribuição de velocidade, e consequentemente, caracterizar interfaces onde as ondas são refletidas ou refratadas (SHARMA, 1997). Salienta-se que o comportamento de reflexão e refração das ondas sísmicas, se baseia no mesmo princípio da geometria óptica.

As ondas geradas pelas fontes sísmicas em superfície percorrem o caminho obliquamente da camada superior para a camada inferior, sofrendo mudança na direção de propagação. Esta mudança esta relacionada com refração da onda, fato que ocorre quando a onda passa de uma camada para outra, onde as velocidades de propagação nas camadas sejam diferentes (índice de refração relativo, $\eta$ ). A Figura 9 mostra a direção de propagação da onda na interface de duas camadas distintas, sendo neste caso, a velocidade da camada superior menor que a da camada inferior (KEAREY, 2009).

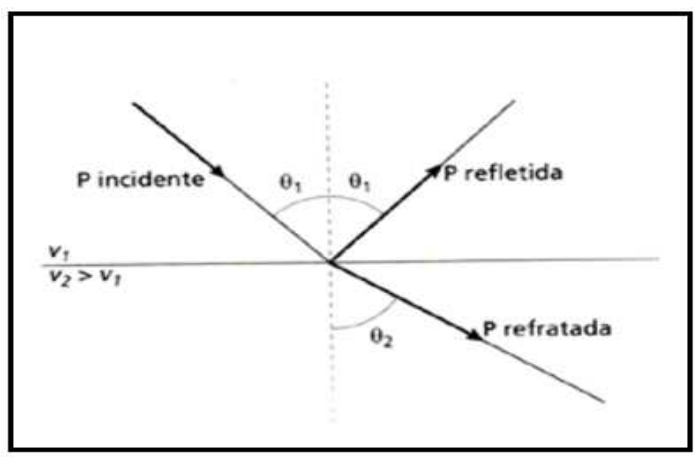

Figura 9: Direção de propagação da onda (refletido e refratado)

Fonte: Kearey (2009) 
A refração e reflexão das ondas sísmicas podem ser analisadas pelo princípio da geometria óptica. Deste modo, a Lei de Snell (Snell's Law of Refraction) é igualmente aplicável à sísmica (KEAREY, 2009).

A Lei de Snell se resume no desvio angular sofrido por um raio de luz ao passar para um meio com índice de refração diferente do qual ele estava percorrendo. A lei é caracterizada pelo parâmetro do raio $\mathrm{p}=\operatorname{sen} \theta / v$, sendo $\operatorname{sen} \theta$ o seno do ângulo de incidência do raio e v a velocidade de propagação desse raio. A lei é regida pela equação 2 apresentada a seguir (KEAREY, 2009).

$\frac{\sin \theta_{1}}{V_{1}}=\frac{\sin \theta_{2}}{V_{2}}$

A aplicação da Lei de Snell é muito importante no ensaio híbrido S-SPT, pois os receptores (geofones) se encontram longe do furo de sondagem, existindo uma diferença considerável entre o raio reto e o refratado, que deve ser considerado no cálculo das velocidades de onda (BANG;KIM, 2007).

\subsection{Parâmetros Geotécnicos a partir de Ensaios Geofísicos}

Existe uma enorme variedade de ensaios de laboratório e de campo para analisar o comportamento de solos submetidos a esforços (BARROS, 1997). A seguir, serão apresentados os principais parâmetros geotécnicos determinados a partir de ensaios geofísicos.

\subsubsection{Módulo de Elasticidade (E)}

No momento em que um corpo material é submetido a uma força normal de compressão, o corpo se deforma através de um encurtamento, na direção do esforço, mostrado na Figura 10. Ao dividir o encurtamento pelo comprimento inicial, temos a denominada deformação $(\varepsilon)$ que é proporcional à tensão $(\sigma)$, gerada pela aplicação da força, atuando na seção transversal do corpo material, portanto, o módulo de elasticidade é caracterizado pela 
relação entre uma tensão longitudinal (força/área) pela deformação longitudinal $(\Delta \mathrm{l} / \mathrm{l})$, conforme a Figura 10. Esta relação se baseia na Lei de Hooke. Na equação 3 é apresentado o módulo de elasticidade a partir da velocidade de propagação de ondas de compressão $\left(\mathrm{V}_{\mathrm{P}}\right)$ :

$E=\rho \cdot V_{P}^{2}=\frac{(1-2 v)(1+v)}{(1-v)}$

onde:

E: módulo de elasticidade ou módulo de Young do material;

$\rho$ : massa específica;

$\mathrm{V}_{\mathrm{P}}$ : velocidade de onda de compressão;

v: coeficiente de Poisson.

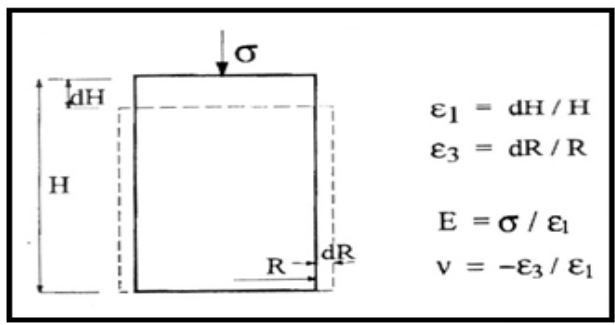

Figura 10: Carregamento de compressão

Fonte: Barros (1997)

\subsubsection{Coeficiente de Poisson (v)}

Conforme representado na Figura 10, ao ocorrer uma deformação numa direção, surge também deformações transversais a esta direção. A relação entre essas deformações é denominada por coeficiente de Poisson. Este coeficiente é um parâmetro complexo de se obter, sendo comum sua estimativa em cálculos de engenharia. Seu valor varia para solos entre 0,2 e 0,5 . O coeficiente de Poisson pode ser calculado, para pequenas deformações, através da equação 4 , através das velocidades de propagação de ondas, $V_{P}$ e $V_{S}$.

$v=\frac{\left(\frac{V_{P}}{V_{S}}\right)-2}{2 \cdot\left(\frac{V_{P}}{V_{S}}\right)^{2}-2}$

onde:

v: coeficiente de Poisson;

$\mathrm{V}_{\mathrm{P}}$ : velocidade da onda de compressão;

$\mathrm{V}_{\mathrm{S}}$ : velocidade da onda de cisalhamento. 


\subsubsection{Módulo de Cisalhamento Máximo $\left(G_{0}\right)$}

O módulo de cisalhamento $(\mathrm{G})$ é um dos principais parâmetros dinâmicos necessários para projeto de engenharia submetido a esforços dinâmicos (fundações sujeitas a vibrações, plataformas de petróleo "offshore", regiões de terremoto, entre outros). O módulo de cisalhamento é influenciado por vários fatores, sendo o nível de deformação cisalhante aplicado o fator preponderante.

O nível de deformação cisalhante é inversamente proporcional ao módulo de cisalhamento, isso significa dizer que com o aumento dos níveis de deformação, o módulo de cisalhamento diminui. Logo, para se determinar o módulo de cisalhamento máximo $\left(\mathrm{G}_{\mathrm{o}}\right)$, é necessário ensaios que geram o mínimo de deformação possível, sendo o material ensaiado em regime elástico. Segundo Giacheti (1999) tais níveis de deformação devem ser inferiores a $10^{-3} \%$. A Figura 11 apresenta alguns níveis de deformação e seus respectivos problemas de engenharia.

Para representar a variação do módulo de cisalhamento com os níveis de deformação é utilizado o gráfico da Figura 12, onde no eixo da abscissa encontra-se o nível de deformação e no eixo das ordenadas a relação entre o módulo de cisalhamento e o módulo de cisalhamento máximo (fator de redução do módulo). Esta curva é denominada de "curva de degradação do módulo" (GIACHETI, 1991).

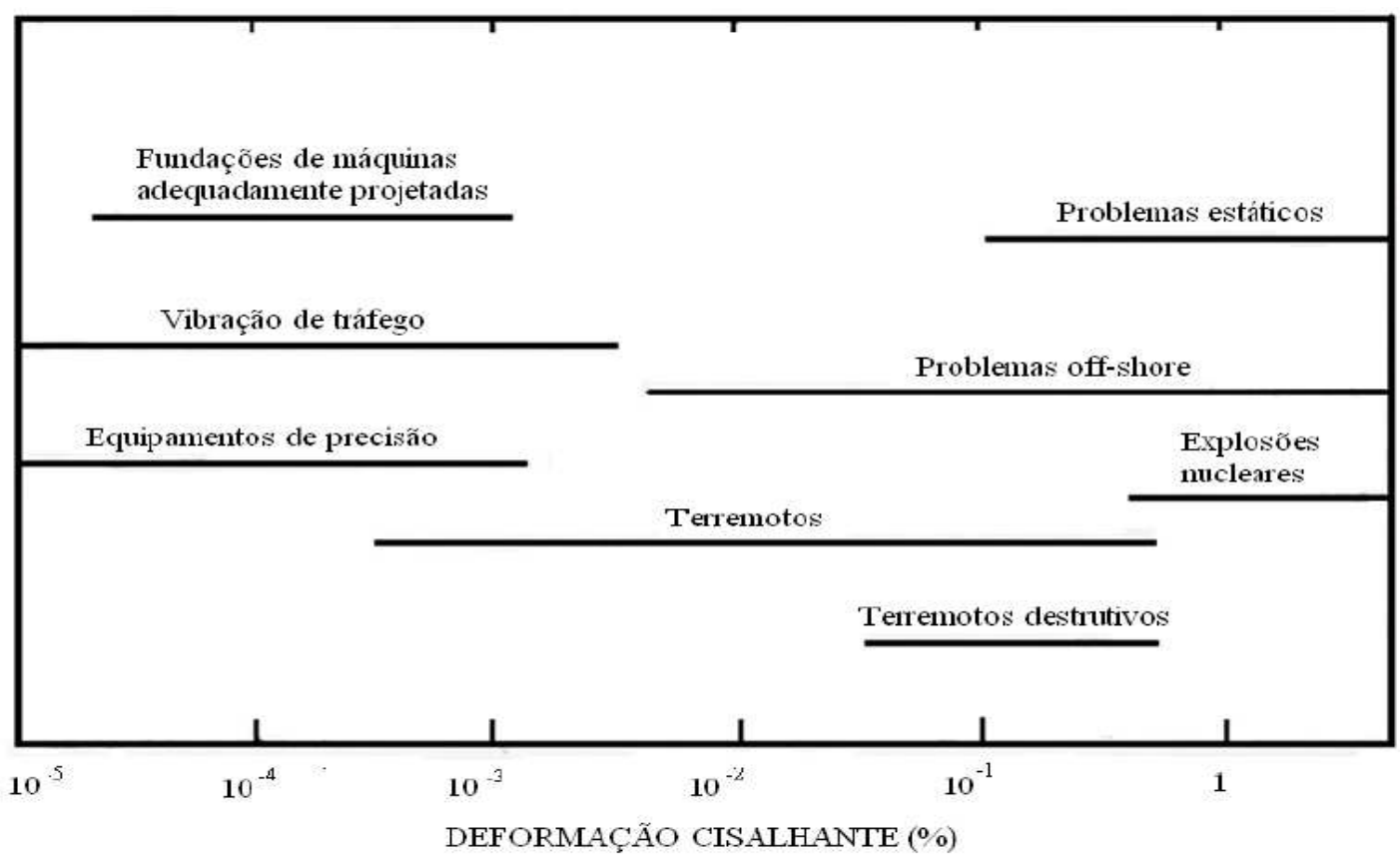

Figura 11: Problemas dinâmicos e seus respectivos níveis de deformação

Fonte: Machado (2010) 


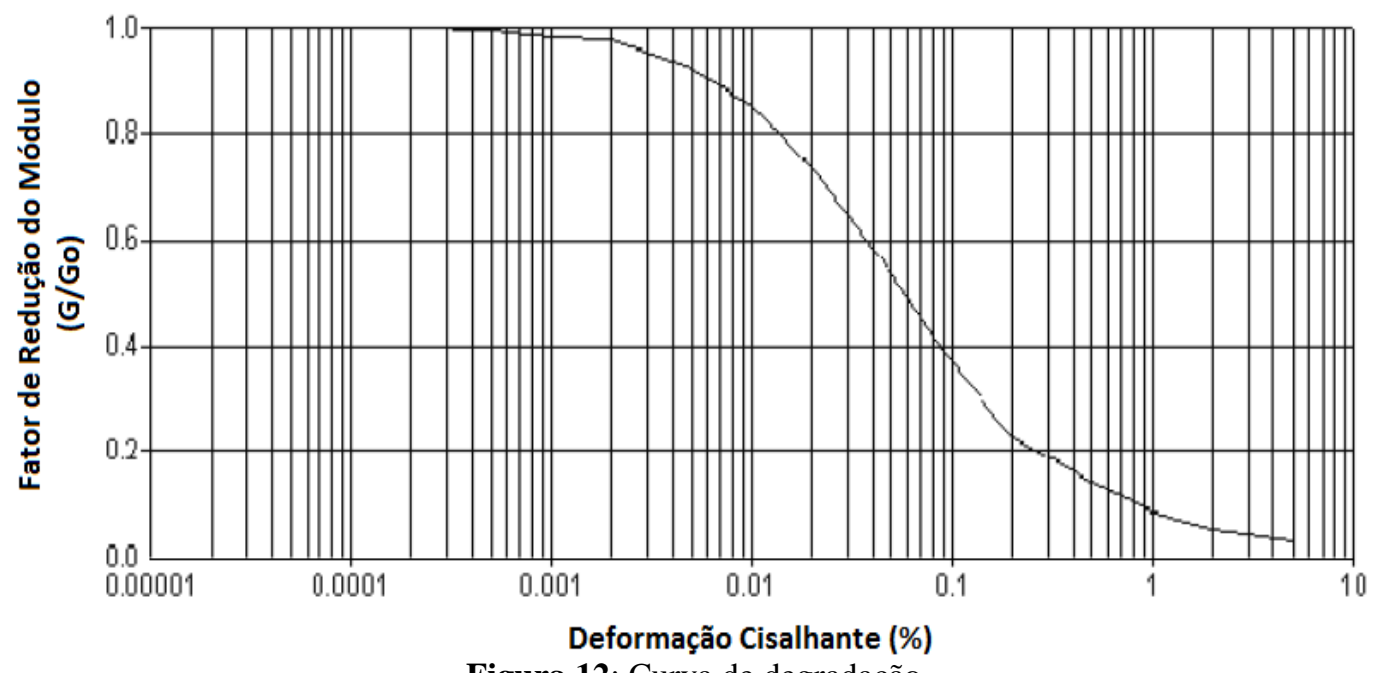

Figura 12: Curva de degradação

Fonte: adaptado Seed e Idriss (1970)

Com os níveis de deformações aplicados no regime elástico, é possível determinar o valor do módulo de cisalhamento máximo $\left(\mathrm{G}_{\mathrm{o}}\right)$ através da teoria da elasticidade, pela equação 5 a seguir:

$G_{0}=\rho \cdot V_{s}^{2}=\frac{\gamma}{g} \cdot V_{s}^{2}$

onde:

$\mathrm{G}_{\mathrm{o}}=$ módulo de cisalhamento máximo;

$\rho=$ massa específica;

$\mathrm{V}_{\mathrm{S}}=$ velocidade da onda cisalhante;

$\gamma=$ peso específico;

$\mathrm{g}=$ aceleração da gravidade.

Para se determinar o módulo de cisalhamento máximo existem várias técnicas, tanto em campo, como em laboratório. Os ensaios de laboratório mais utilizados são o de coluna ressonante, pulso ultrassônico, cisalhamento torcional, cisalhamento simples, entre outros. Os ensaios de campo são a refração sísmica, sísmica em furos de sondagem (cross-hole, downhole, up-hole), com citado anteriormente e o de cone sísmico.

Os ensaios de cisalhamento simples e torcional apresentam um nível de deformação entre $10^{-2}$ a $5 \%$, não sendo aconselhados para determinação do módulo de cisalhamento máximo, enquanto que, os ensaios in situ (cross-hole, down-hole, up-hole, refração sísmica) apresentam um nível de deformação de aproximadamente $5 \times 10^{-4}$, valor esse coerente para determinação do módulo de cisalhamento máximo (GIACHETI, 1999). 


\subsubsection{Estimativa de $G_{0}$ através de Correlações}

Inúmeras expressões empíricas para a estimativa do módulo de cisalhamento máximo foram desenvolvidas (HARDIN e DRNEVICH, 1972; HARDIN, 1978; SAXENA e REDDY, 1989) em função do índice de vazios (e), tensão normal efetiva octaédrica $\left(\sigma_{0}{ }^{\prime}\right)$ e razão de sobre adensamento (OCR). Elas foram elaboradas em países localizados em climas temperados para emprego, na maioria das vezes, em solos sedimentares. Dentre essas expressões, uma muito utilizada é a proposta por Hardin (1978) (GIACHETI, 1991). Ela é apresentada na equação 6 , sendo utilizada na estimativa de $G_{0}$ tanto para solos arenosos como argilosos.

$G_{o}=\frac{625 . O C R^{k}}{\left(0,3+0,7 e^{2}\right)} \cdot \sqrt{\sigma_{m}^{\prime} \cdot P a}$

onde:

OCR: razão de sobre adensamento;

e: índice de vazios;

Pa: pressão atmosférica;

$\sigma_{m}^{\prime}$ : tensão normal efetiva octaédrica;

$\mathrm{k}$ : coeficiente relacionado ao índice de plasticidade.

Na Tabela 3 encontra-se o valor de k em função do índice de plasticidade.

Tabela 3: Coeficiente k em função do IP do solo (GIACHETI, 1991)

\begin{tabular}{cc}
\hline $\begin{array}{c}\text { Índice de } \\
\text { Plasticidade (\%) }\end{array}$ & Valor de $\mathbf{k}$ \\
\hline 0 & 0 \\
20 & 0,18 \\
40 & 0,30 \\
60 & 0,41 \\
80 & 0,48 \\
$>100$ & 0,50 \\
\hline
\end{tabular}

Além da equação proposta por Hardin (1978), baseada em parâmetros obtidos em laboratório, inúmeras equações foram desenvolvidas com base em resultados de ensaios in situ. 


\subsubsection{Estimativa de $G_{0}$ a partir de Ensaios SPT}

Inúmeros pesquisadores investigaram a relação entre a velocidade de propagação de onda cisalhante $\left(\mathrm{V}_{\mathrm{S}}\right)$, e o índice de resistência à penetração $\mathrm{N}$ do SPT. Na Tabela 4, Hanumantharo e Ramana (2008) apresentam várias dessas correlações.

Tabela 4: Correlações entre N (SPT) e Vs (adaptado Hanumantharao e Ramana, 2008)

\begin{tabular}{|c|c|c|c|}
\hline Autor & Correlação & Solo & País \\
\hline Imai e Yoshimura (1970)\$ & $V_{s}=76.0 \mathrm{~N}^{0.39}$ & Todos & Japão \\
\hline Ohba e Toriumi (1970)\$ & $\mathrm{Vs}=84.0 \mathrm{~N}^{0.31}$ & Aluvião & Japão \\
\hline Shibata $(1970) * *$ & $\mathrm{VS}_{\mathrm{S}}=32.0 \mathrm{~N}^{0.50}$ & Areias & Japão \\
\hline Ohta et. al. (1972)\$ & $V_{s}=87.0 \mathrm{~N}^{0.36}$ & Areias & Japão \\
\hline Ohsaki e Iwasaki (1973) & $V_{s}=82.0 \mathrm{~N}^{0.39}$ & Todos & Japão \\
\hline Ohsaki e Iwasaki (1973) & $V_{s}=59.0 \mathrm{~N}^{0.47}$ & Sem coesão & Japão \\
\hline Imai et. al. (1975) ** & $\mathrm{Vs}_{\mathrm{s}}=90.0 \mathrm{~N}^{0.34}$ & Todos & Japão \\
\hline Imai (1977) & $\mathrm{Vs}=91.0 \mathrm{~N}^{0.34}$ & Todos & Japão \\
\hline Ohta e Goto (1978) & $\mathrm{V}_{\mathrm{s}}=85.3 \mathrm{~N}^{0.35}$ & Todos & Japão \\
\hline JRA (1980) ** & $\mathrm{Vs}=100.0 \mathrm{~N}^{0.33}$ & Argilas & Japão \\
\hline JRA $(1980) * *$ & $\mathrm{Vs}=80.0 \mathrm{~N}^{0.33}$ & Areias & Japão \\
\hline Imai e Tonouchi (1982) & $\mathrm{Vs}=97.0 \mathrm{~N}^{0.31}$ & Todos & Japão \\
\hline Yokota et. al. (1991) ** & $\mathrm{Vs}=121.0 \mathrm{~N}^{0.27}$ & Todos & Japão \\
\hline Seed e Idriss (1981) $* *$ & $\mathrm{Vs}=61.0 \mathrm{~N}^{0.50}$ & Todos & USA \\
\hline Seed et. al. (1983) & $\mathrm{Vs}=56.4 \mathrm{~N}^{0.50}$ & Areias & USA \\
\hline Sykora e Stokoe (1983) & $\mathrm{Vs}=106.7 \mathrm{~N}^{0.27}$ & Granulares & USA \\
\hline Fumal e Tinsley (1985) & $\mathrm{Vs}_{\mathrm{s}}=152+5.1 \mathrm{~N}^{0.27}$ & Areias & USA \\
\hline Sykora e Koester (1988) & $\mathrm{Vs}=63.0 \mathrm{~N}^{0.43}$ & Holoceno - cascalho & USA \\
\hline Sykora e Koester (1988) & $\mathrm{Vs}=132.0 \mathrm{~N}^{0.32}$ & Pleistoceno - cascalho & USA \\
\hline Lee $(1990)$ & $V_{s}=57.0 \mathrm{~N}^{0.49}$ & Areias & USA \\
\hline Lee (1990) & $\mathrm{Vs}=114.0 \mathrm{~N}^{0.31}$ & Argilas & USA \\
\hline Lee $(1990)$ & $\mathrm{Vs}=106.0 \mathrm{~N}^{0.32}$ & Siltes & USA \\
\hline Rollins et. al. (1998a, b) & $\mathrm{Vs}=63.0\left(\mathrm{~N}_{60}\right)^{0.43}$ & Holocene - cascalho & USA \\
\hline Rollins et. al. (1998a, b) & $\mathrm{Vs}=132.0\left(\mathrm{~N}_{60}\right)^{0.32}$ & Pleistocene - cascalho & USA \\
\hline Rollins et. al. (1998a, b) & $\mathrm{Vs}=222.0 \mathrm{~N}^{0.06}$ & Aterro recente & USA \\
\hline Andrus et. al. (2004) & Vs1cs $=87.8\left(\mathrm{~N}_{1,60 \mathrm{cs}}\right)^{0.25}$ & Todos & USA \\
\hline Pitikilas et. al. (1992) & $\mathrm{Vs}=155.1 \mathrm{~N}^{0.17}$ & Aterro de detritos & Grécia \\
\hline Pitikilas et. al. (1992) & $\mathrm{Vs}=162.0 \mathrm{~N}^{0.17}$ & Areia siltosa & Grécia \\
\hline Pitikilas et. al. (1992) & $V_{s}=165.7 \mathrm{~N}^{0.19}$ & Argilas moles & Grécia \\
\hline Pitikilas et. al. (1992) & $\mathrm{Vs}=357.5 \mathrm{~N}^{0.19}$ & Argilas rijas & Grécia \\
\hline Kalteziotis et. al. (1992) & $\mathrm{Vs}=76.2 \mathrm{~N}^{0.24}$ & Todos & Grécia \\
\hline Kalteziotis et. al. (1992) & $V_{s}=76.6 \mathrm{~N}^{0.45}$ & Coesivos & Grécia \\
\hline Kalteziotis et. al. (1992) & $\mathrm{Vs}=49.1 \mathrm{~N}^{0.50}$ & Sem coesão & Grécia \\
\hline Athanasopoulos (1995) & $V_{s}=107.6 \mathrm{~N}^{0.36}$ & Todos & Grécia \\
\hline Raptakis et. al. (1995) & $V_{s}=123.4 N^{0.29}$ & Areia fofa & Grécia \\
\hline Raptakis et. al. (1995) & $\mathrm{Vs}_{\mathrm{s}}=100.0 \mathrm{~N}^{0.24}$ & Areia meio densa & Grécia \\
\hline Raptakis et. al. (1995) & $V_{s}=105.7 \mathrm{~N}^{0.33}$ & Argilas moles & Grécia \\
\hline Raptakis et. al. (1995) & $\mathrm{Vs}=184.2 \mathrm{~N}^{0.17}$ & Argilas rijas & Grécia \\
\hline Raptakis et. al. (1995) & $\mathrm{Vs}=192.4 \mathrm{~N}^{0.13}$ & Cascalho & Grécia \\
\hline Jafari et. al. (1997) ** & $\mathrm{Vs}=22.0 \mathrm{~N}^{0.85}$ & Todos & Iran \\
\hline Jafari et. al. (2002) & $V_{s}=27.0 \mathrm{~N}^{0.73}$ & Argilas & Iran \\
\hline Jafari et. al. (2002) & $V_{s}=22.0 \mathrm{~N}^{0.77}$ & Siltes & Iran \\
\hline Jafari et. al. (2002) & $\mathrm{Vs}_{\mathrm{s}}=19.0 \mathrm{~N}^{0.85}$ & Solo bem graduado & Iran \\
\hline Chein et. al. (2000) & $\mathrm{Vs}=22.0 \mathrm{~N}^{0.76}$ & Areias siltosa & Taiwan \\
\hline
\end{tabular}

\$Adotado de Ohsaki e Iwasaki (1973); **Adotado de Jafari et. al.(2002); Adotado de Athanasopoulos (1995). 


\subsubsection{Estimativa de $G_{0}$ a partir de Ensaios de Cone Sísmicos}

Segundo Mayne e Rix (1993) a melhor opção para determinar $G_{o}$ é através da medição direta da velocidade da onda cisalhante, sugerindo o piezocone sísmico (SCPTU) como instrumento mais adequado para este fim, devido à possibilidade de se obter diversas informações, entre elas a resistência de ponta $\left(q_{c}\right)$. Na Figura 13 tem-se a representação da relação entre $q_{c}$ e $G_{o}$, para diferentes tensões verticais efetivas.

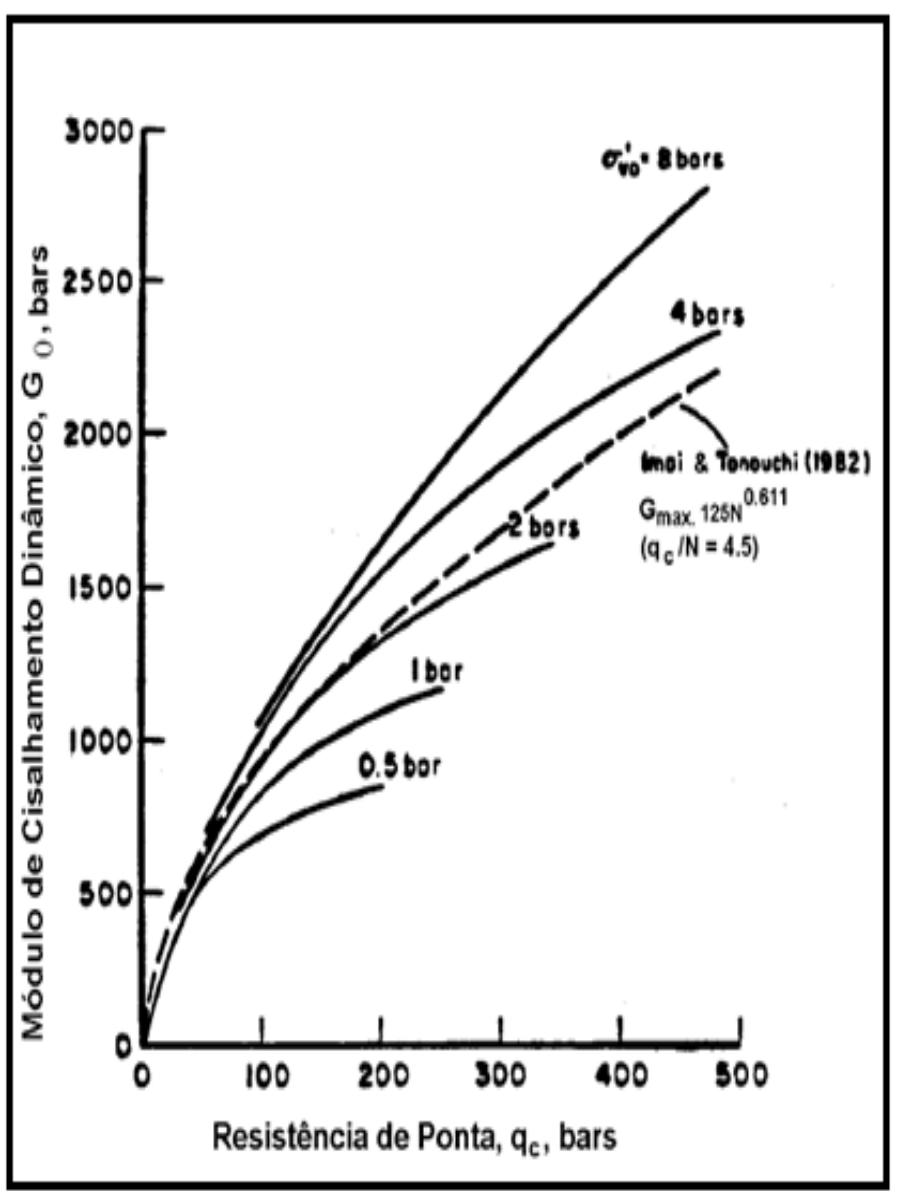

Figura 13: Relação entre o módulo de cisalhamento máximo e a resistência de ponta, considerando as variações da tensão efetiva.

Fonte: Mayne e Mix (1993)

Esses autores, após análise de diversos resultados de ensaios de piezocone sísmico (SCPTU), estabeleceram uma correlação entre $\mathrm{q}_{\mathrm{c}}$ e $\mathrm{G}_{\mathrm{o}}$ para argilas, sendo necessário conhecer o valor do índice de vazios (e). A equação 7 indica esta correlação (DE MIO, 2005).

$$
G_{o}=99.5\left(p_{a}\right)^{0.305} \frac{\left(q_{c}\right)^{0.695}}{e^{1.130}} \quad\left(\mathrm{r}^{2}=0.901\right)
$$




\subsection{Aquisição e Processamento de Dados Sísmicos}

Os ensaios sísmicos visam à determinação da movimentação do terreno gerada por uma fonte sísmica conhecida de localização também conhecida. A movimentação do terreno no tempo é caracterizada através de um sismograma. Para se processar e analisar tal movimentação são necessários os seguintes instrumentos: fonte sísmica para geração de pulso; transdutor apropriado para detecção do sinal; sismógrafo que permita a detecção e registro das ondas sísmicas (KEAREY, 2009).

Nos próximos itens serão apresentadas as descrições dos principais equipamentos utilizados para realização de ensaios sísmicos, com destaque para suas características e configurações.

\subsubsection{Fontes Sísmicas}

Existem inúmeras fontes sísmicas, entre elas: martelo/viga, queda de peso (fonte mecânica) e explosão (fonte explosiva), representada na Figura 14. Segundo Ferreira (2003) as fontes explosivas geram predominantemente ondas $\mathrm{P}$ com muita energia, sendo sua chegada bem definida, tornando difícil a identificação das ondas S. Já as fontes mecânicas geram ondas $\mathrm{S}$ bem claras quase sem produzir ondas $\mathrm{P}$.

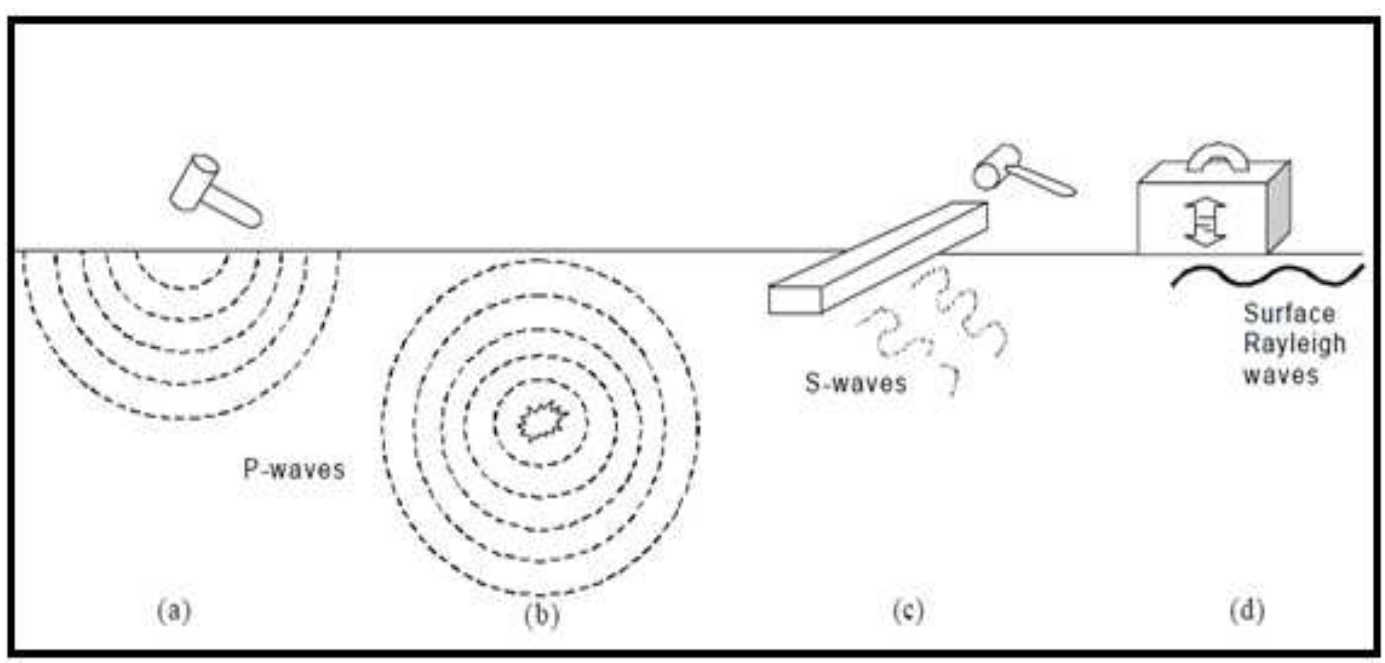

Figura 14: Métodos de geração das ondas de deformação. (a) Impacto vertical, (b) Explosivos, (c) Impacto horizontal, e (d) Ondas de superfície.

Fonte: Luna e Jadi (2000) 
Nos ensaios sísmicos down-hole utiliza-se como fonte sísmica uma fonte mecânica do tipo martelo/viga. Esta fonte é muito apropriada, pois permite empregar o procedimento de polarização da onda S, facilitando sua determinação (CAMPANELLA e STEWART, 1992).

Um dos inconvenientes do uso desse tipo de fonte é a geração de ondas com energia limitada. Entretanto, tal fato pode ser solucionado pela aplicação de um amplificador de sinais durante a aquisição dos dados (GIACHETI, 2005).

As fontes explosivas possuem grande aplicação em ambientes onde não é possível utilizar as fontes mecânicas, por exemplo, em ambientes off-shore. No entanto, não é possível a utilização do efeito de polarização das ondas, impossibilitando o uso do método cross-over para determinação do tempo de viagem das ondas (CAMPANELLA et. al.,1986).

Reynolds (1997) descreve na Tabela 5 alguns requisitos operacionais e técnicos das fontes sísmicas.

Tabela 5: Requisitos técnicos e operacionais de uma fonte sísmica (Reynolds, 1997)

\begin{tabular}{|c|c|}
\hline Técnicos & Operacionais \\
\hline $\begin{array}{l}\text { Energia suficiente para gerar um sinal } \\
\text { mensurável com uma relação sinal/ruído boa; }\end{array}$ & $\begin{array}{c}\text { Uso eficiente, especialmente se no caso são } \\
\text { múltiplos Golpes ou se repetições rápidas são } \\
\text { requeridas; }\end{array}$ \\
\hline $\begin{array}{l}\text { Pulso de pequena duração (com frequência alta } \\
\text { suficiente) para a resolucão requerida: }\end{array}$ & Repetibilidade da forma do pulso; \\
\hline Geração mínima de ruído na fonte. & $\begin{array}{l}\text { Operação segura e com o mínimo de } \\
\text { manutenção, para ser operado com o menos } \\
\text { número de pessoas possível, preços razoáveis } \\
\text { para comprar/criar/alugar e para usá-la; }\end{array}$ \\
\hline
\end{tabular}

\subsubsection{Transdutores Sísmicos}

Butcher et. al. (2005), descreve os transdutores sísmicos como dispositivos que geram uma tensão de saída que depende da excitação de ondas sísmicas, apresentando resposta máxima se forem ativados em frequência natural.

Em ensaios in situ são utilizados com grande frequência geofones ou acelerômetros. Ambos são capazes de registrar ondas $\mathrm{S}$ e ondas $\mathrm{P}$, e os geofones tem custo inferior aos acelerômetros.

Butcher et. al. (2005), define geofone como um sensor que informa uma tensão de saída devido à onda sísmica, a partir da movimentação de uma massa ligada a uma bobina fixada ao habitáculo do sensor, caracterizando a velocidade das partículas. A Figura 15a apresenta um esquema de um geofone e a $15 \mathrm{~b}$ um geofone. 


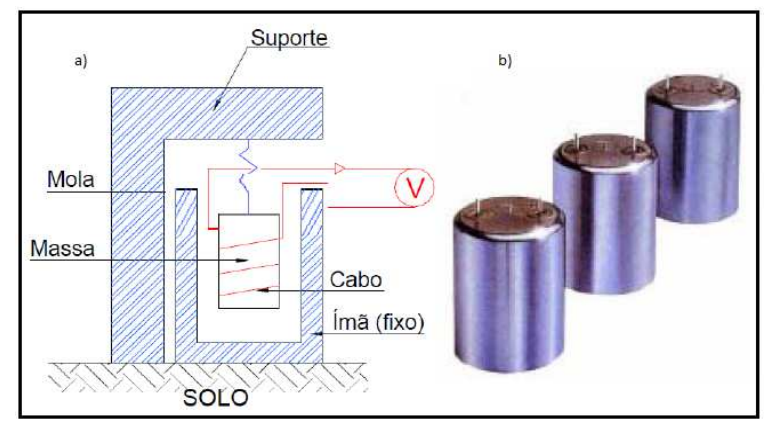

Figura 15: (a) Esquema de um geofone, (b) Geofone

Fonte: Scheffer (2005)

Segundo Vitali (2009), vários autores (Campanella et. al., 1986 e Campanella e Stewart, 1992) utilizaram geofones com frequência natural de $28 \mathrm{~Hz}$ e obtiveram ótimos resultados até profundidades de $50 \mathrm{~m}$.

Conforme Campanella et. al. (1986) os geofones apresentam bons resultados em função do seu alto amortecimento e sua baixa ressonância, tanto para fontes mecânicas como para explosivas.

\subsubsection{Aplicação de Filtros}

A interferência do meio externo e a ressonância dos transdutores sísmicos (geofones e acelerômetros) geram ruídos nos sinais das ondas cisalhantes (S), além da possibilidade das ondas de compressão (P) interferir também. Este fato ocorre principalmente em solos não saturados e em profundidades maiores, onde a amplitude das ondas $\mathrm{S}$ é próxima das ondas $\mathrm{P}$ devido ao efeito da atenuação (GIACHETI, 2005). Em função disso, é necessário utilizar filtros para uma maior confiabilidade dos resultados, uma vez que os ruídos mascaram as ondas P (CAMPANELLA e STEWART, 1992).

Existem dois tipos de filtros: os analógicos e os digitais. Stokoe e Hoar (1978) sugerem que os filtros analógicos devam ser pouco utilizados, uma vez que podem distorcer o sinal verdadeiro e levar a tempos de chegada das ondas incorretos. Os filtros digitais não apresentam distorções e atrasos nos sinas, além de permitir analisar trechos do sinal (CAMPANELLA e STEWART, 1992). Reynolds (1997) demonstra a importância da relação entre a amplitude do sinal gerado e do ruído, para que este não interfira no sinal. Na Figura 16 é apresentada tal relação em função da qualidade dos sinais. As fontes de ruídos geradas pelo meio externo são: vibração de árvores, veículos, linhas de eletricidade, tempestades elétricas e magnéticas, entre outras. 


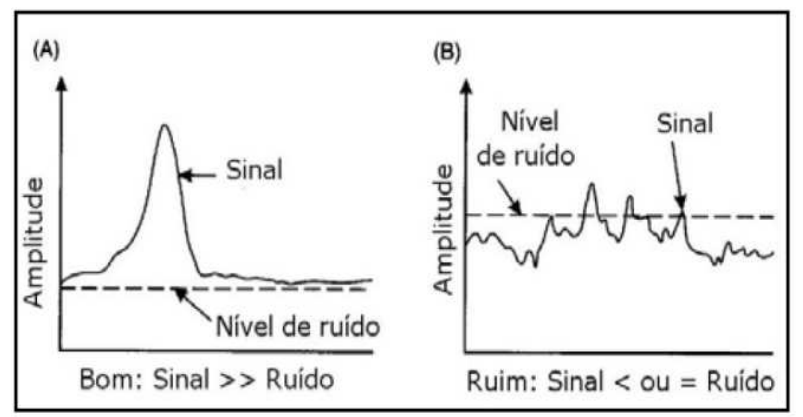

Figura 16: Relação sinal-ruído

Fonte: adaptado Reynolds (1997)

\subsection{Ensaios Híbridos}

\subsubsection{Considerações Iniciais}

Ensaios híbridos possibilitam determinar parâmetros a partir da combinação de duas ou mais técnicas em um único ensaio. Existe uma infinidade de ensaios híbridos, como demonstrado por Mayne (2000). A Tabela 6 apresenta os ensaios de campo, suas designações, metodologia de ensaio (ASTM), medidas determinadas e as acrescentadas em cada ensaio. Entre os ensaios híbridos mais utilizados, o ensaio de piezocone sísmico (SCPTU) é um dos mais utilizados, devido sua versatilidade e rapidez na determinação de perfis verticais de resistência de ponta $\left(\mathrm{q}_{\mathrm{c}}\right)$, atrito lateral $\left(\mathrm{f}_{\mathrm{s}}\right)$, poro-pressão $(\mathrm{u})$ e velocidade de onda cisalhante $\left(\mathrm{V}_{\mathrm{S}}\right)$, sendo esta última utilizada na determinação do módulo de cisalhamento máximo $\left(\mathrm{G}_{\mathrm{o}}\right)$ (MAYNE, 2000).

\subsubsection{Piezocone Sísmico (SCPTU)}

No início da década de 1980, foi incorporado ao ensaio de piezocone (CPTU) um sistema de aquisição de ondas sísmicas, sendo denominado de piezocone sísmico (SCPTU). O ensaio possibilita a determinar além dos parâmetros do ensaio do piezocone o valor de velocidade de ondas cisalhantes $\left(\mathrm{V}_{\mathrm{S}}\right)$. A velocidade de propagação de ondas sísmicas pode ser determinada com rapidez, precisão e alta repetibilidade.

A cravação do cone proporciona um contato mecânico entre o solo e o geofone muito eficiente, permitindo uma excelente recepção do sinal. O ensaio consiste na realização do 
ensaio de piezocone (CPTU), acrescido da realização do ensaio down-hole. A etapa mais A etapa mais importante da interpretação desse ensaio é a medida precisa do tempo de chegada da onda S. A Figura 17 apresenta um esquema da realização do ensaio SCPTu.

Tabela 6: Principais ensaios híbridos e parâmetros obtidos (Mayne, 2000).

\begin{tabular}{|c|c|c|}
\hline Ensaios Geotécnicos & Designação & Número de parâmetros medidos \\
\hline \multirow{2}{*}{ Sondagem de simples Reconhecimento } & SPT & $1 \quad(+$ amostra $)$ \\
\hline & SPTT & 2 (+ amostra) \\
\hline \multirow{2}{*}{ Ensaio da palheta } & VST & 2 (pico e deformado) \\
\hline & $\mathrm{VST} / \mathrm{r}$ & 3 (nível de tensão) \\
\hline \multirow{6}{*}{ Ensaio do Cone } & $\mathrm{CPT}$ & $2(\mathrm{qc}, \mathrm{fs})$ \\
\hline & SCPT & $4\left(+V_{p},+V_{S}\right)$ \\
\hline & PCPT & $3(+u)$ \\
\hline & $\mathrm{PCPT} / \mathrm{d}$ & 3 (efeito do tempo) \\
\hline & SPCPT & 5 (combinado) \\
\hline & RCPT & 3 ( + condutividade) \\
\hline \multirow{6}{*}{ Ensaio Pressiométrico } & PMT & $4\left(\mathrm{p}_{\mathrm{L}}, \mathrm{E}, \mathrm{o}_{\mathrm{h}} \mathrm{O}, \mathrm{x}_{\max }\right)$ \\
\hline & SBPMT & 4 (de difícil execução) \\
\hline & PIPMT & $3\left(\mathrm{p}_{\mathrm{L}}, \mathrm{E}, \mathrm{Tj}\right)$ \\
\hline & FDPMT & $3\left(\mathrm{P}_{\mathrm{L}}, \mathrm{E}, \mathrm{T}_{\mathrm{m}} \mathrm{J}\right)$ \\
\hline & CPMT & 5 (+ dados CPT) \\
\hline & PCPMT & $6(+$ dados PCPT $)$ \\
\hline \multirow{4}{*}{ Ensaio do Dilatômetro Plano } & DMT & $2\left(\mathrm{p}_{0} \mathrm{e} \mathrm{p}_{1}\right)$ \\
\hline & $\mathrm{DMT} / \mathrm{t}$ & $3\left(\mathrm{p}_{0}, \mathrm{p}_{1}, \mathrm{q}_{\mathrm{D}}\right)$ \\
\hline & $\mathrm{DMT} / \mathrm{c}$ & $3\left(\mathrm{p}_{0}, \mathrm{p}_{\mathrm{l}}, \mathrm{p}_{2}\right)$ \\
\hline & $\mathrm{DMT} / \mathrm{d}$ & 3 (+ decaimento no tempo) \\
\hline \multirow{4}{*}{ Ensaio de ondas de superfície } & & \\
\hline & $\mathrm{SPv}$ & 1 (ondas de compressão) \\
\hline & SASW & 1 (ondas Rayleigh) \\
\hline & $\mathrm{SASW} / \mathrm{d}$ & 2 (+ atenuação) \\
\hline \multirow{2}{*}{ Ensaio cross-hole } & CHT & 2 (ondas de corpo) \\
\hline & $\mathrm{CHT} / \mathrm{d}$ & 3 (+ atenuação) \\
\hline \multirow{2}{*}{ Ensaio down-hole } & DHT & 2 (ondas de corpo) \\
\hline & DHT/d & 3 (+ atenuação) \\
\hline \multicolumn{3}{|l|}{ Ensaios híbridos: } \\
\hline \multirow{2}{*}{ Cone pressiométrico } & CPMT & 5 (CPT + PMT completo $)$ \\
\hline & PCPMT & $6(\mathrm{PCPT}+\mathrm{FDPMT})$ \\
\hline Piezocone sísmico & SPCPT & $6(\mathrm{DHT}+\mathrm{PCPT})$ \\
\hline Dilatômetro sísmico & SDMT & $5(\mathrm{DHT}+\mathrm{DMT})$ \\
\hline Pressiômetro sísmico & SPCPMT & $9 \quad(\mathrm{DHT}+\mathrm{PCPT}+\mathrm{PMT})$ \\
\hline
\end{tabular}

O cone sísmico apresenta as mesmas características de um cone padrão, diferenciandose apenas pela existência de um ou mais geofones ou acelerômetros localizados em seu interior (Figura 18). Para se determinar as velocidades das ondas $\mathrm{S}$ existem vários métodos. Estes métodos foram criados em função da refração das ondas devida à rigidez de cada camada. Esses métodos são: o método direto, método do intervalo, método do intervalo modificado e o método do intervalo modificado considerando a Lei de Snell (KIM et. al., 2004). 

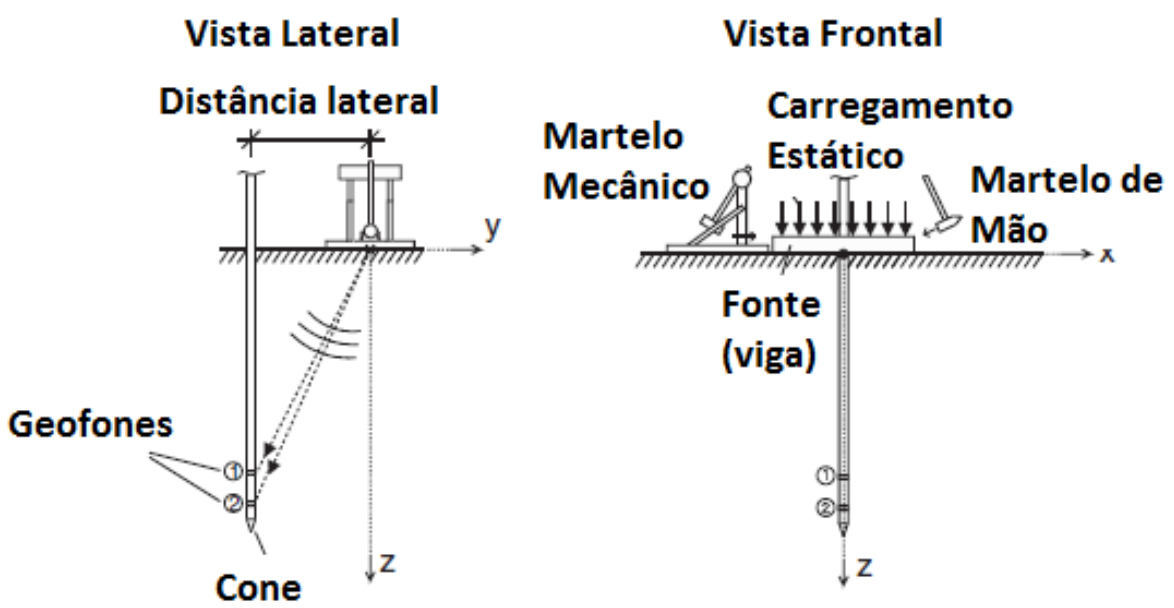

Figura 17: desenho esquemático da realização do ensaio SCPTU Fonte: adaptado Karl, Haegeman e Degrande (2006)

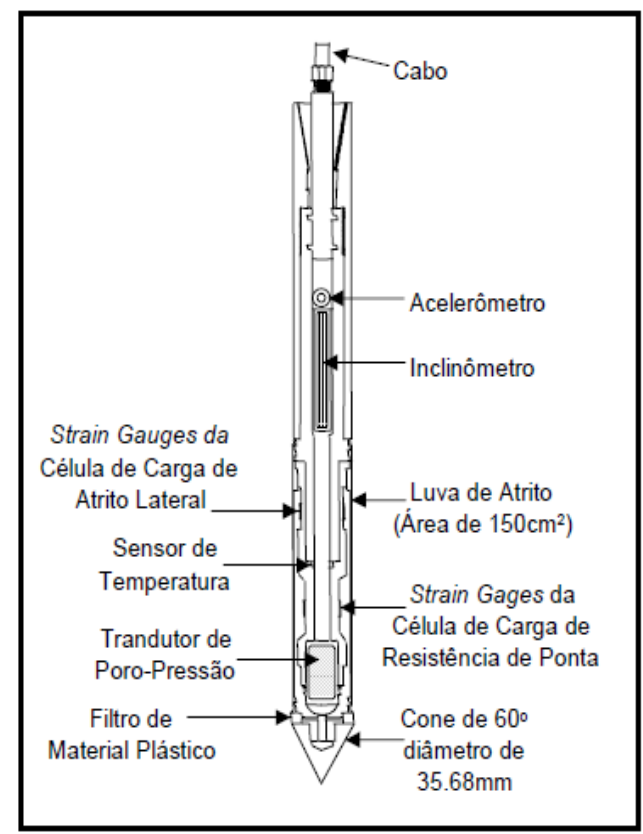

Figura 18: piezocone sísmico-SCPTU Fonte: Davies e Campanella (1995)

\subsection{Ensaio SPT com Sísmica Up-Hole (S-SPT)}

A determinação do perfil de velocidade da onda cisalhante $\left(V_{S}\right)$ e consequentemente o módulo de cisalhamento máximo $\left(\mathrm{G}_{\mathrm{o}}\right)$ é muito importante na prática geotécnica. Há alguns métodos sísmicos para se determinar o perfil de velocidade cisalhante, entre eles os ensaios em furos de sondagem são os mais utilizados (cross-hole, down-hole e up-hole). Na prática, a utilização do método up-hole original é pouco comum, em função da dificuldade de gerar a componente da onda cisalhante $\left(\mathrm{V}_{\mathrm{S}}\right)$. Uma forma modificada do método up-hole foi 
desenvolvida para se obter o perfil de $\mathrm{V}_{\mathrm{S}}$ de forma eficiente. Este método é mostrado na Figura 19, sendo denominado de método S-SPT (BANG e KIM, 2007). Este novo método utiliza a energia do impacto do martelo do SPT como fonte, sendo interessante uma vez que o ensaio SPT é uma técnica de ensaio muito utilizado em investigações geotécnicas.

Durante a penetração do amostrador no solo, através da queda do martelo do SPT, uma quantidade significativa de ondas de compressão e ondas de cisalhamento causadas pela ponta e lado do amostrador (Figura 19), é gerada no solo. O SPT é normalmente realizado em intervalos de 1,0 ou 1,5 m, se fossem colocados uma série de receptores na superfície do solo, seria viável a realização do método up-hole durante o SPT. Este método (S-SPT) pode ser realizado sem custo adicional, sem necessidade de terceirizar o trabalho, muito econômico e de fácil execução (BANG; KIM, 2007).

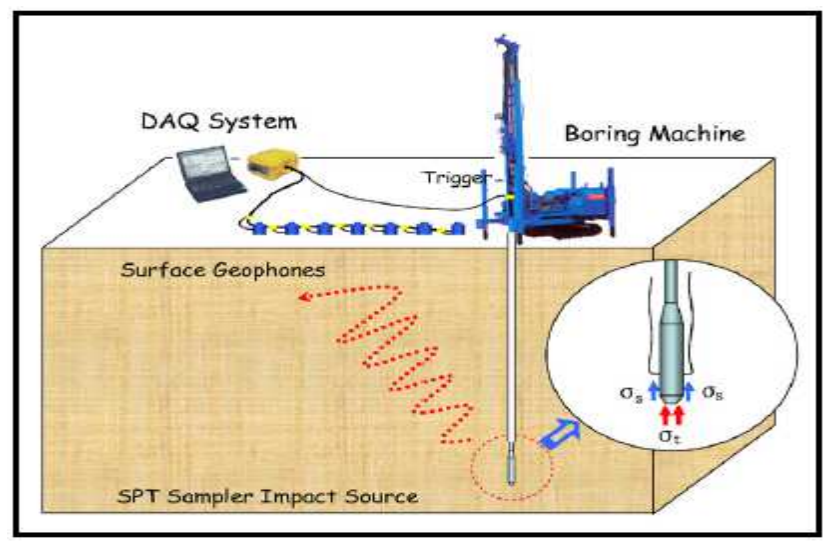

Figura 19: Esquema do método S-SPT

Fonte: Bang e Kim (2007)

Para o desenvolvimento do método S-SPT, é de suma importância à compreensão dos tipos de ondas geradas pelo martelo do SPT. À medida que o amostrador penetra no solo, ele gera ondas de cisalhamento (S), gerando um movimento vertical das partículas, denominado de onda tipo SV, além de ondas de compressão (P), mostrado na Figura 20.a. A componente P da onda é detectada principalmente em uma direção radial a superfície do solo, quando a fonte de SPT está localizada a uma pequena profundidade, enquanto é detectada principalmente no sentido vertical em profundidades maiores. A componente de onda $\mathrm{S}$ é detectada principalmente no sentido vertical na superfície do solo quando a fonte está localizada em profundidades rasas e detectada na direção radial, quando localizada em profundidades maiores, como mostrado na Figura 20.a. Salienta-se que a direção principal de cada movimento de onda irá variar dependendo da localização da fonte e receptor. Para se investigar os tipos de ondas geradas pelo martelo do SPT em um estado real, um estudo 
numérico usando o Método de Elementos Finitos foi feito. Como mostrado na Figura 20.b, um modelo de duas camadas com valores diferentes de $\mathrm{V}_{\mathrm{S}}$ foram selecionados. Pode ser notado que as ondas $\mathrm{S}$ e $\mathrm{P}$ propagam-se esfericamente, como representado na Figura 21 (BANG; KIM, 2007).
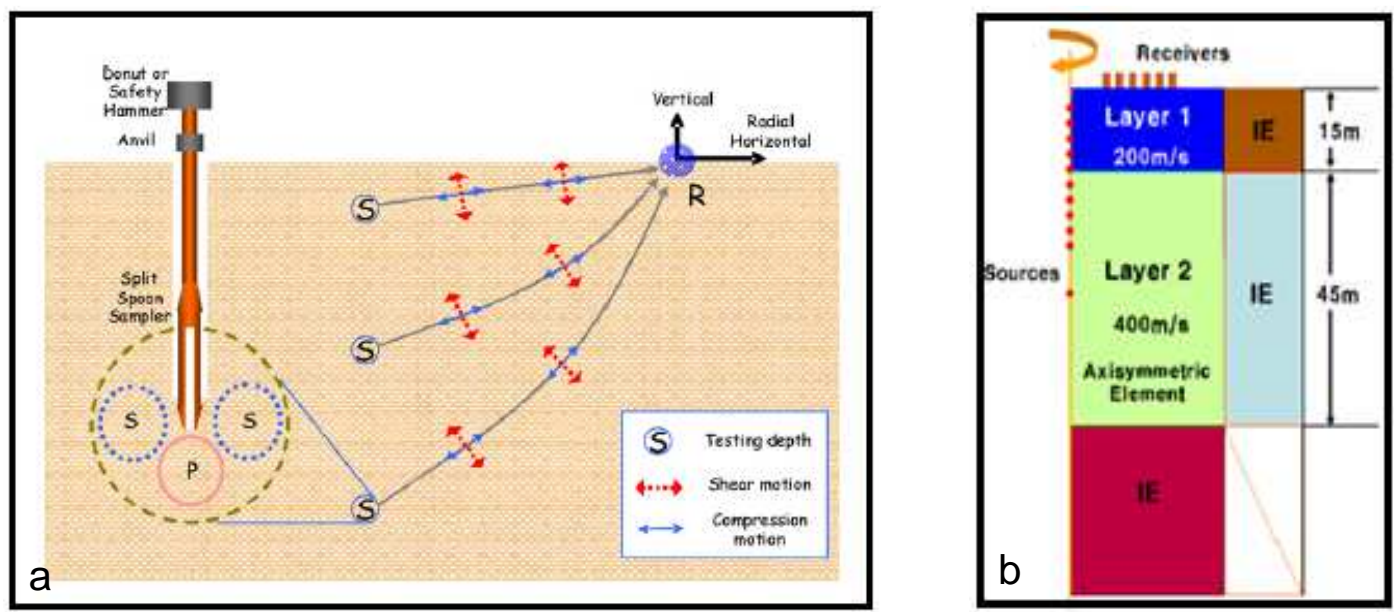

Figura 20:(a)-Movimentação das partículas no solo gerada pela penetração do amostrador;(b)-Modelo numérico para análise de movimento das partículas.

Fonte: Bang e Kim (2007)

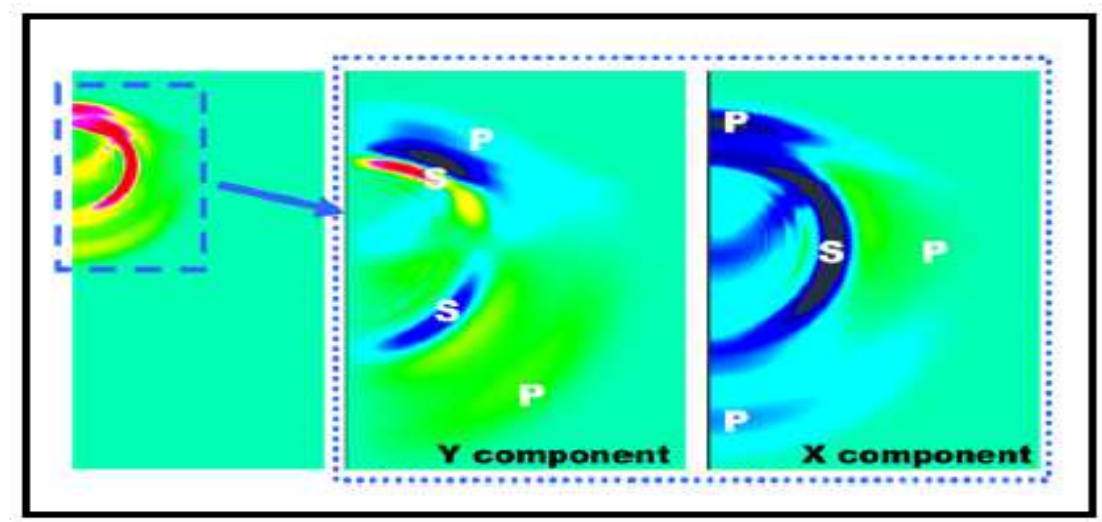

Figura 21: Forma de propagação de ondas

Fonte: Bang e Kim (2007)

\subsubsection{Avaliações e determinação do perfil de $V_{S}$}

Os métodos de avaliação e interpretação do perfil de $\mathrm{V}_{\mathrm{S}}$ no método up-hole são semelhantes aos do método do modelo down-hole. O princípio é que o valor da velocidade pode ser determinado pelo tempo de viagem e pela diferença nas distâncias de cada raio, ou seja, o caminho entre dois raios. As profundidades, a distância do receptor e tempo de viagem são informações necessárias para a interpretação (BANG; KIM, 2007). 
Para a análise dos resultados do ensaio S-SPT, Bang e Kim (2007) apresentaram dois métodos. Ambos consideram a Lei de Snell e que o local de ensaio apresente camadas horizontais de espessura constantes e iguais ao intervalo em que são registrados os sinais. $\mathrm{O}$ primeiro é denominado tempo de atraso entre os receptores de série (DTR) e o segundo é designado tempo de atraso entre fontes de série (DTS). No método DTR, o valor de $V_{S}$ da primeira camada é obtido utilizando o intervalo de tempo entre os receptores, como mostrado na Figura 22. No método de DTS, a diferença de tempo de viagem é utilizada como informação entre as fontes de série ou profundidades do ensaio.

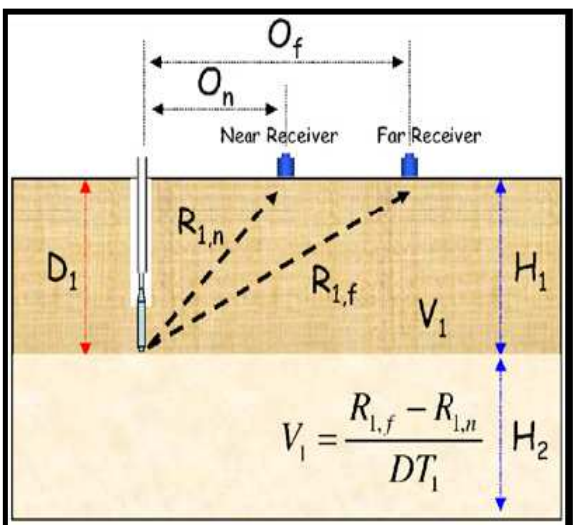

Figura 22: Determinação do valor $\mathrm{V}_{\mathrm{S}}$ pelo método DTR Fonte: Bang e Kim (2007)

Para o método DTR, na determinação de $\mathrm{V}_{\mathrm{S}}$ da primeira camada é utilizado o intervalo de tempo entre receptores, próximo e longe do furo, como visto na Figura 22 e determinado pela equação 8 .

$D T R_{1}=P T_{1, f}-P T_{1, n}$

onde:

$D T R_{1}$ : tempo de atraso entre os dois receptores em série;

$P T_{1, f} ; P T_{1, n}$ : tempo de viagem entre o ponto de gatilho até o ponto de chegada dos receptores.

Através da equação 9, podemos determinar a velocidade de cisalhamento da primeira camada.

$V_{1}=\frac{R_{1, f}-R_{1, n}}{D T R_{1}}$ 
onde:

$R_{1, n} ; R_{1, f}$ : distância da fonte aos receptores.

Na determinação das velocidades de onda cisalhante $\left(\mathrm{V}_{\mathrm{S}}\right)$ das camadas $i$ restantes são considerados o perfil de solo com camadas heterogêneas e o caminho refratado dos raios, segundo a Lei de Snell, porém inicialmente supõe-se a velocidade da camada a ser calculada, e através de um processo interativo ajusta-se essa, até que as equações de contorno se equilibrem, utilizando para isto um método de cálculo.

As equações de contorno são provenientes da Lei de Snell, equação 10, e da geometria, equação 11 .

$\frac{\sin \alpha_{i 1 f}}{V_{1}}=\frac{\sin \alpha_{i 2 f}}{V_{2}}=\frac{\sin \alpha_{i 1, f}}{V_{j}}=\frac{\sin \alpha_{i i f}}{V_{i}}$

$H_{1} \cdot \tan \alpha_{i 1, f}+\cdots+H_{j} \cdot \tan \alpha_{i j, f}+\cdots+H_{i} \cdot \tan \alpha_{i i, f}=O_{f}$

onde:

$\mathrm{V}_{\mathrm{j}}$ e $\mathrm{V}_{\mathrm{i}}$ : velocidades das camadas, na Figura 22, a diferentes profundidade do ensaio;

$\alpha_{i j, f}$ : ângulo de incidente da camada de índice $j$ com a vertical, quando calculada a velocidade da camada $i$

$H_{j}$ : altura da camadas do perfil de solo;

$O_{f}$ : distância horizontal entre o furo de sondagem e a posição dos geofones.

Com o cálculo da trajetória da onda, realiza-se continuidade ao procedimento de cálculo das velocidades nas camadas subsequentes. O comprimento percorrido pela onda em cada camada pode ser calculado segundo a equação 12 .

$L_{i j, f}=\frac{H_{j}}{\cos \alpha_{i j, f}}$

onde:

$L_{i j, f}$ : comprimento de passagem da onda na camada analisada; 
$\alpha_{i j, f}$ : ângulo de incidente da camada de índice $j$ com a vertical, quando calculada a velocidade da camada $i$

O tempo de viagem a partir da fonte para cada receptor na profundidade do ensaio é dada pela equação 13

$T_{i j, f}=\sum_{j=1} \frac{L_{i j, f}}{V_{j}}=\frac{L_{i 1, f}}{V_{1}}+\frac{L_{i 2, f}}{V_{2}}+\cdots+\frac{L_{i j, f}}{V_{i}}$

onde:

$T_{i j, f}:$ tempo de viagem da onda gerada aos receptores;

$L_{i j, f}:$ comprimento de passagem da onda na camada analisada;

$\mathrm{V}_{\mathrm{j}}$ e $\mathrm{V}_{\mathrm{i}}$ : velocidades das camadas, na Figura 22, a diferentes profundidade do ensaio.

O tempo de atraso entre os receptores de série pode ser calculado pela equação 14 .

$D T R_{i}=P T_{i, f}-P T_{i, n}=T_{i, f}-T_{i, n}$

onde:

$D T R_{i}$ : tempo de atraso, entre o receptor mais próximo e mais distante, da geração da onda na camada $i$;

$P T_{i, f}$ : tempo de atraso, entre a geração da onda e o receptor mais próximo ou mais distante.

Finalmente, para determinação da velocidade de onda de cisalhamento $\left(\mathrm{V}_{\mathrm{S}}\right)$, dada pela Equação 15, interpretada a partir das Equações 13 e 14.

$V_{S}=V_{i}=\frac{L_{i i, f}-L_{i i, n}}{D T R_{i}-\left(\sum_{j=1}^{i-1}\left(\frac{L_{i j, f}}{V_{j}}\right)-\sum_{j=1}^{i-1}\left(\frac{L_{i j, n}}{V_{j}}\right)\right)}$

onde:

$L_{i j, f}$ : comprimento de passagem de cada camada aos receptores, na profundidade do ensaio; $T_{i, f}$ : tempo de viagem entre o ponto de gatilho até o ponto de chegada dos receptores; $D T R_{i}$ : tempo de atraso entre os receptores, na profundidade do ensaio; 
$P T_{i, f}$ igual a $T_{i, f}$.

Após a determinação da velocidade da camada (equação 15), compara-se essa com o valor inicialmente adotado para a mesma. Se ela estiver dentro da tolerância imposta pelo método, segue-se para próxima camada, caso contrário, inicia-se novamente a determinação da trajetória da onda (equação 10 e 11), porém sendo utilizada a velocidade obtida pela equação 15. Este processo é repetido até que a tolerância do método seja alcançada.

Para o método DTS, a utilização de apenas um receptor já possibilita a determinação da velocidade de onda S. No estudo de Bang e Kim (2007) o método DTS apresentou os melhores resultados. O procedimento é semelhante ao do método DTR. Inicialmente determina-se a trajetória da onda, pelo perfil de solo, utilizando as equações 10 e 11, porém neste método adota-se a velocidade da segunda camada igual a da primeira, como representado na Figura 23.

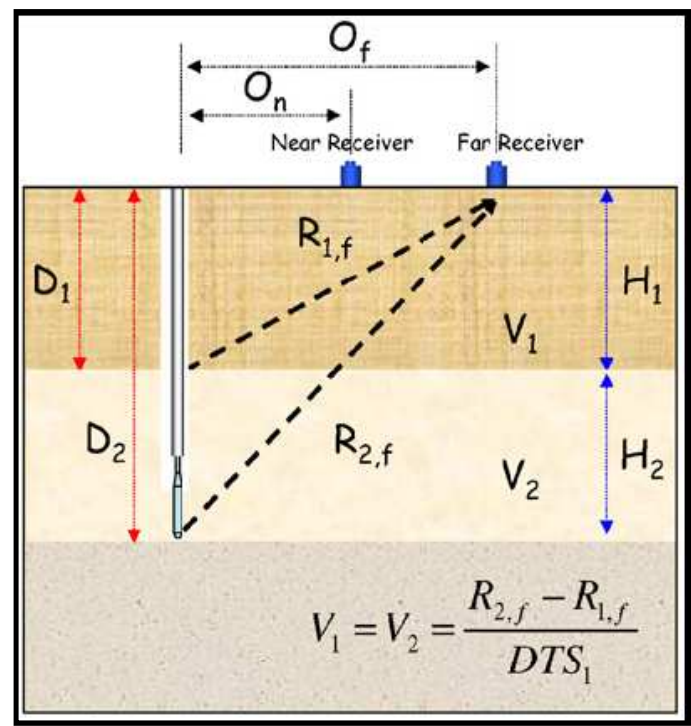

Figura 23: Determinação do valor $\mathrm{V}_{\mathrm{S}}$ na primeira e segunda camada pelo método convencional Fonte: Bang e Kim (2007)

Dando continuidade a aplicação desse método, determina-se o comprimento de onda em cada camada utilizando a equação 12. Através da equação 16 a velocidade pelo método DTS é determinada, através o quociente entre o comprimento da onda na última camada $\left(L_{i i, f}\right)$ e a diferença entre o tempo de chegada na profundidade $i$ subtraído do tempo gasto para onda percorrer as camadas anteriores. 
$V_{i}=\frac{L_{i i, f}}{T_{i, f}-\sum_{j=1}^{i-1}\left(\frac{L_{i j, f}}{V_{j}}\right)}$

onde:

$V_{i}$ : velocidade da camada de índice $i$;

$T_{i, f}$ : tempo de chegada da onda.

Da mesma forma que o método DTR, é feita a verificação da velocidade avaliando à tolerância imposta pelo método de cálculo e verifica-se a necessidade de recalcular-se a trajetória da camada ou parte-se para a próxima camada.

\subsection{Desenvolvimento do sistema para realização do ensaio S-SPT}

Pedrini (2012) adaptou a metodologia e os equipamentos para realização do ensaio SSPT conforme proposto por Bang e Kim (2007). Ensaios foram realizados no campo experimental da UNESP de Bauru, sendo seus resultados comparados a ensaios de referência da técnica down-hole (SCPT e down-hole), para validar sua técnica.

Os equipamentos desenvolvidos por Pedrini (2012) são constituídos pelo sistema de aquisição de dados, da National Instrumensts, modelo NI-USB-6353, e um software para tratamento e análise dos sinais. O sistema de aquisição apresenta as seguintes especificações:

- Entradas analógicas:

- Canais: 32 em single-ended channel e 16 em differential channel;

- Resolução: 16 bits;

- Taxa de aquisição: $1.25 \mathrm{MS} / \mathrm{s}$;

- Saídas analógicas:

- Canais: 4;

- Resolução: 16 bits;

- Taxa de atualização: $2.86 \mathrm{MS} / \mathrm{s}$;

- Trigger: Analógico, Digital

Um programa de processamento e análise de sinais foi desenvolvido por Pedrini (2012) em função da complexibilidade da análise dos sinais sísmicos gerados no ensaio SSPT. Esse programa foi elaborado em plataforma LabView 8.5. 
Em função das 32 entradas analógicas, podem ser instalados até 16 geofones, já que o tipo de aquisição utilizada é a diferencial, devido a sua melhora na qualidade do sinal (PEDRINI, 2012).

O programa tem como objetivo principal, fornecer de forma simples e funcional, uma ferramenta para a determinação do tempo de chegada das ondas $\mathrm{S}$ e $\mathrm{P}$ ou determinar a defasagem de tempo entre ondas subsequentes. Pedrini (2012) apresenta a estrutura básica e as inúmeras funcionalidades do programa. Estas funcionalidades podem ser visualizadas pelas letras A, até J, na Figura 24, onde:

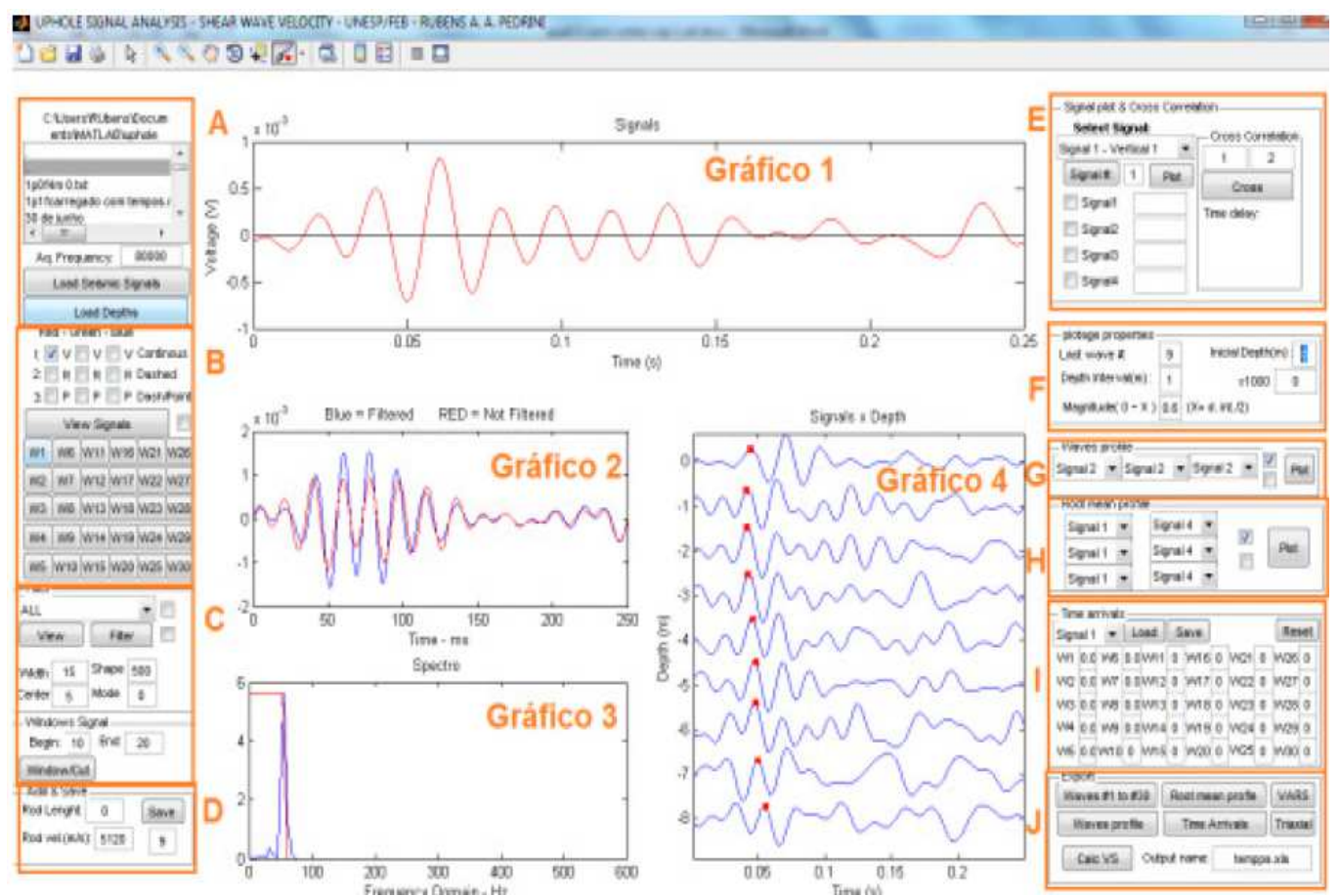

Figura 24: Tela do programa de análise dos sinais

Fonte: Pedrini (2012)

- A: Carregamento dos Sinais;

- B: Visualização dos sinais gravados;

- C: Filtragem do sinal;

- D: Adicionar ondas no banco de dados;

- E: Análise da correlação cruzada;

- F: Configuração para apresentação dos perfis;

- G: Ferramenta para visualizar o perfil de ondas;

- H: Ferramenta para visualizar perfil das raízes média dos sinais;

- I: Preenchimento dos tempos de chegada;

- J: Exportação dos dados e janela para o cálculo de velocidades. 
Na Figura 25 é mostrada a tela inicial do programa de aquisição de dados.

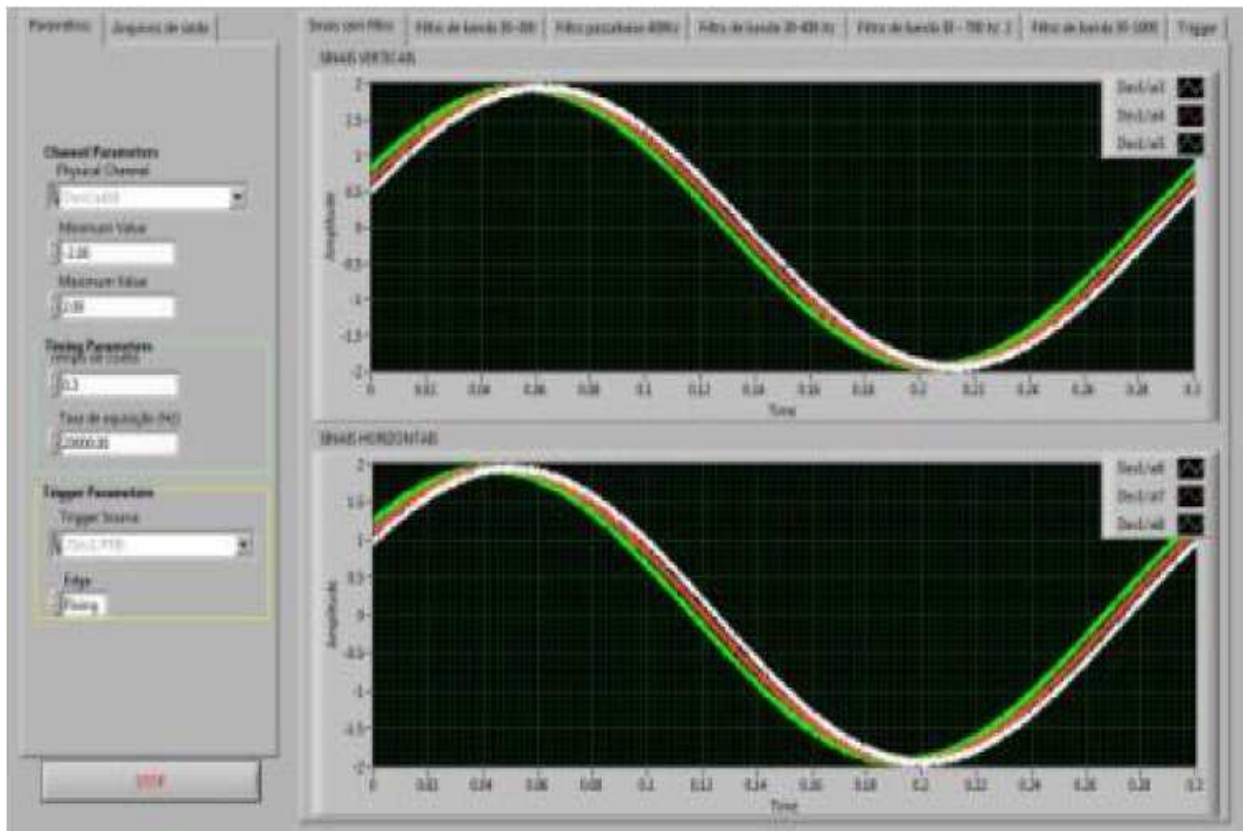

Figura 25: Tela inicial do programa de aquisição de dados

Fonte: Pedrini (2012)

Pedrini (2012), para facilitar o transporte e manuseio do equipamento durante os ensaios em campo, construiu uma caixa que protege o sistema de aquisição de dados. Ela possui os conectores que são ligados aos cabos das caixas que contêm os geofones, além de saída para alimentação elétrica, aterramento e a conexão com o computador. Essa caixa facilita a conexão de todos os cabos no sistema de aquisição, além de protegê-lo durante os ensaios em campo. A Figura 26 ilustra a caixa confeccionada.

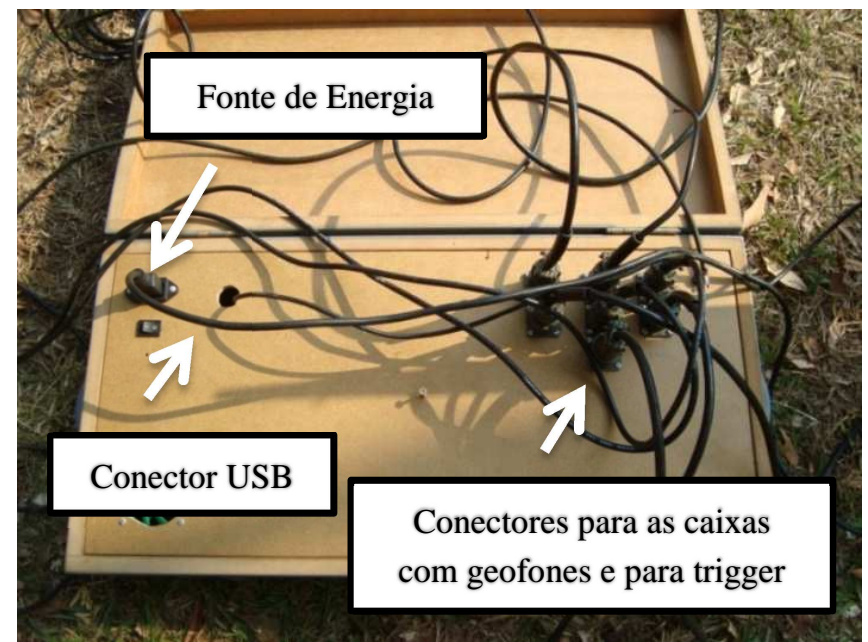

Figura 26: Caixa para acondicionamento do equipamento de aquisição de dados e seus conectores. Fonte: adaptado de Pedrini (2012) 
Pedrini (2012), para facilitar a execução do ensaio S-SPT, propôs através de fluxogramas a síntese da metodologia de execução (Figura 27) e a síntese da metodologia de análise (Figura 28).

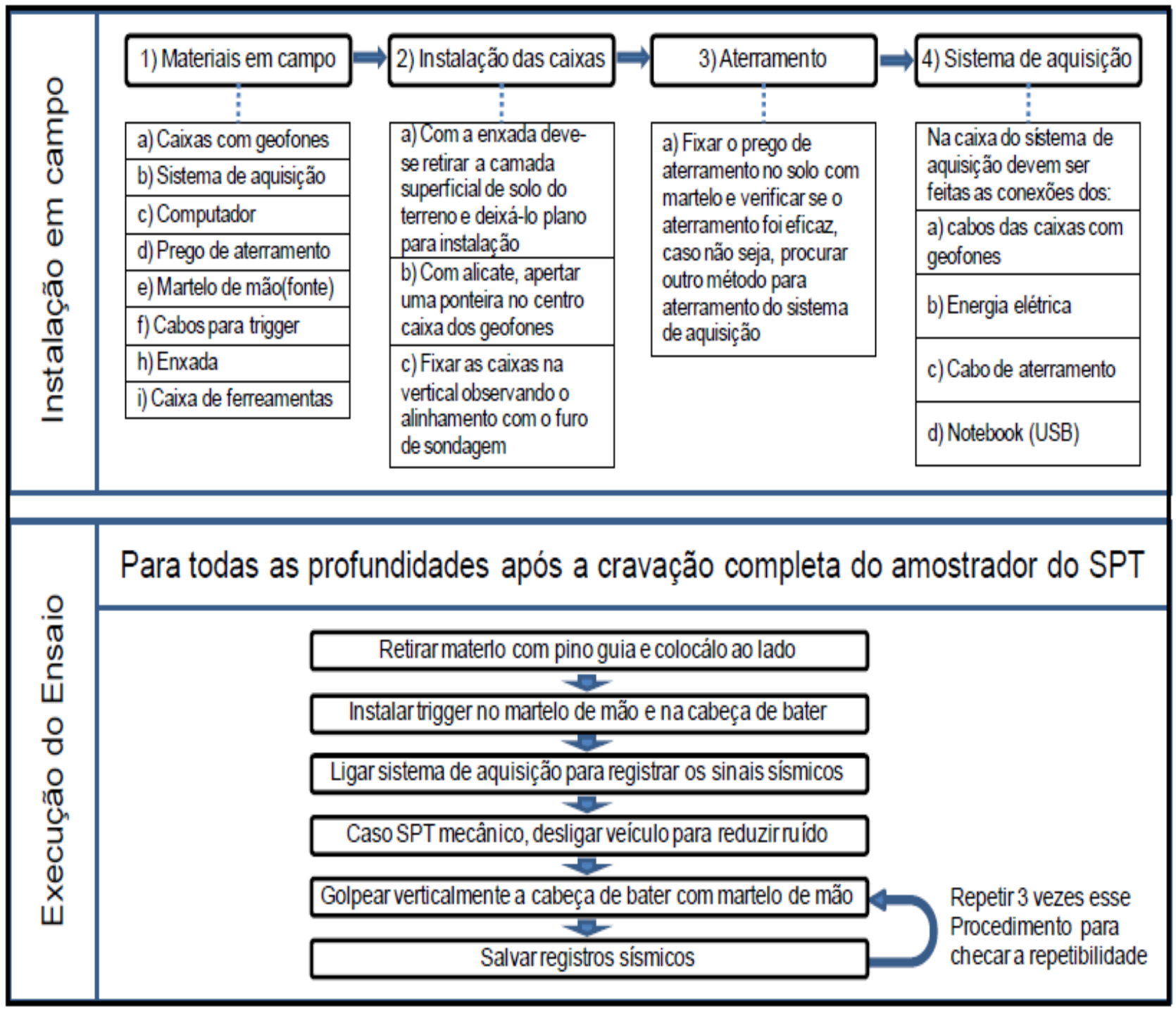

Figura 27: Síntese da metodologia de execução desenvolvida

Fonte: Pedrini (2012) 


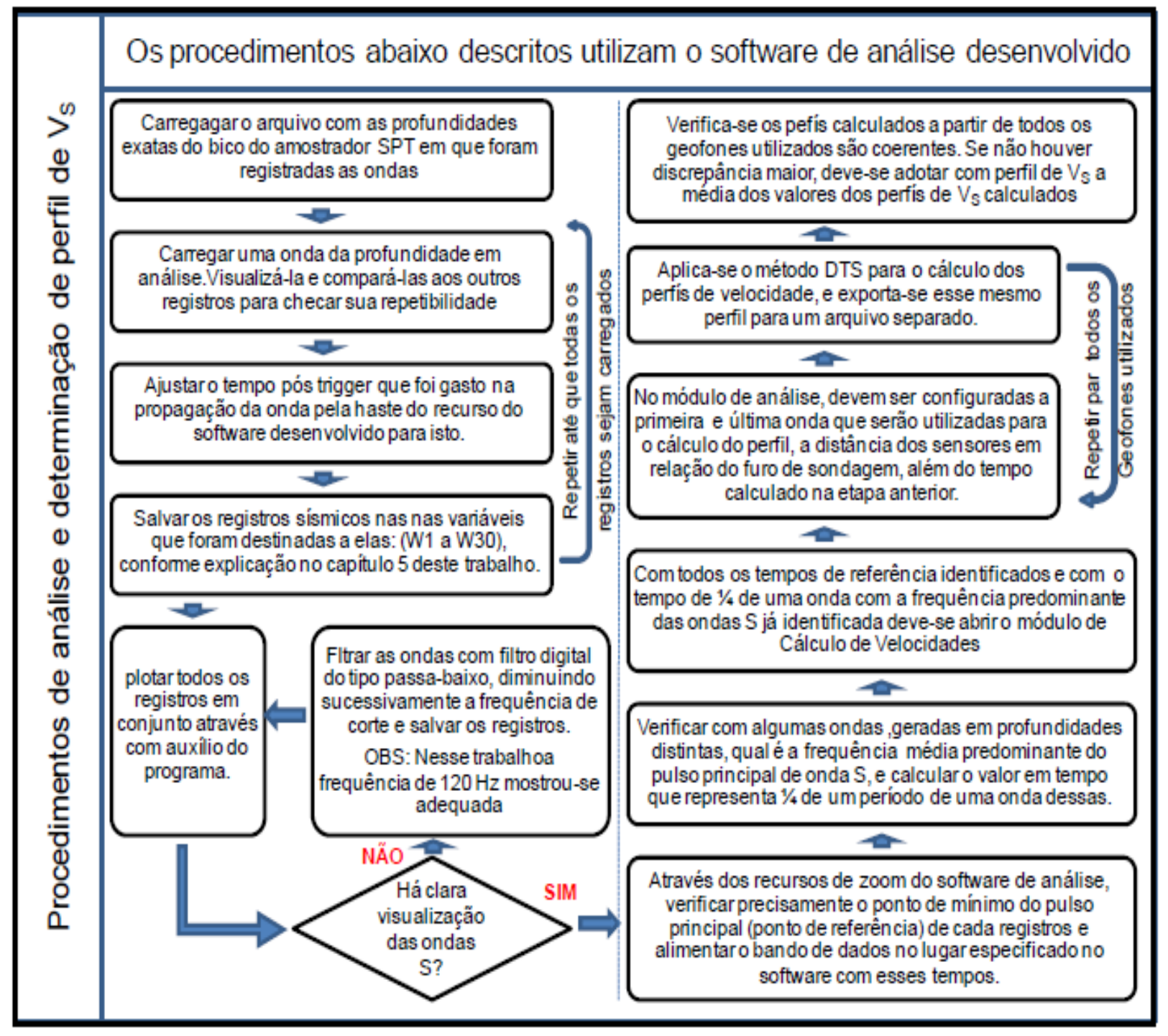

Figura 28: Síntese da metodologia de análise desenvolvida

Fonte: Pedrini (2012)

\subsubsection{Verificação e Validação do Equipamento Desenvolvido}

Pedrini (2012) realizou-se inicialmente três ensaios S-SPT no campo experimental da UNESP-Bauru, para fazer uma análise quantitativa dos sinais produzidos, além de permitir o aperfeiçoamento do hardware e software e da metodologia de execução do ensaio. Posteriormente, para validação do equipamento, foi realizado outro ensaio S-SPT 3, até a profundidade de $21 \mathrm{~m}$, determinando-se o perfil de velocidade de onda $\mathrm{S}$, e comparando os resultados obtidos com os ensaios sísmicos (SCPT e Down-hole) anteriormente realizados no local. Na Figura 29 são apresentados às posições dos ensaios sísmicos S-SPT0, 1, 2 e 3, SCPT e DH. 


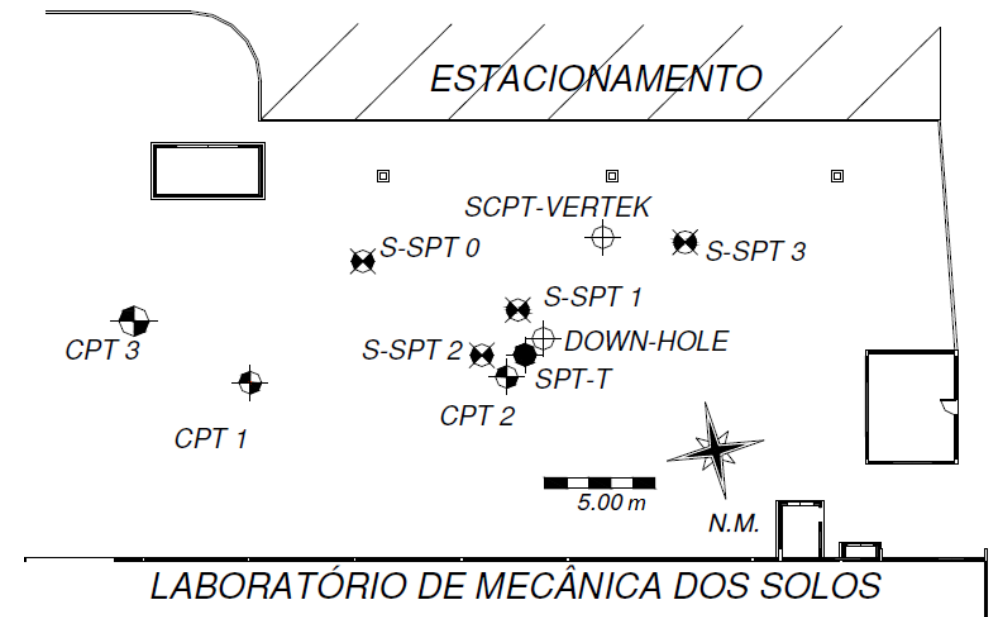

Figura 29: Posição dos ensaios sísmicos realizados no campo experimental da UNESP-Bauru Fonte: Pedrini (2012)

A análise do perfil de velocidade $\left(\mathrm{V}_{\mathrm{S}}\right)$ determinado através do ensaio S-SPT3, validando o equipamento e metodologia desenvolvida por Pedrini (2012) será abordado no item 5.1.1 deste trabalho. Após esta análise, o emprego da técnica mostra-se muito interessante, pois além de permitir a aquisição de mais um parâmetro sem muito custo ao ensaio SPT, ensaio mais utilizado no Brasil e na maioria dos países do mundo, diminui a subjetividade do ensaio, com uma análise quantitativa, e não mais só uma análise qualitativa.

\subsection{Parâmetros Dinâmicos em Solos Tropicais}

\subsubsection{Solos Tropicais}

De maneira geral, o Committee on Tropical Soils of ISSMFE (1985), defini solo tropical como aquele que apresenta peculiaridades de propriedades e de comportamento, relativamente aos solos não tropicais, em decorrência da atuação no mesmo de processos geológicos e/ou pedológicos típicos de regiões tropicais úmidas.

Para se caracterizar o comportamento e identificar a variabilidade dos solos tropicais, é necessário conhecer e entender sua gênese e estrutura (De MIO, 2005).

Nogami e Villibor (1983) descrevem e caracterizam as duas principais classes dos solos tropicais, que são: solos lateríticos e os solos saprolíticos. Segundo Barros (1997) os solos lateríticos podem ter origem tanto residual como transportada, apresentando o processo 
de laterização. Os solos saprolíticos são obrigatoriamente residuais, caracterizados por apresentarem estruturas herdadas da rocha matriz.

\subsubsection{Solos Lateríticos}

Segundo Gidigasu (1990) os solos lateríticos são solos que sofreram evolução pedogenética em regiões de clima subtropical e tropical úmido em condições favoráveis de drenagem. Nesta situação ocorre a lixiviação de sílica e bases, acarretando numa concentração de óxidos e hidróxidos de ferro e alumínio, sendo esse processo denominado de laterização. Vale salientar que o processo de laterização não ocorre somente em solos residuais, mas também em solos coluvionares e transportados (BARROS, 1997).

Os solos lateríticos são caracterizados por apresentar coloração avermelhada ou amarelada, suas camadas vão de um a vários m de profundidade (GIDIGASU, 1990).

A mineralogia dos solos lateríticos varia consideravelmente, sendo parcialmente herdado da rocha matriz ou derivado dos processos de intemperismo envolvidos na formação dos solos lateríticos (GEOLOGIAL SOCIETY, 1990).

Estes solos apresentam um comportamento associados a sua gênese, grau de alteração, composição química e mineralógica, que conduzem à formação de agregados estáveis, cimentados, resultante da grande concentração de sesquióxidos, não podendo ser esquecido também às tensões de sucção, já que esses solos são na maioria das vezes encontrados na condição não saturada (FONTOURA; LITTLE; COLLINS, 1985).

Através de resultados de microscopia eletrônica Nogami e Villibor (1995) concluíram que a parcela fina dos solos lateríticos está agregada, formando uma massa de aspecto esponjoso. Esta organização pode formar solos porosos com alta permeabilidade.

\subsubsection{Solos Saprolíticos}

As características dos solos saprolíticos estão intimamente relacionadas com a rocha matriz. Desta forma, as camadas podem variar de algumas a várias dezenas de metros e apresentarem diferentes comportamentos e cores, sendo encontrada em camadas subjacentes a do solo laterítico. Eles são identificados macroscopicamente por apresentarem xistosidades, manchas, vazios e outras características inerentes à rocha matriz. Sua composição 
mineralógica é muito variada, devido ao intemperismo da rocha, dependendo, portanto, do grau de alteração e do tipo de rocha (FUTAI, 1999).

Segundo Presa (1994) os solos saprolíticos possuem mineralogia muito variada, apresentando, em muitos casos, mineralogias em todas as frações granulométricas. Na fração argila ocorrem argilominerias expansivos, como a montmorilonita e ilita e na fração areia ocorrem minerais não estáveis ao intemperismo, como o feldspato e a mica. Na Figura 30 é apresentado um perfil de solo tropical, onde se pode verificar a presença de solo laterítico (camada superior) e saprolítico (camada inferior).

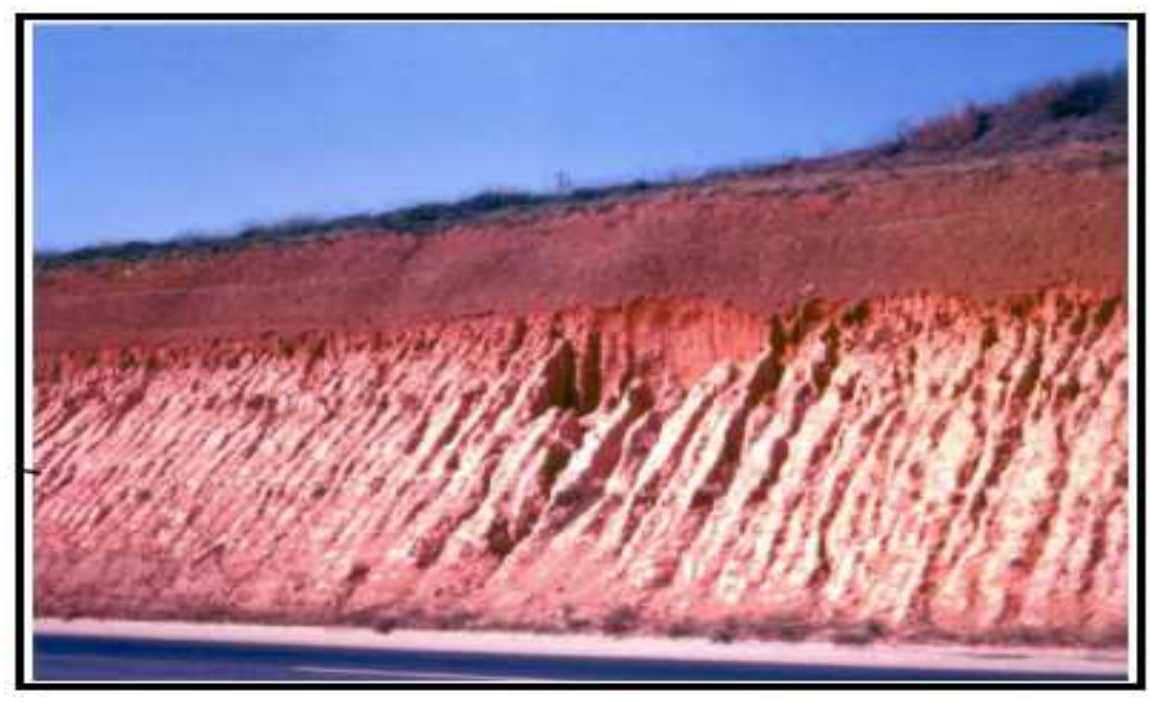

Figura 30: Perfil típico de solos tropicais

Fonte: Mackenzie (2011)

\subsubsection{Módulo de Cisalhamento Máximo $\left(G_{0}\right)$ de Solos Tropicais}

O estudo de parâmetros dinâmicos em solos tropicais no Brasil iniciou-se na década 80. Samara e Martins (1986) realizaram ensaios de coluna ressonante e cross-hole na cidade de São José dos Campos-SP, em um solo argiloso não saturado da Bacia Terciária de Taubaté. Na Figura 31 são apresentados os resultados dos ensaios de campo (cross-hole) e de laboratório (coluna ressonante). 


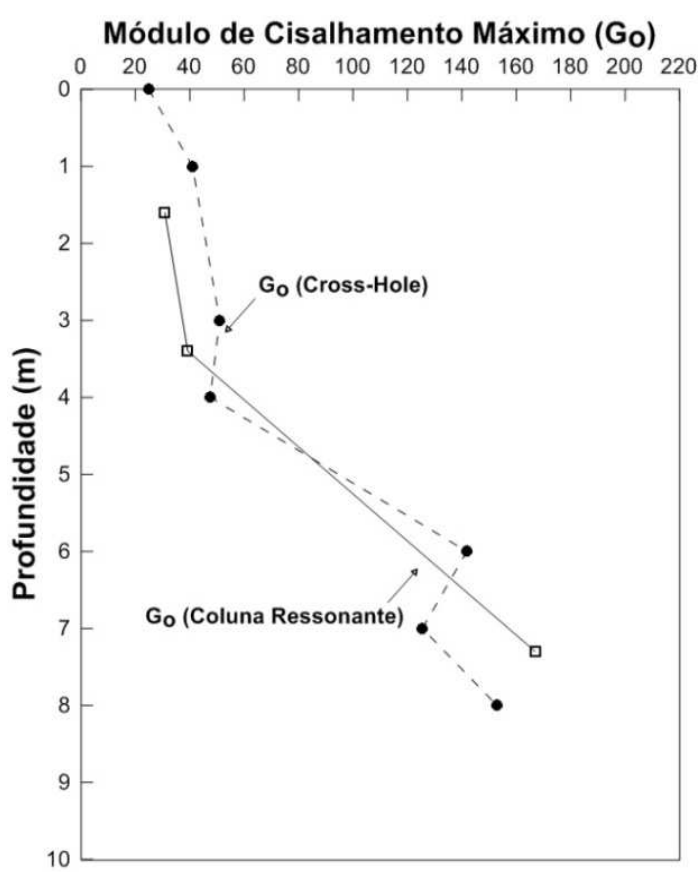

Figura 31: Comparação entre valores de $G_{0}$ obtidos por coluna ressonante e cross-hole Fonte: adaptado de Samara e Martins (1986)

Barros, Giacheti e Martins (1991) demonstraram e discutiram o comportamento peculiar dos solos tropicais brasileiros, baseados em ensaios realizados em onze amostras de solo, sendo sete argilosas e quatro arenosas. Dentre as amostras argilosas, haviam cinco de origem sedimentar e duas residuais. As amostras arenosas foram duas com grande quantidade de conchas e duas sem a presença de concha. O autor comparou os valores do módulo de cisalhamento máximo obtido por ensaios de coluna ressonante, com os valores estimados pela correlação proposta por Hardin (1978), apresentada pela equação 6. Nas amostras arenosas com grande quantidade de conchas, o valor do módulo de cisalhamento máximo medidos foi da ordem de $50 \%$ superior ao obtido pela equação 6, fato este, associado a presença das conchas. As outras duas amostras arenosas apresentaram valores medidos superiores ao estimados na ordem de $10 \%$. No caso das amostras argilosas, as de origem sedimentar apresentaram valores medidos foram cerca de $10 \%$ superiores aos obtidos pela equação 6 . Entretanto, as duas amostras de origem residual apresentaram valores superiores aos estimados na ordem de 100 a 150\%. O autor atribui este fato a influência das tensões capilares, já que os solos não se apresentavam saturados. Vale ressaltar que Samara e Martins (1986) encontraram discrepâncias dessa ordem em solos não saturados da Bacia Terciária de Taubaté.

Giacheti (1991) agrupou os dados obtidos por Samara e Martins (1986), ABEF (1989) e Barros (1990) em dois gráficos (Figura 32), para ressaltar as diferenças observadas entre os solos de origem sedimentar e residual. 

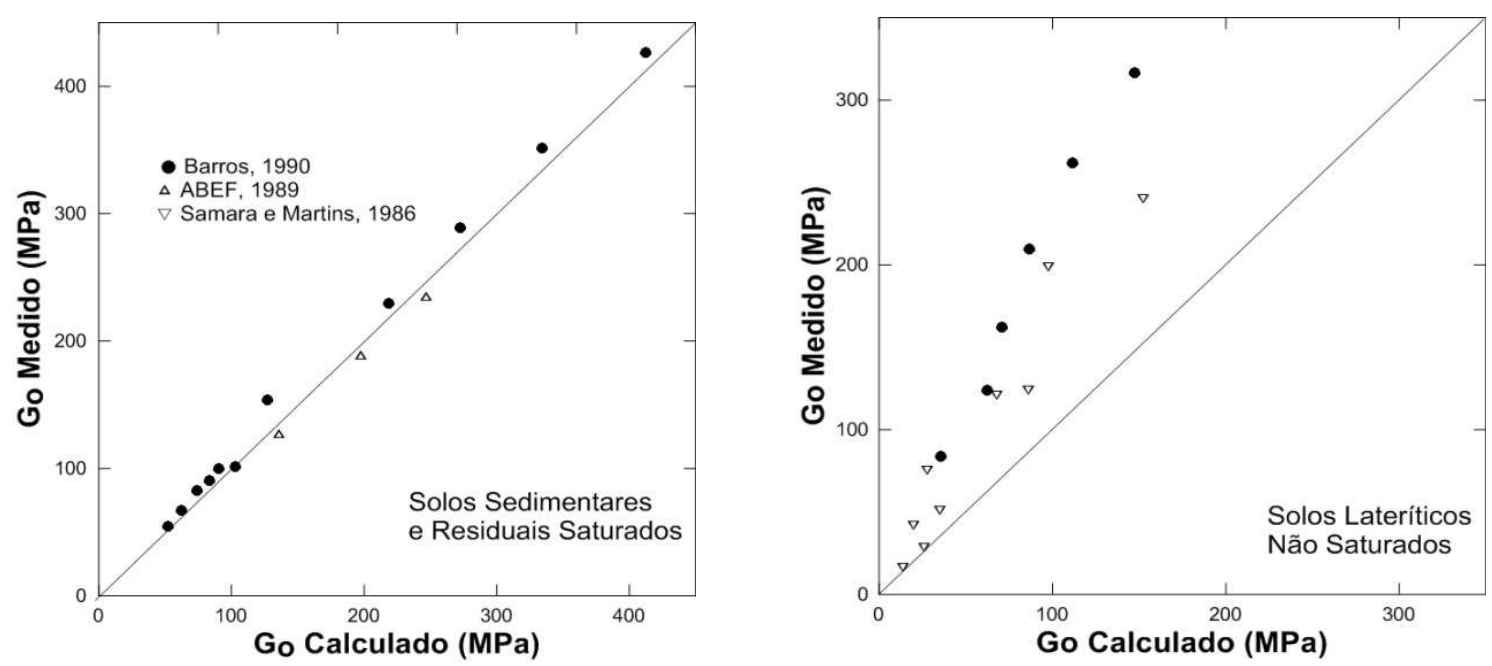

Figura 32: Comparação dos valores de $\mathrm{G}_{\mathrm{o}}$ medidos versus $\mathrm{G}_{\mathrm{o}}$ calculado

Fonte: adaptado de Giacheti (1991)

Giacheti (1991) realizou um amplo estudo sobre os parâmetros dinâmicos dos solos tropicais que ocorrem em Bauru, Campinas e São Carlos. Neste estudo o módulo de cisalhamento máximo $\left(\mathrm{G}_{\mathrm{o}}\right)$ foi determinado por meio de ensaios de coluna ressonante e crosshole. $\mathrm{O}$ autor também comparou os resultados obtidos nos ensaios com a expressão empírica proposta por Hardin (1978). Para a cidade de Bauru, encontrou diferenças variando entre 20 a $75 \%$, em Campinas esta diferença esteve entre 50 a 200\% e em São Carlos variou de 25 a 110\%. Giacheti (1991) apresenta como possíveis fatores que explicam esse comportamento duas características peculiares dos solos tropicais: a cimentação das partículas e a condição não saturada.

Wu (1983), verificou um acréscimo significativo em $\mathrm{G}_{\mathrm{o}}$ para solos arenosos finos para graus de saturação entre 5 e 25\% (Figura 33). Outra característica interessante é que o valor de $G_{o}$ na condição saturada é igual ou um pouco diferente da condição seca. Outro fato observado pelo autor é o efeito da tensão confinante, que diminui o efeito da tensão de sucção.

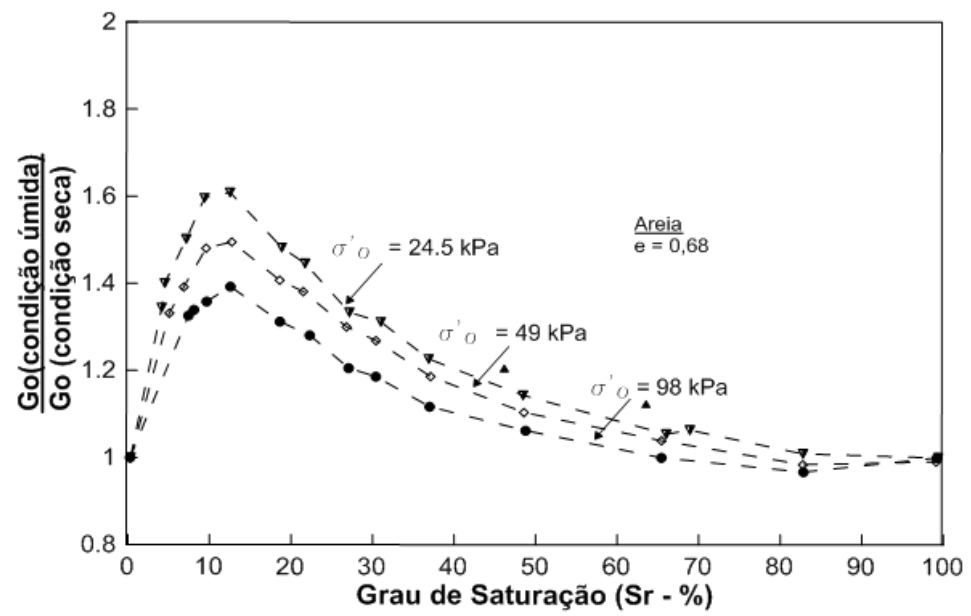

Figura 33: Relação $\mathrm{G}_{\mathrm{o}}$ (condição úmida) e $\mathrm{G}_{\mathrm{o}}$ (condição seca) versus o grau de saturação para uma areia em diferentes tensões de confinamento

Fonte: adaptado $\mathrm{Wu}(1984)$ 
Giacheti e Rohm (1996) estudando o efeito da sucção matricial no módulo de cisalhamento máximo $\left(\mathrm{G}_{\mathrm{o}}\right)$ de um solo arenoso laterítico da região de Bauru-SP, obtido a 4,8 m de profundidade, obteve resultados semelhantes ao de Wu (1983) (Figura 34).

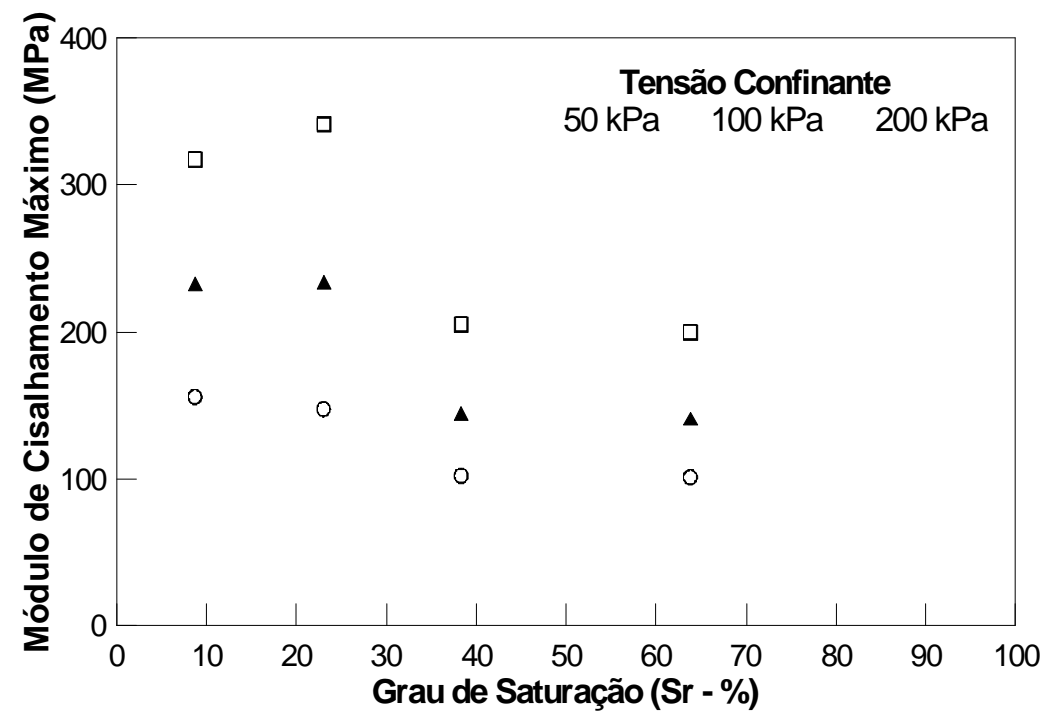

Figura 34: Relação $G_{0}$ versus grau de saturação para um solo arenoso laterítico de Bauru

Fonte: Adaptado de Giacheti e Rohm (1996)

No caso da cimentação das partículas, Giacheti (1991), cita inúmeras pesquisas (Chiang e Chae, 1972; Acar e El-Thair, 1986; Chang e Woods, 1987) em solos cimentados artificialmente, que indicam que o aumento da porcentagem de cimento (c) na mistura, causa um aumento na rigidez a baixa amplitude de deformação $\left(\mathrm{G}_{\mathrm{o}}\right)$.

\subsubsection{Cone Sísmico e a Relação $G_{0} / q_{c}$ na Investigação de Solos Tropicais}

O uso do ensaio de Cone sísmico tem aumentado no Brasil nos últimos anos. Francisco (1997) foi um dos pioneiros a realizar ensaios SCPTU em areais de Maceió/AL e em argilas do Rio de Janeiro/RJ, utilizando um sistema de aquisição de dados desenvolvido por ele mesmo. De Mio (2005) realizou estes ensaios em três campos experimentais do interior de São Paulo comprovando que a cimentação das partículas dos solos tropicais promove um aumento na rigidez à baixa amplitude de deformação, por isso tem-se um aumento na velocidade de propagação das ondas $S$.

Os solos tropicais apresentam condição não saturada, tornando as medidas de poropressão muitas vezes inconsistentes e incoerentes para classificar um solo. Em função disso correlações entre a rigidez a pequenas deformações $\left(\mathrm{G}_{\mathrm{o}}\right)$ e a resistência de ponta do cone $\left(\mathrm{q}_{\mathrm{c}}\right)$ 
tem sido formuladas para areias e argilas, bem como uma ampla gama de tipos de solos (LUNNE; ROBERTSON; POWELL, 1997).

Schnaid, Fahey e Lehane (2004), sugerem que ensaios SCPT podem ser utilizados para avaliação do tipo de solo, a partir da relação $\mathrm{G}_{\mathrm{o}} / \mathrm{q}_{\mathrm{c}}$, que é a relação entre rigidez elástica e resistência última, sendo assim possível esperar um aumento com o envelhecimento e cimentação, primeiramente por que estes efeitos atuam principalmente em $\mathrm{G}_{0}$. $\mathrm{O}$ autor propôs um gráfico e limites para correlacionar $\mathrm{G}_{\mathrm{o}} / \mathrm{q}_{\mathrm{c}}$ versus $\mathrm{q}_{\mathrm{c} 1}$, sendo $\mathrm{q}_{\mathrm{c} 1}$ a resistência de ponta do cone normalizado adimensional definida pela equação 17 :

$q_{c 1}=\left(\frac{q_{c}}{p_{a}}\right) \cdot \sqrt{\frac{p_{a}}{\sigma_{v}^{\prime}}}$

onde:

$\mathrm{p}_{\mathrm{a}}$ : pressão atmosférica;

$\sigma_{v}^{\prime}$ : tensão vertical efetiva

Robertson et. al.(1995) propôs um ábaco onde se plota a resistência de ponta do cone normalizada $\left(\mathrm{Q}_{\mathrm{t}}\right)$ versus a relação $\mathrm{G}_{\mathrm{o}} / \mathrm{q}_{\mathrm{c}}$. Este ábaco pode ser utilizado como ferramenta adicional para identificação de solos compressíveis, bem como, os efeitos de envelhecimento e cimentação.

Giacheti e De Mio (2008) interpretaram resultados de ensaios de cone sísmicos (SCPT) e cross-hole $(\mathrm{CH})$ realizados em três campos experimentais brasileiros (Bauru, São Carlos e Campinas) e mostraram que os solos lateríticos apresentam uma relação $\mathrm{G}_{\mathrm{o}} / \mathrm{q}_{\mathrm{c}}$ superiores aos solos saprolíticos, de modo que este índice pode ser empregado para diferenciar esses horizontes.

Giacheti e De Mio (2008) plotaram os resultados desses ensaios nos ábacos de Robertson et. al. (1995) e Schnaid, Fahey e Lehane. (2004), (Figuras 35 e 36) apresentam estes resultados para os três campos experimentais. Estes autores verificaram que a proposta de Schnaid, Fahey e Lehane (2004) indica que a estrutura cimentada dos solos arenosos tropicais produzem $\mathrm{G}_{\mathrm{o}} / \mathrm{q}_{\mathrm{c}}$ maiores do que aqueles medidos em solos sedimentares. Constatou ainda que em ambos os ábacos, o efeito da maior cimentação das partículas nos solos lateríticos do que nos solos saprolíticos. Com base nesse estudo, os autores concluíram que: 
- O ensaio SCPT, em função da possibilidade da determinação de dois parâmetros no mesmo ensaio, simplifica a interpretação e reduz a variabilidade dos resultados;

- Através da interpretação dos ensaios SCPT, verificou que a estrutura cimentada dos solos tropicais produzem valores maiores $\mathrm{de}^{\mathrm{G}_{\mathrm{o}}} / \mathrm{q}_{\mathrm{c}}$ do que em solos sedimentares;

- Foi verificado que a relação $\mathrm{G}_{\mathrm{o}} / \mathrm{q}_{\mathrm{c}}$ apresenta valores maiores para solos lateríticos do que para solos saprolíticos.

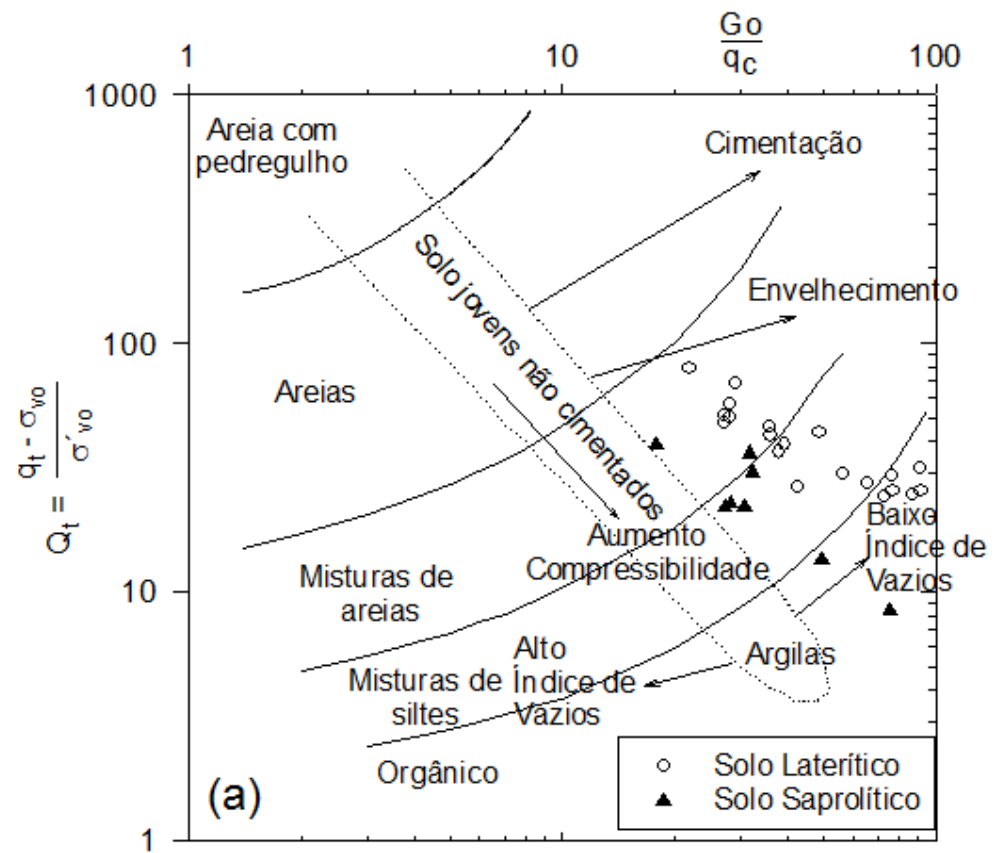

Figura 35: Relação entre $G_{o}$ e $q_{c}$ para os solos de São Carlos, Bauru e Campinas no ábaco de Robertson et. al. (1995)

Fonte: adaptado de Giacheti e De Mio (2008)

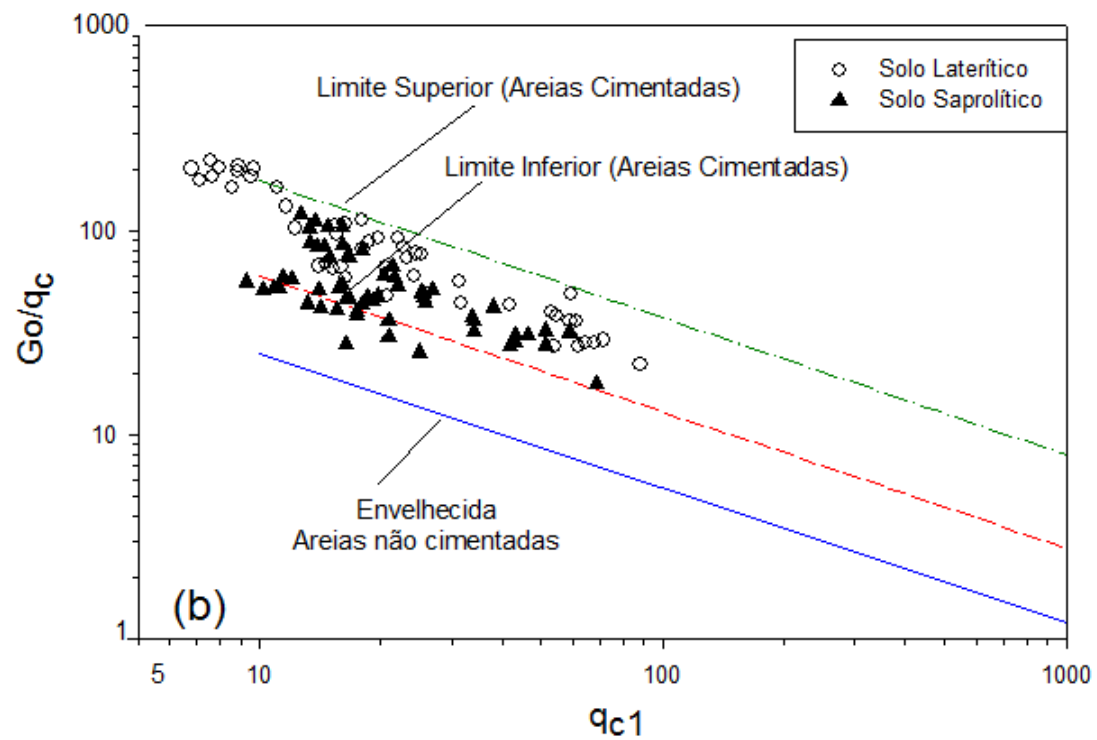

Figura 36: Relação entre $G_{o}$ e $q_{c}$ para os solos de São Carlos, Bauru e Campinas segundo Schnaid, Fahey e Lehane, (2004)

Fonte: Adaptado de Giacheti e De Mio (2008) 
Da mesma forma que no ensaio SCPT, Schnaid, Fahey e Lehane (2004), demonstram a possibilidade da combinação do $\mathrm{N}$ do ensaio $\mathrm{SPT}$ com $\mathrm{G}_{\mathrm{o}}$, para auxiliar na avaliação da presença de estruturas cimentantes e sua variação, com a profundidade. Esta combinação é apresentada na Figura 37. No qual se tem $\left(\mathrm{G}_{\mathrm{o}} / \mathrm{p}_{\mathrm{a}}\right) / \mathrm{N}_{60}$ versus $\left(\mathrm{N}_{1}\right)_{60}$ em solos residuais. $\left(N_{1}\right)_{60}$ é um parâmetro normalizado adimensional definido pela equação 18 :

$$
\left(N_{1}\right)_{60}=N_{60} \cdot\left(\frac{p_{a}}{\sigma^{\prime} v o}\right)^{0.5}
$$

onde:

$N_{60}$ : Índice de resistência à penetração do Ensaio SPT para eficiência de $60 \%$

$\mathrm{p}_{\mathrm{a}}$ : pressão atmosférica;

$\sigma^{\prime}{ }_{v o}:$ tensão vertical efetiva

Os autores constatam que a cimentação das partículas acarreta um efeito marcante no comportamento dos solos residuais, produzindo valores de $\mathrm{G}_{0} / \mathrm{N}_{60}$ consideravelmente maiores que os observados nos solos sedimentares.

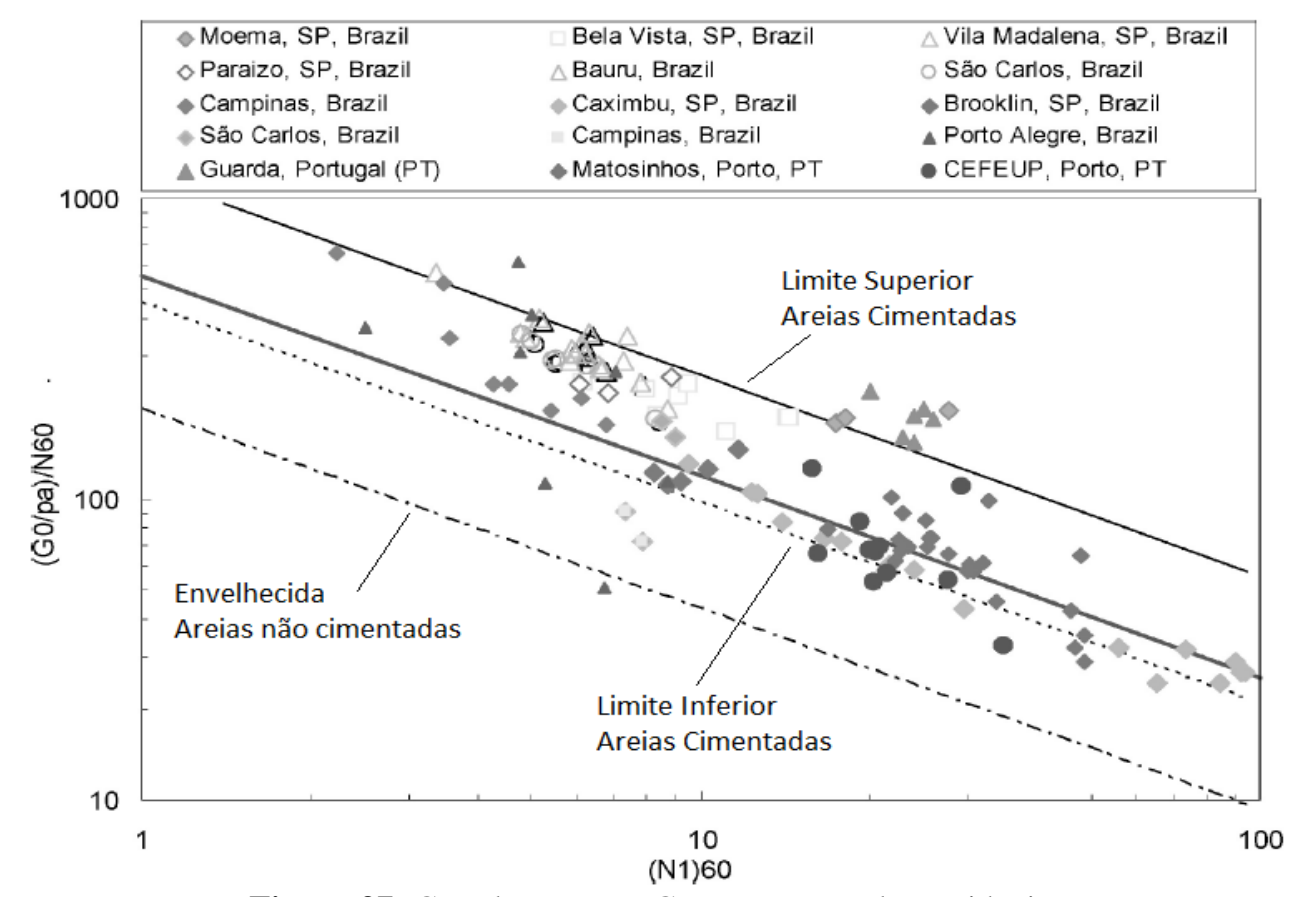

Figura 37: Correlação entre $\mathrm{G}_{0}$ e $\mathrm{N}_{60}$ para solos residuais

Fonte: Schnaid, Fahey e Lehane (2004), completado por Viana da Fonseca e Coutinho (2008)

Em seu estudo, Schnaid, Fahey e Lehane, (2004) também propuseram limites superior e inferior para a variação de $\mathrm{G}_{\mathrm{o}} \operatorname{com} \mathrm{N}$, que são expressos nas equações apresentadas a seguir. 
$G_{O}=1200 \sqrt[3]{N_{60} \sigma^{\prime}{ }_{v o} p a^{2}}:$ limite superior - estrutura cimentada;

$G_{o}=450 \sqrt[3]{N_{60} \sigma^{\prime}{ }_{v o} p a^{2}}:$ limite inferior - estrutura cimentada;

limite superior - estrutura não cimentada;

$G_{o}=200 \sqrt[3]{N_{60} \sigma^{\prime}{ }_{v o} p a^{2}}$ : limite inferior - estrutura não cimentada;

Os resultados dessas pesquisas encoraja a continuidade dos trabalhos e indicam à necessidade do emprego de equipamentos e técnicas de tratamento de dados e interpretação, mais apurados na tentativa de se tirar todas as vantagens que a ferramenta oferece especialmente para investigação de solos tropicais.

A possibilidade de se medir, ao mesmo tempo e no mesmo furo de sondagem valores de $\mathrm{N}$ do SPT e velocidade de onda $\mathrm{S}\left(\mathrm{V}_{\mathrm{S}}\right)$, através do ensaio S-SPT, que permite calcular o módulo de cisalhamento máximo $\left(\mathrm{G}_{\mathrm{o}}\right)$, abre uma nova perspectiva para investigação de solos tropicais colapsíveis, a partir da relação $\mathrm{G}_{\mathrm{o}} / \mathrm{N}$, similar a relação entre $\mathrm{G}_{\mathrm{o}} / \mathrm{q}_{\mathrm{c}}$. 


\section{MATERIAIS E METÓDOS}

Este capítulo apresenta os equipamentos utilizados e os programas de aquisição, análise e processamento dos registros sísmicos obtidos a partir da execução do ensaio S-SPT.

\subsection{Ensaio S-SPT}

A Figura 38.a mostra uma visão geral do ensaio S-SPT, onde se verifica o equipamento de ensaio e a correta instalação das caixas contendo os geofones. Deve-se salientar a necessidade de um bom aterramento, visando à redução dos ruídos, fato este que será abordado no item 3.1.2 desse capítulo. Na Figura 38.b o sistema de aquisição de dados instalado em uma caixa que possui os conectores dos cabos dos geofones, e o notebook utilizado nos ensaios de campo são demonstrados.

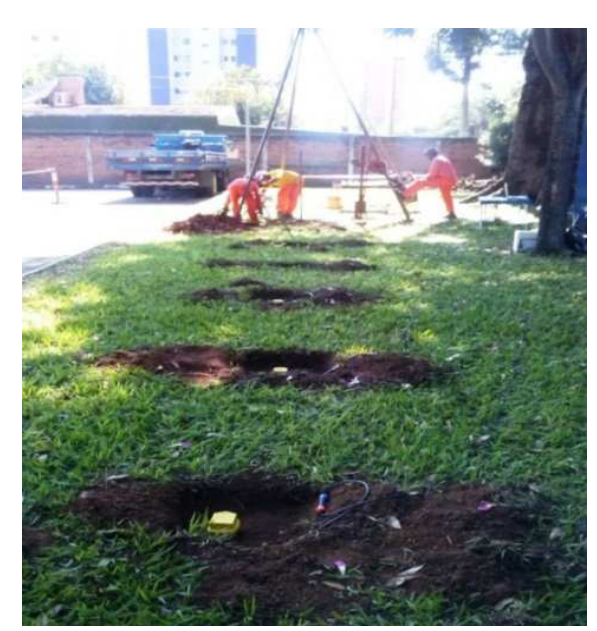

(a)

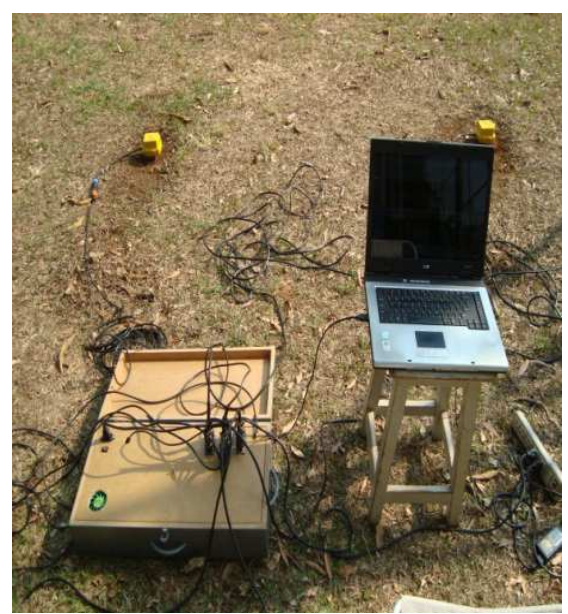

(b)

Figura 38: Esquema do ensaio S-SPT (a); sistema de aquisição dos sinais (b).

\subsubsection{Sondagem de Simples Reconhecimento com medida de SPT}

Os ensaios SPT realizados nesta pesquisa atendem as determinações da norma NBR 6484/01. Nos ensaios foi utilizado o equipamento leve tradicional, do tipo manual, com utilização de tripé, martelo cilíndrico de $65 \mathrm{~kg}$ com pino-guia, cabeça de bater com 3,6 kg, 
coxim de madeira, corda de sisal, hastes e amostrador padrão. A Figura 39 apresenta o tripé e o martelo apoiado na cabeça de bater, e o amostrador contendo uma amostra de solo.
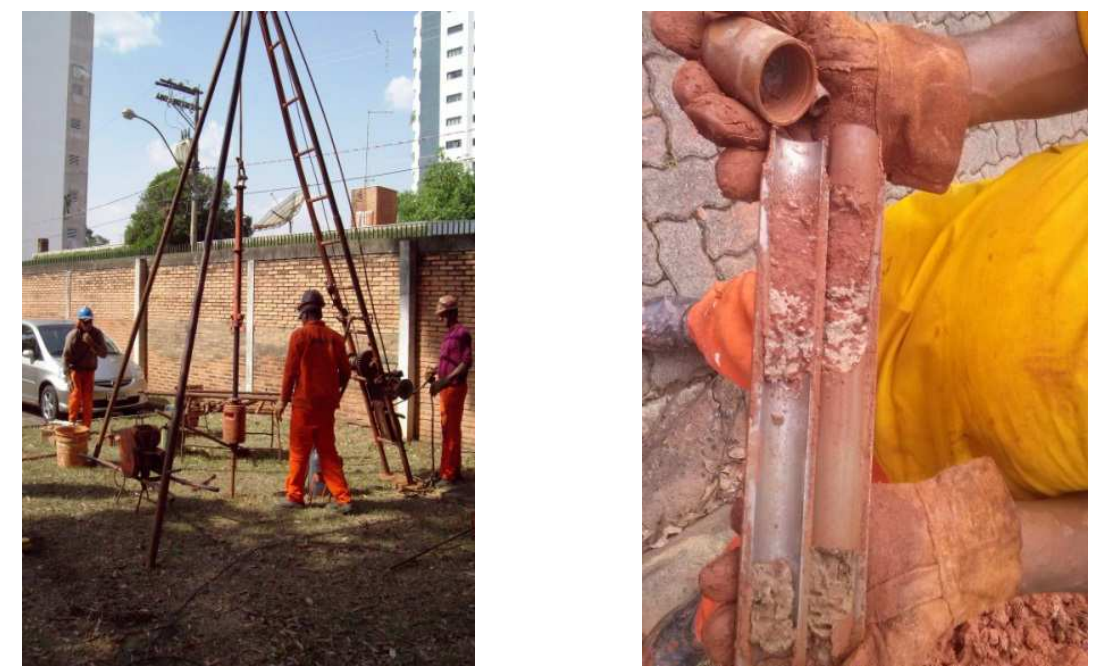

Figura 39: Equipamentos utilizados nos ensaios SPT

\subsubsection{Geofones e aterramento}

Foram utilizadas seis caixas contendo dois geofones cada, espaçadas de 2 em $2 \mathrm{~m}$, conforme sugerido por Pedrini (2012). Cada caixa apresentava um geofone vertical e um horizontal para captação dos sinais propagados no maciço. Os geofones utilizados são do modelo GS-20DH, fabricado pela GeoSpace Technologies. Eles são instalados em caixas fabricadas também pela GeoSpace, do modelo GS-3C. Estas caixas são constituídas de resina termoplástica rígida, vedada por borracha de silicone. Elas apresentam nível de bolha para melhor fixação no solo. As caixas permitem a captação de registros triaxiais (V/H1/H2), sendo um na direção vertical e dois ortogonais na horizontal. Elas são fixadas no solo através de uma ponteira metálica rosqueada em sua base. Como ilustração, a Figura 40 apresenta uma caixa, ponteira metálica rosqueada na caixa e os geofones instalados na caixa, respectivamente. Cada caixa possui um conector (Figura 40.b) que é ligado ao cabo que se conecta ao sistema de aquisição de dados.

Para uma melhor recepção dos sinais, a fixação das caixas no solo é feita de acordo com os seguintes passos:

1) Abertura de valas, com retirada da matéria orgânica da superfície e execução de bases planas; 
2) Boa fixação entre ponteira metálica e as caixas;

3) Cravar a caixa no solo, firmemente, nivelada, sem contato direto com o solo. Somente a ponteira deve ter contato com solo;

4) Garantir o alinhamento entre as caixas e o furo de sondagem;

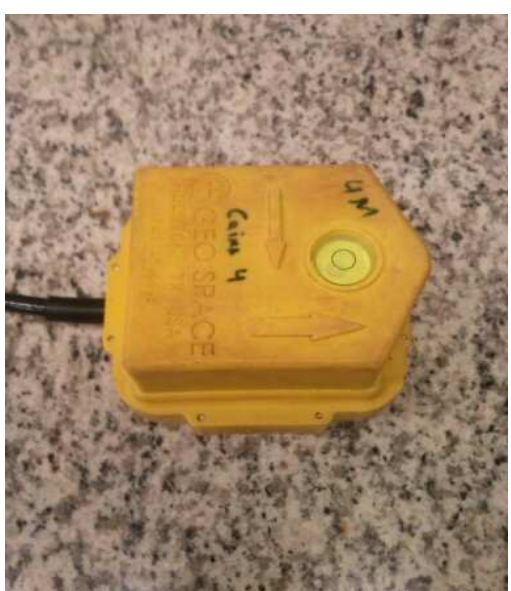

(a)

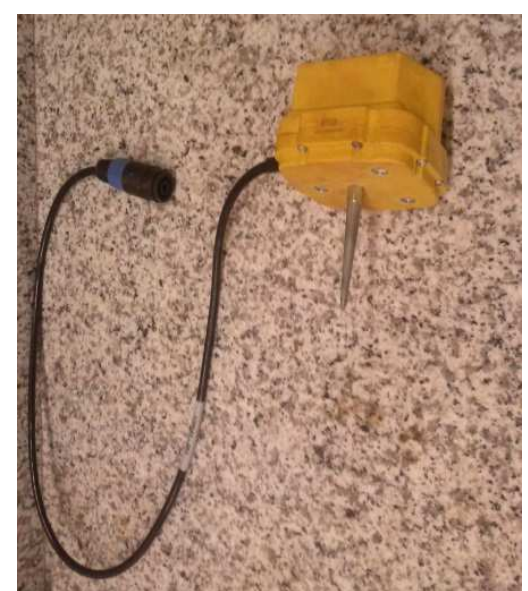

(b)

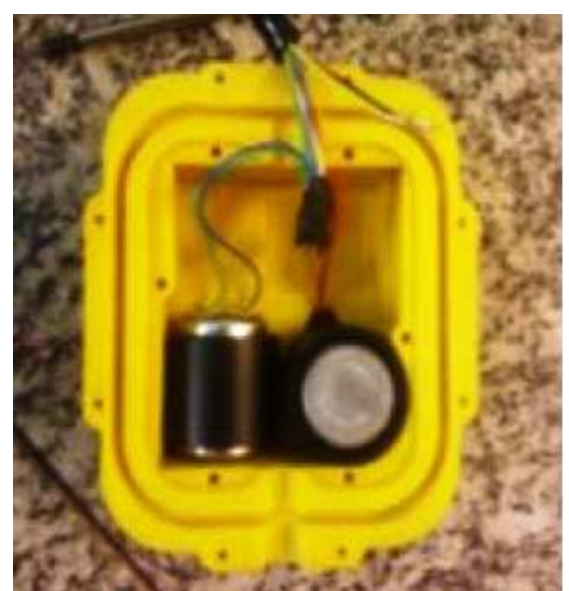

(c)

Figura 40: Caixas e geofones utilizados na sísmica up-hole

O aterramento foi feito utilizando uma barra de aço de 1,3 $\mathrm{m}$ de comprimento, visando à diminuição dos ruídos, conforme recomendado por Pedrini (2012). A Figura 41 apresenta a barra de aço e a mesma cravada no solo.

\subsubsection{Fonte Sísmica e trigger}

A fonte sísmica utilizada na pesquisa foi um martelo de mão de aço, de aproximadamente $2 \mathrm{~kg}$ e foi utilizado um trigger digital de contato (PEDRINI, 2012). Trigger é um dispositivo que indica o início do registro dos sinais sísmicos propagados, sendo ativado no momento em que o martelo toca a cabeça de bater, fechando o circuito. As ondas se propagam pelas hastes até chegarem ao amostrador, onde são transmitidas ao meio. A Figura 42 apresenta o procedimento de ativação do trigger (fechamento do circuito), quando o martelo toca a cabeça de bater, acarretando na geração das ondas durante o ensaio S-SPT.

A seguir é apresentado o procedimento que deve ser utilizado para geração de ondas sísmicas no ensaio S-SPT, segundo as orientações de Pedrini (2012).

1) Com o amostrador completamente cravado, retira-se o martelo do ensaio SPT;

2) Instala-se o trigger, sendo um fio na cabeça de bater e o outro no martelo de mão, como ilustrado na Figura 42; 
3) Inicia-se o programa de aquisição de dados;

4) Com o martelo de mão, golpear verticalmente a cabeça de bater;

5) Golpear-se mínimo 3 vezes verificando a repetibilidade dos sinais no programa de aquisição;

6) Controla-se a profundidade do amostrador e o comprimento de hastes acima da superfície do terreno;

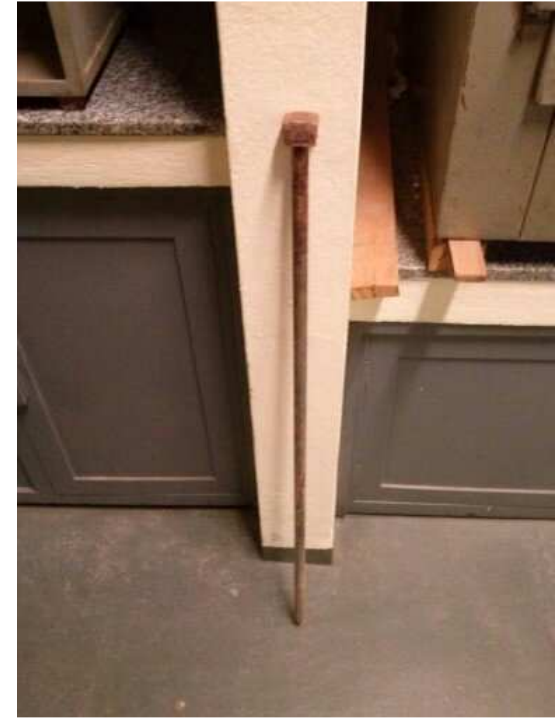

(a)

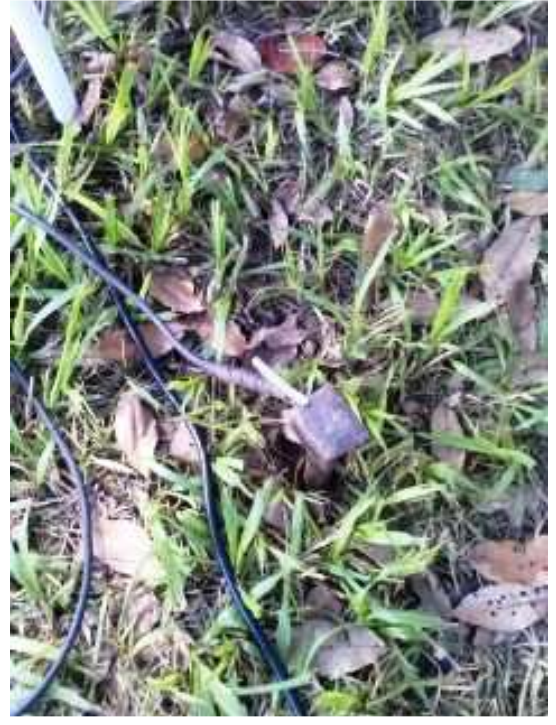

(b)

Figura 41: Barra de aço utilizado para aterramento do sistema de aquisição

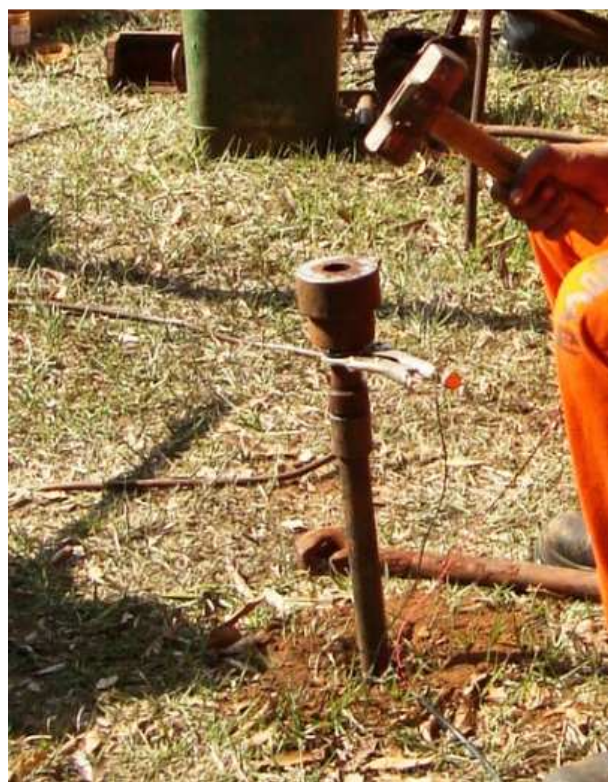

Figura 42: Ativação do trigger e geração de ondas no ensaio S-SPT 
Este último procedimento é muito importante para o ensaio S-SPT, uma vez que, a profundidade do amostrador é fundamental para determinação das velocidades de propagação das ondas, determinadas pelo método DTS.

O procedimento de aquisição e processamento dos sinais sísmicos será abordado nos próximos itens.

\subsubsection{Programas Computacionais}

\subsubsection{Programa de aquisição}

O procedimento para utilização do programa de aquisição dos sinais foi realizado seguindo as recomendações de Pedrini (2012). Como já mencionado, o programa de aquisição foi desenvolvido em plataforma LabView 8.5 e permite adquirir os dados captados pelos geofones e salvá-los conforme o interesse do usuário. O programa é subdividido em três tópicos: Parâmetros para a Aquisição, Apresentação dos registros sísmicos e Arquivo de saída de dados. Os parâmetros para aquisição são: configuração de filtro de frequências, nome dos arquivos de saída, entre outros. A apresentação dos registros sísmicos permite a visualização dos registros obtidos pelos geofones verticais (Figura 43, item 1) e horizontais (Figura 43, item 2). Na Figura 43 é possível visualizar os sinais sísmicos captados pelos seis geofones. Estes sinais são salvos em arquivos de texto em formato.txt (PEDRINI, 2012).

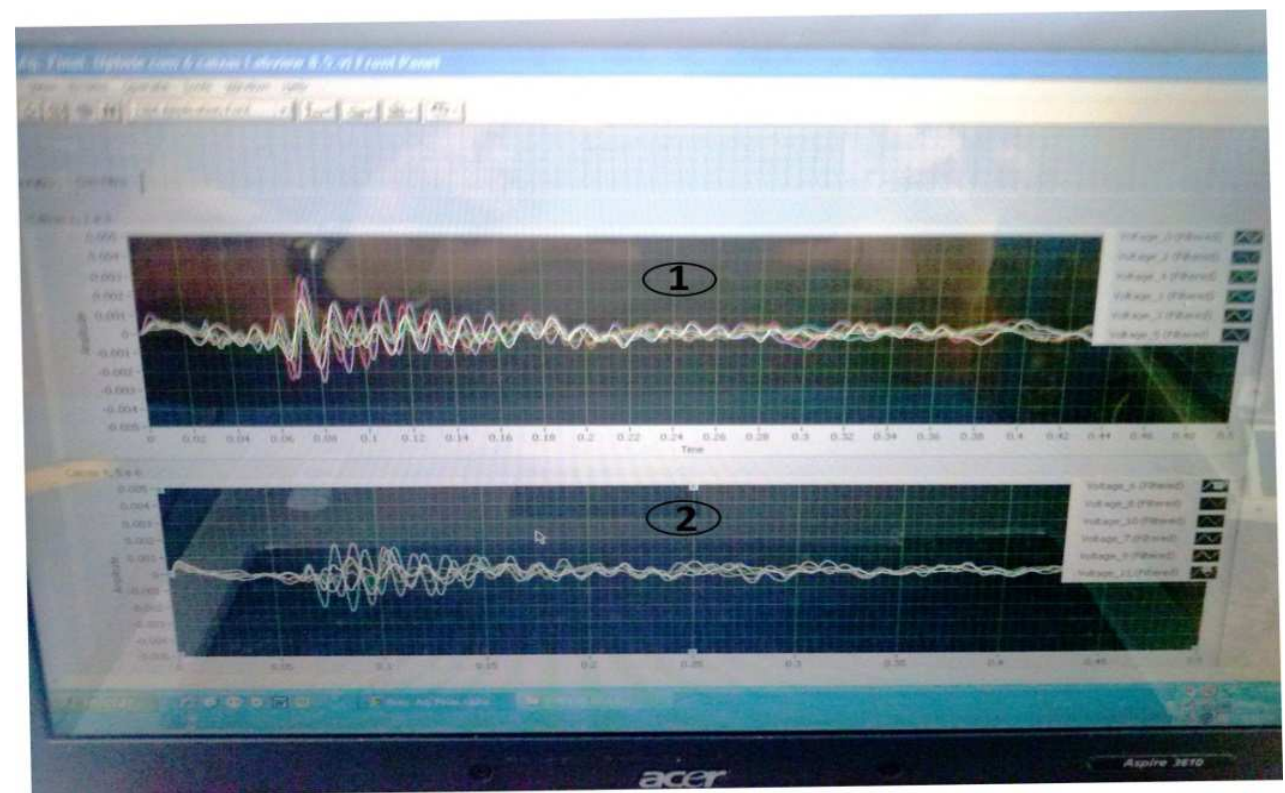

Figura 43: Tela inicial do programa de aquisição e visualização dos sinais sísmicos 


\subsubsection{Programa de processamento e análise dos sinais}

O programa de processamento e análise de dados foi desenvolvido devido à complexibilidade na análise dos dados sísmicos obtidos no ensaio S-SPT. Pedrini (2012) descreve todas as funcionalidades do programa de processamento e análise. A seguir serão apresentadas as funções utilizadas nesta pesquisa, similarmente a Pedrini (2012). A Figura 44 apresenta a tela inicial do programa de processamento e análise dos sinais e as funções numeradas, que foram utilizadas para o desenvolvimento desta pesquisa.

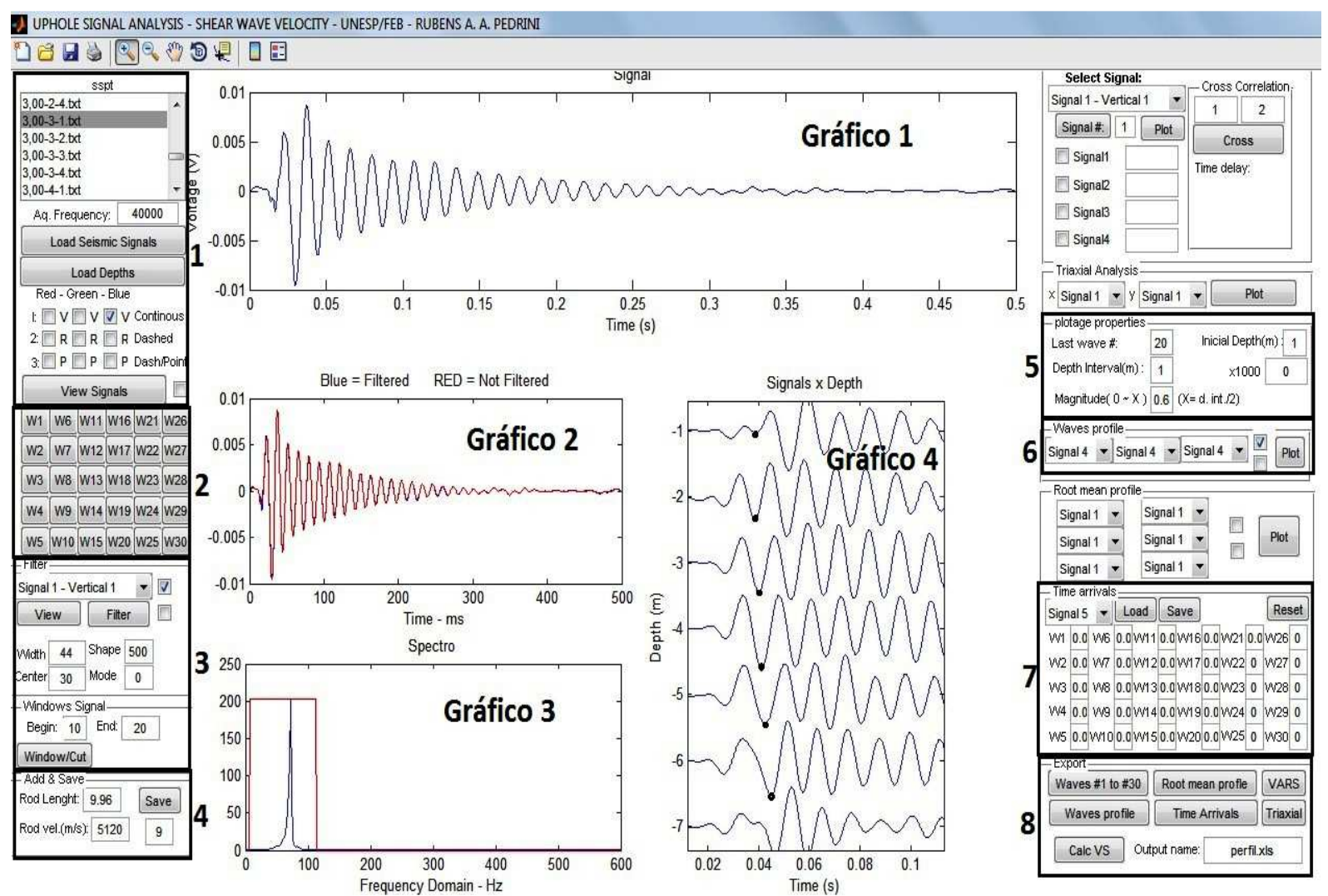

Figura 44: Programa de análise dos sinais e algumas das funções do programa

\section{1) Carregamento e visualização dos sinais}

O item 1 apresenta os arquivos salvos em formato .txt, obtidos pelo programa de aquisição dos sinais e sua taxa de aquisição dos mesmos. Ao selecionar o arquivo de interesse, basta clicar em Load Seismic Signals para visualizar as ondas registradas. Conforme já informado, foram utilizadas 6 caixas com 2 geofones em cada uma. Como cada caixa da GeoSpace permite a instalação de até 3 geofones no seu interior, Pedrini (2012) coloca 9 checkbox, sendo possível escolher qual onda será visualizada. Os três primeiros checkbox 
correspondem aos sinais verticais, os seis últimos aos sinais horizontais, sendo os três centrais relacionadas aos registros no sentido radial e os três últimos ao sentido perpendicular ao radial. Os sinais escolhidos são visualizados no Gráfico 1. É possível visualizar as ondas em uma nova janela, através do checkbox ao lado do botão View Signal, que efetivamente plota os sinais selecionados. O botão LoadDepths é utilizado para informar a profundidade de geração de cada onda. Esta informação é necessária, para determinação do perfil de velocidade através do Módulo de cálculo de velocidade, descrito no item 3.1.4.2.1.

O item 2 apresenta os botões de "W1 a W30", que representam o banco de dados das ondas visualizadas no Gráfico 1, assim para re-visualizar os golpes salvos, basta clicar nestes botões.

\section{2) Análise dos sinais}

No item 3 da Figura 44 é possível realizar um tratamento nos sinais através da utilização de filtros de banda ou trabalhar com o período de onda desejado. Como demonstrado por Pedrini (2012), nesta pesquisa foi utilizado filtro passa-baixo com frequência de corte de $120 \mathrm{~Hz}$, recomendado por Campanella e Stewart (1992).

Inicialmente o usuário deve escolher qual sinal será tratado pelo filtro ou todos, conforme demonstra a Figura 45. Esta função do programa possibilita que o usuário determine parâmetros de filtragem, como o comprimento do filtro em $\mathrm{Hz}$, localização de centro de banda e permite, no caso de escolha de parte do sinal, ajustar o início e o fim do sinal (Figura 45).

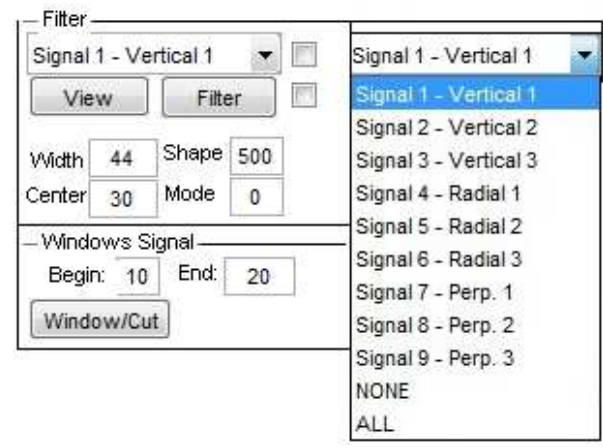

Figura 45: Aplicação do filtro passa-baixo ou selecionar parte do sinal a ser analisado

Com o sinal escolhido o usuário pode visualizá-lo no Gráfico 1, clicando no botão View da Figura 45. Após a visualização do sinal "bruto" o mesmo pode filtrá-lo clicando no botão Filter. Ao clicar, o sinal filtrado é apresentado no Gráfico 2. O Gráfico 3 apresenta o espectro de frequência e o alcance do filtro utilizado pelo usuário. Este procedimento de 
filtragem é uma ferramenta a mais do programa, uma vez que durante a aquisição dos sinais, os mesmos podem ser salvos já filtrados.

\section{3) Adicionando e salvando os registros no banco de dados}

O item 4 da Figura 44 é utilizado para salvar os registros carregados e filtrados ao banco de dados (W1 a W30) para posteriormente serem plotados no Gráfico 4. Como mencionado, as ondas geradas pelo golpe do martelo na cabeça de bater do ensaio SPT se propagam até o amostrador, entretanto, a aquisição dos sinais inicia-se no momento em que trigger é ativado, acarretando numa defasem do sinal. Para resolver este problema Pedrini (2012) implementou no programa um algoritmo que corrigi o início da gravação do sinal. Esta correção é realizada através do comprimento de hastes, pelas quais, a onda propagou-se antes de ser propagada para o solo (Figura 46).

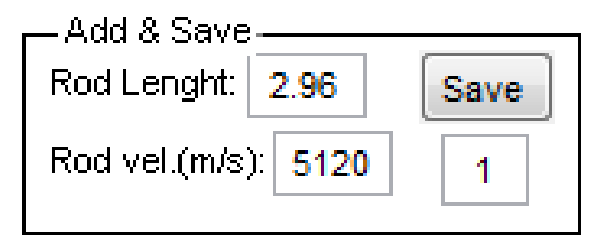

Figura 46: Salvando e adicionado os sinais sísmicos

Para realizar a correção, o usuário deve colocar no campo Rod Lenght o comprimento total de hastes que a onda percorre até chegar à profundidade do amostrador do SPT, onde efetivamente a onda começa a propagar pelo maciço. No campo Rod vel. $(\mathrm{m} / \mathrm{s})$ deve-se colocar a velocidade de propagação da onda no aço, que é aproximadamente $5120 \mathrm{~m} / \mathrm{s}$. No campo abaixo do botão Save deve-se colocar em qual onda, no banco de dados (W1 a W30), será armazenada.

\section{4) Visualização dos perfis das ondas}

Para visualizar qualquer uma das ondas geradas e salvas (W1 a W30) é necessário inicialmente configurar as propriedades de plotagem, apresentado pelo item 5 da Figura 44, demonstrados pela Figura 47. 


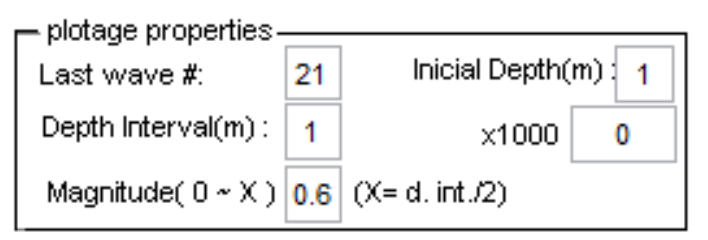

Figura 47: Parâmetros para plotagem dos perfis de onda

No campo Last wave compete ao usuário determinar qual será a última onda carregada (W1 a W30). O campo Depth Interval representa, aproximadamente, o espaçamento entre os sinais, sendo neste caso de $1 \mathrm{em} 1$ metro, devido ao ensaio SPT. O campo Magnitude é utilizado para melhorar a visualização das ondas, através de uma escala gráfica, gerando os perfis de onda na mesma amplitude. Igual a Pedrini (2012), o valor utilizado para a uma melhor visualização foi de 0,6. No campo Inicial Depth é informado em qual profundidade o ensaio foi iniciado, no caso a profundidade de W1.

No item 6 da Figura 44, ampliado na Figura 48, o usuário deve escolher quais ondas serão plotadas no Gráfico 4. Para isso o usuário deve escolher até 3 ondas para serem plotadas, através de 3 combobox apresentados na mesma figura, que apresentam os 9 sinais possíveis de serem captados pelos geofones. Na mesma figura verifica-se a marcação do checkbox superior que corresponde ao ajuste de magnitude da amplitude demonstrado no item 5. Vale ressaltar a possibilidade de visualização desses sinais em janelas separadas, através da marcação do checkbox inferior, mostrado na Figura 48.

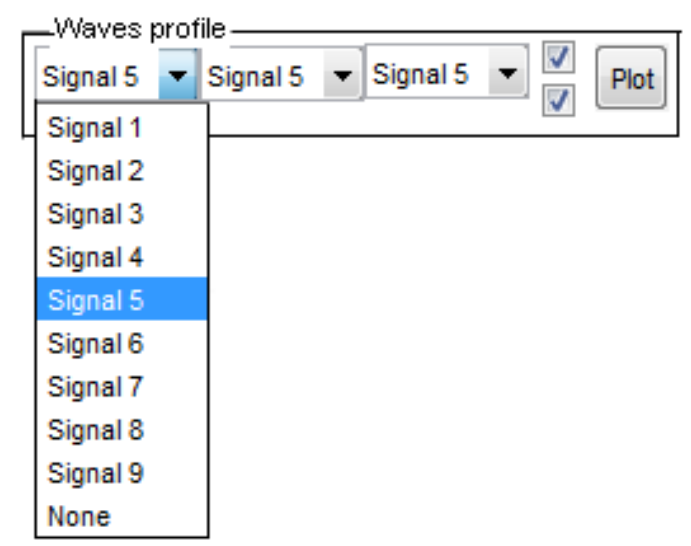

Figura 48: Escolha da onda a ser plotada

\section{5) Preenchimento e determinação do tempo de chegada da onda $S$}

A determinação do tempo de chegada da onda $S$ depende da interpretação feita pelo usuário. Através onda plotada no Gráfico 4 o usuário pode identificar o tempo de chegada 
através de um ponto de referência (máximo ou mínimo), ou conforme sugeriu Bang e Kim (2007), a partir da raiz média dos quadrados dos sinais horizontais e verticais. Neste trabalho foi adotado como ponto de referência o ponto de mínimo. Esta determinação, ilustrada na Figura 49, é realizada através da ferramenta Zoom in e Data cursor na barra de ferramentas mostrada na parte superior da tela, já representada na Figura 44.

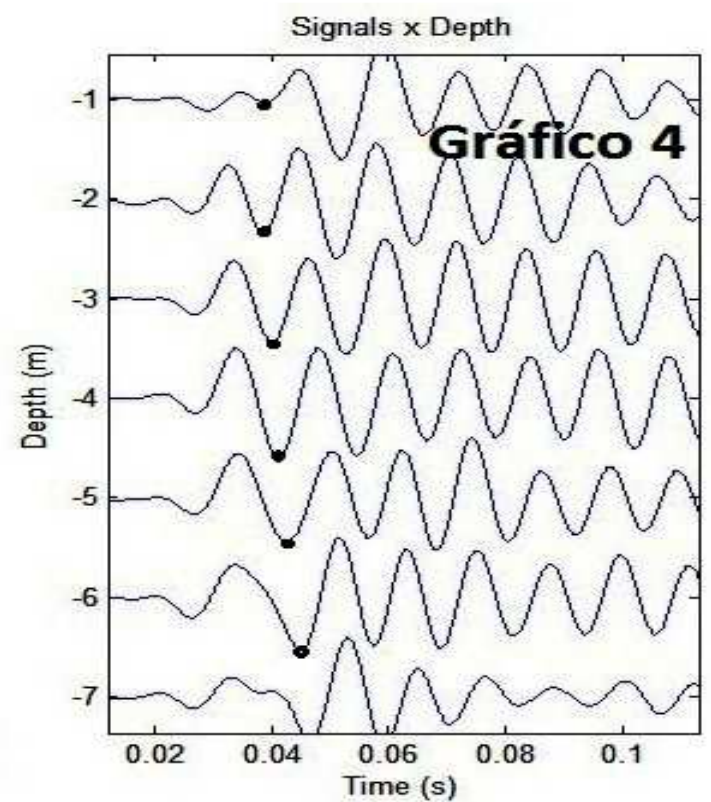

Figura 49: Procedimento para determinação do tempo de chegada das ondas $S$

Com a determinação do tempo de chegada das ondas é utilizado o item 7 da Figura 44, onde o usuário cadastra o tempo de chegada de cada onda, sendo possível escolher qual sinal será registrado. A Figura 50 apresenta o item 7, onde verifica-se as opções Load, Save e Reset, sendo a primeira responsável por carregar as ondas para o cálculo das velocidade pelo Módulo de velocidades (abordado no próximo tópico), a segunda por salvar os registros dos tempos de chegada e o terceiro por deletar os dados cadastrados.

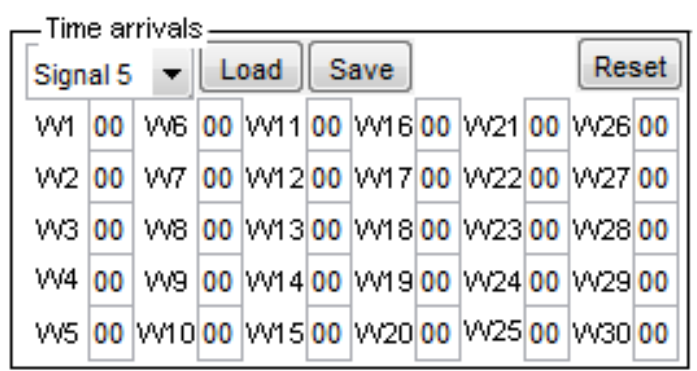

Figura 50: Preenchimento do tempo de chegada das ondas $S$

6) Exportar os dados em formato .xls 
O programa permite, através do item 8 da Figura 44, que todos os sinais sejam fornecidos em formato do aplicativo Microsoft Excel. A Figura 51 apresenta o item 8 com suas funcionalidades.

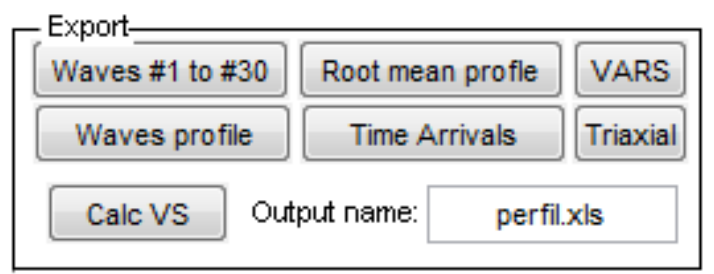

Figura 51: Exportação dos sinais para o aplicativo do Microsoft Excel

Os botões Waves \#1 to \#30, Root mean profile, Waves profile, Triaxial e Times Arrivals exportam os 9 sinais obtidos em cada golpe em formato .xls. O botão VARS exporta as variáveis utilizadas no programa em um arquivo do Matlab de extensão . $m$, possibilitando o recarregamento destas, mesmo com o fechamento do programa, para dar continuidade a análise. Através do botão Calc VS o Módulo de cálculo de velocidades iniciará, onde as velocidades de onda $\mathrm{S}$ podem ser determinadas pelo método do intervalo ou pelo método DTS.

\subsection{Modulo para cálculo da velocidade de onda $\mathrm{S}$}

Para o cálculo das velocidades de onda S Pedrini (2012) desenvolveu o Módulo de cálculo de velocidades, apresentado na Figura 52, juntamente com suas funcionalidades. Com a determinação do tempo de chegada da onda $S$, item 7 , e a informação da posição da geração de cada onda (Load Depths-item 1), clica-se em Calc VS (item 8) e inicia-se o processamento do Módulo de Cálculo de Velocidade do programa.

Esse Módulo permite comparar rapidamente dois métodos de cálculo de velocidade: Método do intervalo e o Método DTS. O primeiro foi descrito por Kim et. al. (2004) e o segundo por Bang e Kim (2007). Conforme citado por Bang e Kim (2007), o método DTS apresenta melhores valores principalmente devido ao fato de ser considerada a refração das ondas no solo, através da Lei da Snell. Em função dos melhores resultados, o método DTS será utilizado nesta pesquisa. A seguir serão apresentadas as principais funcionalidades do Módulo de Cálculo de velocidades 


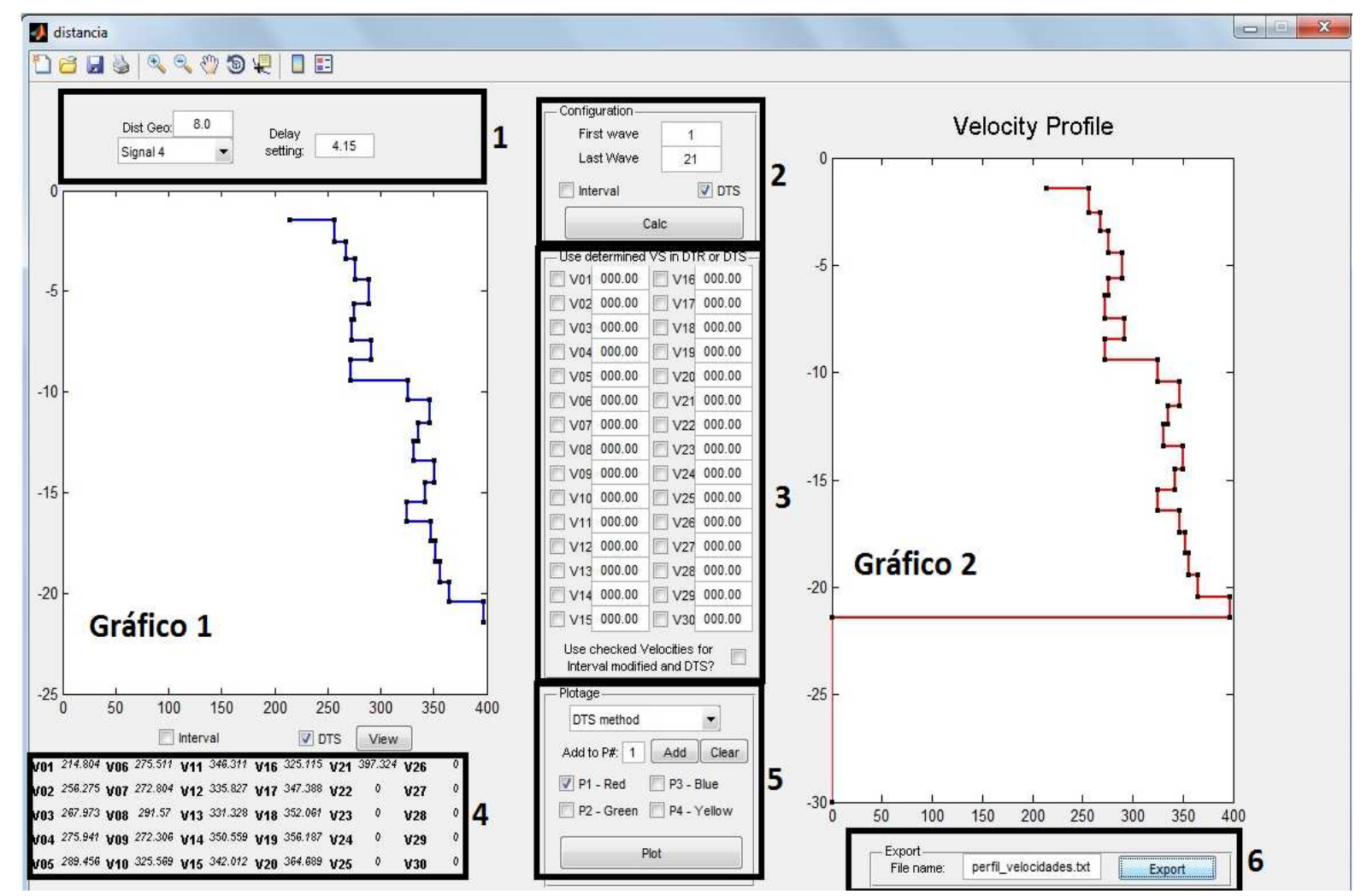

Figura 52: Módulo de cálculo de velocidades

O item 1 da Figura 52, apresenta o campo Dist Geo onde se informa a distância entre o furo de sondagem e a posição do geofone analisado. É apresentado também o campo Delay setting. Neste campo deve-se informar o tempo que será subtraído daquele encontrado pelo ponto de referência (ponto de mínimo), para assim determinar o tempo de chegada da onda $\mathrm{S}$. Como citado anteriormente, o método DTS proposto por Bang e Kim (2007) apresentou melhores resultados, entretanto, para utilização do método são necessários os tempos de chegada das ondas, e não o tempo de referência, como havia sido identificado até agora. Uma alternativa para sua determinação seria a utilização do método cross-over, realizado nos ensaios down-hole. Porém, no ensaio S-SPT é complicado utilizá-lo devido à dificuldade de se golpear a cabeça de bater no sentido de baixo para cima. Pedrini (2012) realizou ambos os registros (golpe de cima para baixo e de baixo para cima), sendo assim possível determinar o ponto de chegada da onda S através do método cross-over. Nesta análise o autor verificou que a distância entre o ponto de mínimo e o ponto de cruzamento das ondas é de aproximadamente $1 / 4$ do período da onda. Logo a determinação do tempo de chegada da onda $S$ pode assim ser obtida indiretamente. Para isso determina-se com algumas ondas geradas em diferentes profundidades a frequência média predominante do pulso principal de onda $S$, e 
calcula-se o tempo que representa $1 / 4$ do período dessas ondas. $\mathrm{O}$ item 1 apresenta também um combobox onde o usuário deve escolher qual sinal será analisado.

No item 2 é possível escolher qual será a primeira e a última onda que será analisada e o método utilizado (Intervalo ou DTS). Vale lembrar que na pesquisa em questão foi utilizado o método DTS. Ao clicar a tecla Calc inicia a determinação das velocidades, sendo estas apresentadas no Gráfico 1.

O item 3 foi desenvolvido para possibilitar a imposição de velocidades em cada profundidade de ensaio. Este procedimento pode ser utilizado, por exemplo, no caso da dificuldade de análise das ondas mais superficiais. Esse fato ocorre principalmente para os sensores posicionados longe do furo de sondagem. Assim é aconselhável determinar as velocidades mais rasas através dos sensores mais próximos (melhor caracterização de ondas S) e posterior utilização dessas velocidades nos mais afastados (melhor caracterização das ondas mais profundas).

O item 4 permite, após a determinação do perfil de velocidade (Gráfico 1), a visualização dos valores das velocidades de onda S. Para isto cabe ao usuário selecionar qual método foi utilizado e clicar no botão View.

O item 5 permite a visualização de até 4 perfis de velocidades. Feita a seleção dos 4 perfis e clicando no botão Plot, o Gráfico 2 apresenta esta combinação. Esta função permite que se analise e compare as velocidades obtidas por 4 geofones, simultaneamente.

O item 6 apresenta a opção de exportar os valores numéricos de velocidade e suas respectivas profundidades, em arquivo .txt. 


\section{4. ÁREAS EXPERIMENTAIS}

\subsection{Considerações iniciais}

Foram realizados ensaios SPT com sísmica up-hole nos campos experimentais da EESC-USP em São Carlos, da UNESP em Bauru e da UNICAMP em Campinas, determinando os perfis geotécnicos, os valores do índice de resistência à penetração $\left(\mathrm{N}_{\mathrm{SPT}}\right)$ e da velocidade de propagação de ondas cisalhantes com a profundidade, e consequentemente, o módulo de cisalhamento máximo $\left(\mathrm{G}_{\mathrm{o}}\right)$.

Em todos os campos experimentais vários outros ensaios de campo e laboratório foram executados. Esses estudos possibilitaram uma boa caracterização geológico-geotécnica de cada uma dessas áreas. A Figura 53 apresenta os resultados de várias sondagens de simples reconhecimento (SPT), permitindo assim a visualização do perfil geotécnico desses locais.

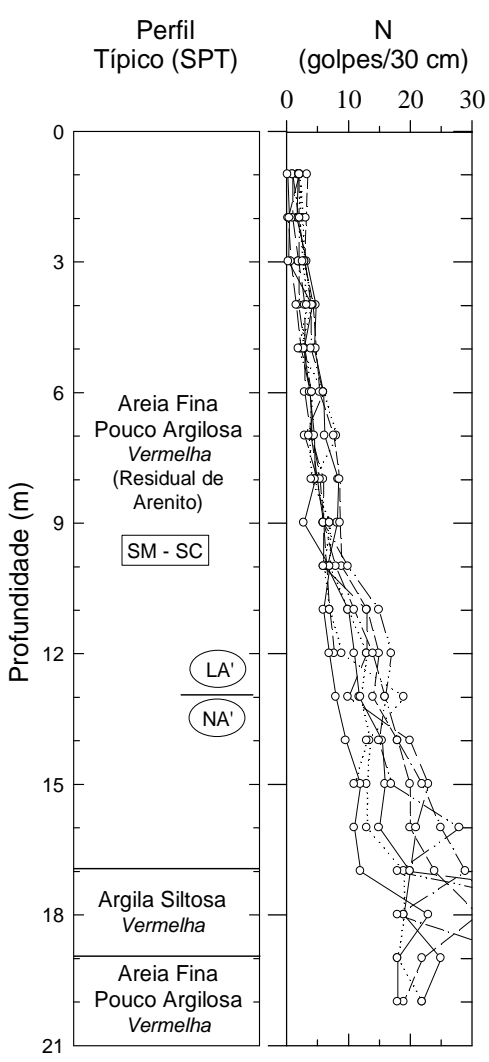

(a) Bauru

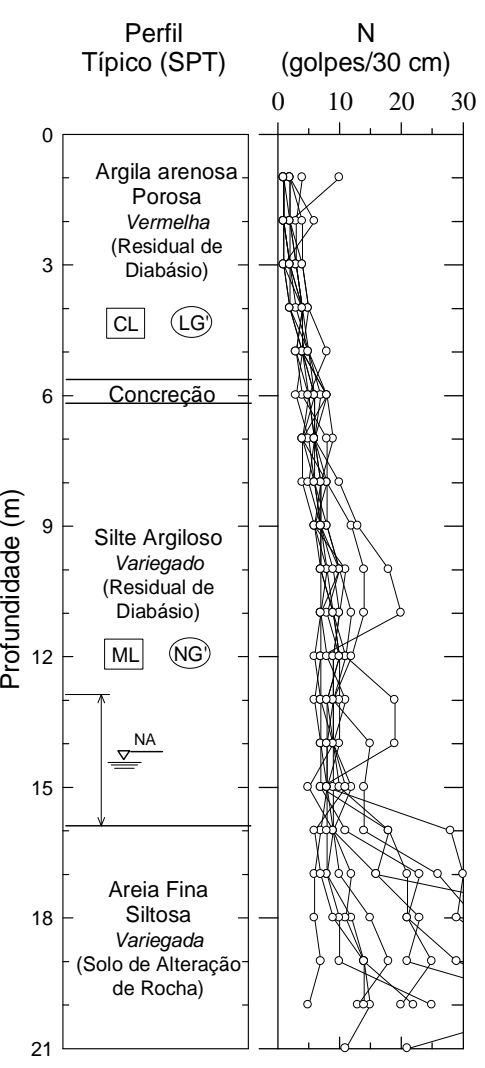

(b) Campinas

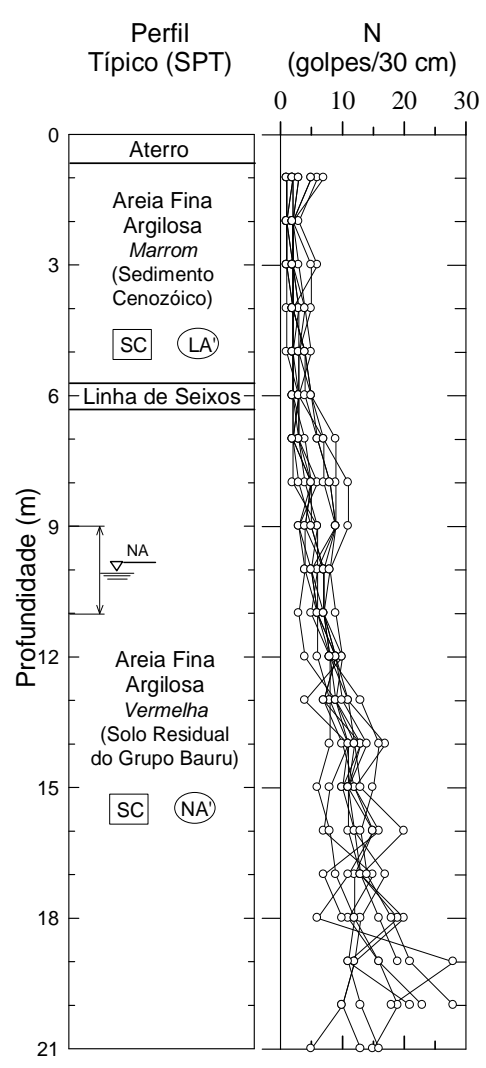

(c) São Carlos

Figura 53: Perfis típicos e resultados de sondagens SPT realizados nos campos experimentais de (a) Bauru, (b) Campinas e (c) São Carlos

Fonte: Giacheti, Peixoto e Mondelli (2004) 


\subsubsection{Campo Experimental da UNESP - Bauru}

\subsubsection{Aspectos Geológicos}

Segundo Giacheti (2001) a região de Bauru é constituída principalmente pelos sedimentos do Grupo Bauru (Formações Marília e Adamantina), recobrindo as rochas vulcânicas da Formação Serra Geral que afloram em direção ao vale do Rio Tietê.

A geologia do campo experimental é a mesma que predomina na cidade de Bauru. Através de um poço tubular, aberto a 100m do local, pode-se constatar uma primeira camada de 52 m da Formação Marília, seguida de 98 m da Formação Adamantina e, abaixo, encontrase a Formação Serra Geral. O solo que ocorre no campo experimental de Bauru é constituído por uma areia fina pouco argilosa, porosa, colapsível, cuja compacidade aumenta com a profundidade. Esta camada de areia fina, resultante da decomposição do Arenito Bauru, apresenta comportamento laterítico até cerca de $13 \mathrm{~m}$ de profundidade e não laterítico a partir daí (GIACHETI, 2001).

Segundo De Mio (2005) para identificar um perfil estratigráfico deve-se considerar a geologia local, além das informações obtidas pela história e gênese do local. No campo experimental da UNESP - Bauru predomina rochas sedimentares da Formação Marilia, posteriormente submetidas a processos de morfogênese e pedogênese. Desta forma, o perfil deve refletir características de rochas sedimentares, como a alternância em camadas, e as transformações destes materiais pelos processos de pedogênese e morfogênese, como o amolecimento pela migração de agua em regiões de fratura, recobrimento por solos coluviais em diversas fases, entre outros.

\subsubsection{2. $\quad$ Ensaios Sísmicos}

No campo experimental da UNESP de Bauru foram realizados por Giacheti et. al. (2006b) três ensaios sísmicos, sendo um ensaio cross-hole e dois ensaios SCPT. O ensaio cross-hole foi realizado até a profundidade de $15 \mathrm{~m}$ com arranjos de três furos alinhados e espaçados em 2 e 3 m registrando dados de 0,5 em $0,5 \mathrm{~m}$, sendo a aquisição realizado por sismógrafo digital. A fonte sísmica utilizada (martelo sísmico) fornece a possibilidade de geração predominante de ondas S. Os ensaios SCPT foram realizados até a profundidade de 
$20 \mathrm{~m}$ com um cone sísmico fabricado pela Vertek, sendo registradas ondas de metro em metro. Para geração das ondas foi utilizado uma placa metálica carregada com pesos, que permite, predominantemente, a geração de ondas S. Na Figura 54 são apresentados os resultados dos três ensaios, a comparação das velocidades $\mathrm{V}_{\mathrm{S}}$ obtidas pelo cross-hole e pelo SCPT, a determinação de $\mathrm{G}_{\mathrm{o}}$ e da relação $\mathrm{G}_{\mathrm{o}} / \mathrm{q}_{\mathrm{c}}$. Na mesma Figura são apresentados resultados de cinco ensaios de cone realizados por Giacheti, Peixoto e Marques (2003).

Verifica-se a semelhança nas velocidades obtidas pelos ensaios até a profundidade de $10 \mathrm{~m}$, apresentando uma diferença relativa média de $9 \%$. Após $10 \mathrm{~m}$ a diferença aumenta para aproximadamente 20\%. De Mio (2005) atribui esse comportamento a variabilidade local dos sedimentos, a diferentes graus de cimentação dos materiais que refletem a complexidade desses perfis sedimentares submetidos a processos de pedogênese tropical. A relação $\mathrm{G}_{\mathrm{o}} / \mathrm{q}_{\mathrm{c}}$, apresentou valores maiores para a camada de solo laterítico mais superficial. $\mathrm{O}$ valor médio da relação até a profundidade de $7 \mathrm{~m}$ foi de 80 e abaixo de $7 \mathrm{~m}$ apresentou valor médio de 31 .

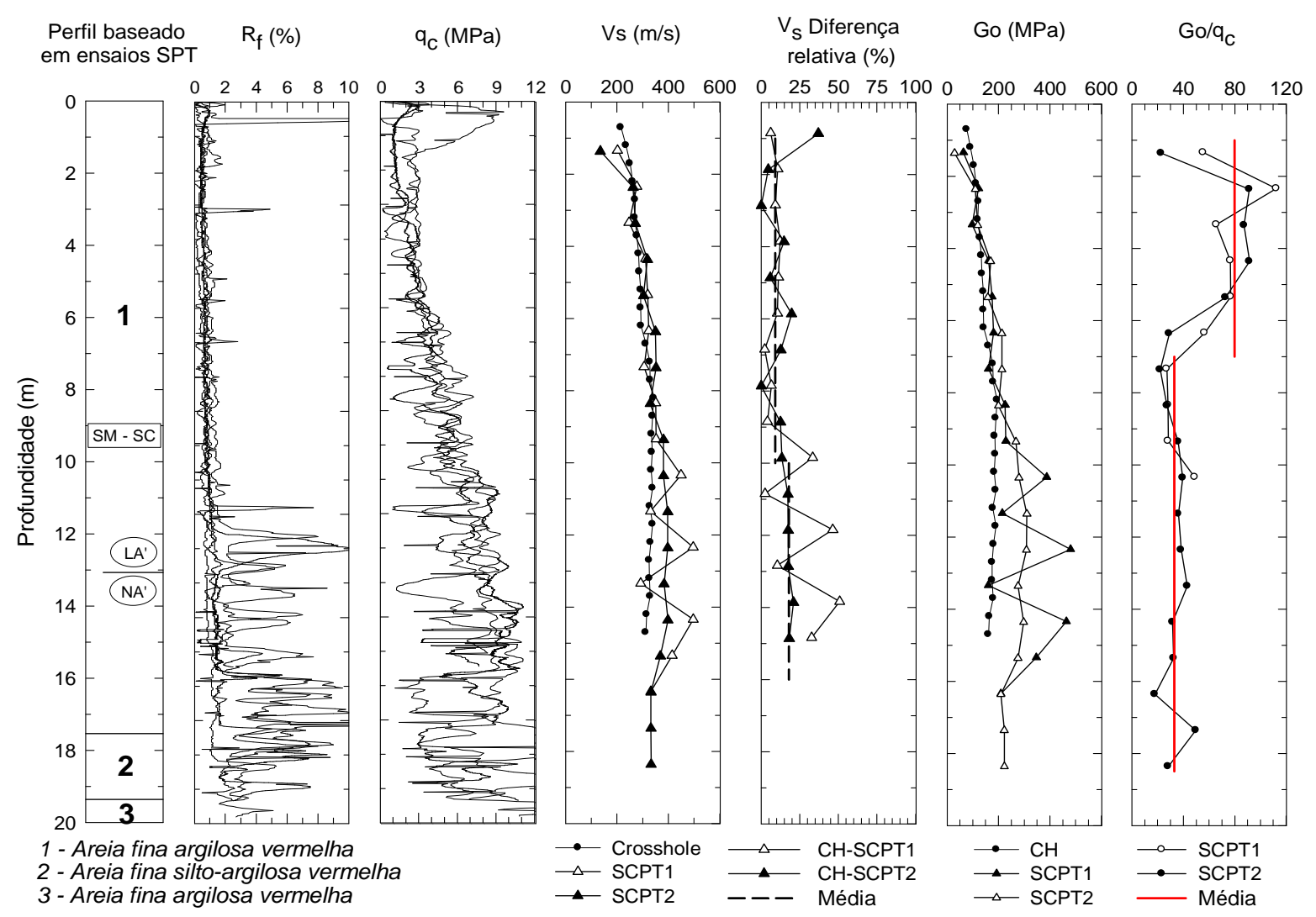

Figura 54: Ensaios sísmicos SCPT e Cross-hole executados no campo experimental da UNESP, Bauru Fonte: modificado de Giacheti, Peixoto e Marques (2003) e Giacheti e De Mio (2008) 


\subsubsection{Campo Experimental da EESC-USP-São Carlos}

\subsubsection{Aspectos Geológicos}

Segundo Bortolucci (1983) a cidade de São Carlos encontra-se assentada sobre as rochas do grupo São Bento, constituídas pelos magmatitos básicos da Formação Serra Geral e dos arenitos da Formação Botucatu. Encontram-se conglomerados e arenitos do Grupo Bauru cobrindo tais rochas, e em seguida, toda a região é coberta pelos Sedimentos Cenozoicos. Segundo Giacheti (2001) os Sedimentos Cenozoicos que cobrem toda a região foram constituídos pelo retrabalhamento dos materiais do Grupo Bauru e das Formações Serra Geral e Botucatu, através de um pequeno transporte em meio aquoso de razoável competência.

Esses sedimentos foram submetidos à ação de intemperismo sob condições climáticas típicas de região tropical, cujas características são: elevada temperatura, intensa pluviosidade e situações de boa drenagem. Isso provocou nesse material o processo de laterização, o qual consiste na concentração de óxidos e hidróxidos de ferro e alumínio. Por isso, são pouco compactos, muito porosos e colapsíveis (GIACHETI, 2001).

O subsolo do campo experimental é constituído por uma areia fina a média argilosa, porosa e colapsível, com comportamento laterítico, até $7 \mathrm{~m}$ de profundidade. Em seguida encontra-se uma linha de seixos de quartzo e limonita com espessuras de até $1 \mathrm{~m}$, que divide o sedimento cenozoico de uma camada de solo residual jovem de Arenito do Grupo Bauru. Esta camada de solo saprolítico pode ser descrita, ao menos nas regiões mais altas, como um arenito médio bem graduado, com cerca de $45 \%$ de areia e $35 \%$ de argila, com cores avermelhadas a rosadas, com pontos brancos constituídos de feldspatos pouco alterados, de comportamento não laterítico (GIACHETI, 2001).

\subsubsection{2. $\quad$ Ensaios Sísmicos}

No campo experimental da EESC-USP foi realizado um grande número ensaios sísmicos. Aqui serão apresentados resultados de quatro ensaios, sendo dois ensaios cross-hole (CH1 e CH2), adotando o procedimento da norma ASTM D - 4428, 1984, e dois ensaios de cone sísmico (SCPT1 e SCPT2) (Giacheti e De Mio, 2008). O ensaio SCPT permite, além da determinação da resistência de ponta $\left(\mathrm{q}_{\mathrm{c}}\right)$ e do atrito lateral $\left(\mathrm{f}_{\mathrm{s}}\right)$, a determinação da velocidade 
de propagação de ondas cisalhantes $\left(\mathrm{V}_{\mathrm{S}}\right)$, sendo assim possível a determinação do módulo de cisalhamento máximo $\left(\mathrm{G}_{\mathrm{o}}\right)$. Os ensaios cross-hole foram realizados até a profundidade de 9 m, já os ensaios SCPT foram até a profundidade de $21 \mathrm{~m}$. Na Figura 55 são apresentados os resultados dos quatro ensaios sísmicos, a comparação das velocidades $\mathrm{V}_{\mathrm{S}}$ obtidas pelo crosshole e pelo SCPT, a determinação de $\mathrm{G}_{\mathrm{o}}$ e da relação $\mathrm{G}_{\mathrm{o}} / \mathrm{q}_{\mathrm{c}}$, além de nove ensaios de cone realizados por Giacheti, Peixoto e Marques (2003).

Os valores de velocidade de propagação de ondas cisalhantes $\left(\mathrm{V}_{\mathrm{S}}\right)$ obtidos nos ensaios cross-hole e SCPT apresentarem, em média, diferenças em torno de 10\%. Notam-se maiores discrepâncias próximo à profundidade de $2 \mathrm{~m}$ e próximo à camada de seixos. De Mio (2005) considera essas discrepâncias devidas a variabilidade do maciço, principalmente porque os ensaios foram realizados em diferentes posições do terreno e as direções de polarização das ondas $\mathrm{S}$ foram praticamente ortogonais. Através da determinação de $\mathrm{G}_{\mathrm{o}}$ é possível caracterizar o solo pela relação $\mathrm{G}_{\mathrm{o}} / \mathrm{q}_{\mathrm{c}}$. Esta relação apresenta a tendência de aumento com a evolução do perfil, fato esse verificado na Figura 55 onde, a camada até a profundidade de $8 \mathrm{~m}$ apresenta um valor médio de 182 , entre 8 e 16 m o valor médio de 86 e entre 16 e 21 m o valor médio de 41. Esses resultados indicam valores maiores para camadas lateríticas e valores menores para camadas saprolíticas.

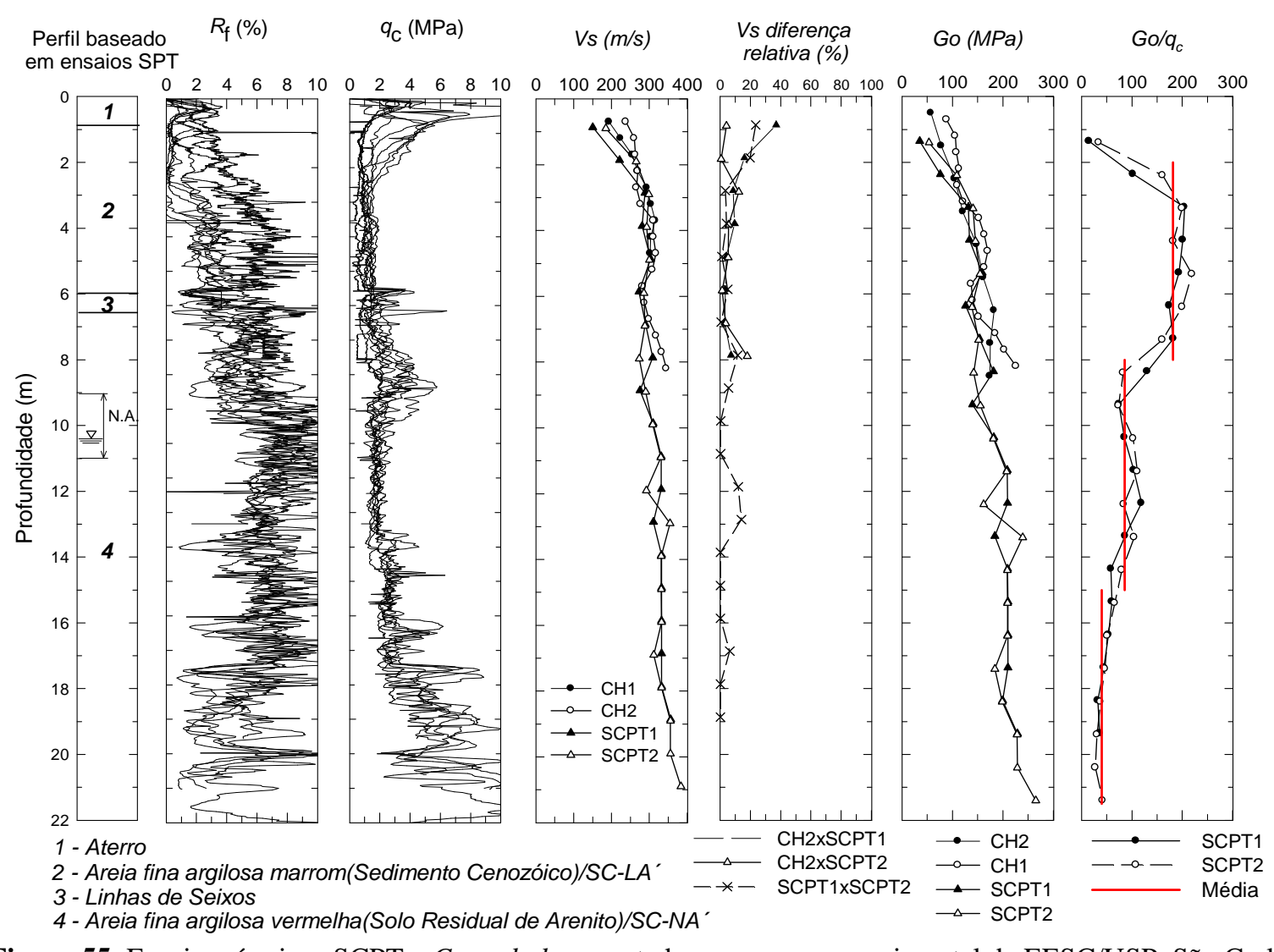

Figura 55: Ensaios sísmicos SCPT e Cross-hole executados no campo experimental da EESC/USP, São Carlos Fonte: modificado de Giacheti, Peixoto e Marques (2003) e Giacheti e De Mio (2008) 


\subsubsection{Campo Experimental da UNICAMP - Campinas}

\subsubsection{Aspectos Geológicos}

A região do campo experimental da UNICAMP, em Campinas, apresenta rochas intrusivas básicas da Formação Serra Geral. Em relação às formações litológicas, o diabásio, mineralogicamente composto por labradorita, clinopiroxênio augita e/ou pigeonita e acessórios, como a titanita, magnetita e apatita aparecem predominantemente (Giacheti, 1991). Os perfis geológicos demonstram a grande ocorrência dos magmatitos básicos na parte norte da região de Campinas, os quais afloram em três áreas, perfazendo $98 \mathrm{~km}^{2}$ e ocupando $14 \%$ da área total da folha de Campinas.

Através dos afloramentos, verifica-se a alta quantidade de fraturas existentes nos diabásios, formando blocos pequenos, e as fraturas normalmente estão abertas ou preenchidas com materiais argilosos. No que se diz respeito ao solo do campo experimental de Campinas, este é formado por duas camadas distintas: até os $6 \mathrm{~m}$ de profundidade tem-se uma argila areno-siltosa, porosa, de comportamento laterítico e colapsível (Giacheti, 2001), seguido de zona de transição com eventual presença de crostas lateríticas e de solo residual maduro até as profundidades variáveis de 15 a $18 \mathrm{~m}$. Em meio ao solo residual maduro é possível encontrar maior concentração de argila nas porções mais superficiais entre 7 e $10 \mathrm{~m}$ que, apesar da profundidade, pode ser sugestivo de processo pedogenético que concentra minerais de argila no horizonte B. Em profundidades maiores que $18 \mathrm{~m}$ ocorrem solos residuais mais jovens, com ocorrência comum de núcleos de rocha menos alterada em meio ao solo residual.

\subsubsection{Ensaios Sísmicos}

Giacheti e De Mio (2008) apresentam o resultado de quatro ensaios sísmicos, sendo dois ensaios cross-hole e dois ensaios SCPT, realizados no campus experimental da UNICAMP- Campinas. Os dois ensaios cross-hole, são denominados respectivamente de $\mathrm{CH} 1$ e $\mathrm{CH} 2$. Os ensaios SCPT, semelhante aos ensaios cross-hole são denominados de SCPT1 e SCPT2. A Figura 56 apresenta os resultados desses quatro ensaios.

$\mathrm{Na}$ mesma Figura apresentam-se os resultados de nove ensaios de cone realizados por Giacheti, Peixoto e Marques (2003) onde se verifica, até 9m de profundidade, uma grande 
dispersão dos valores de resistência de ponta $\left(\mathrm{q}_{\mathrm{c}}\right)$, indicando grande variabilidade no solo daquele local.

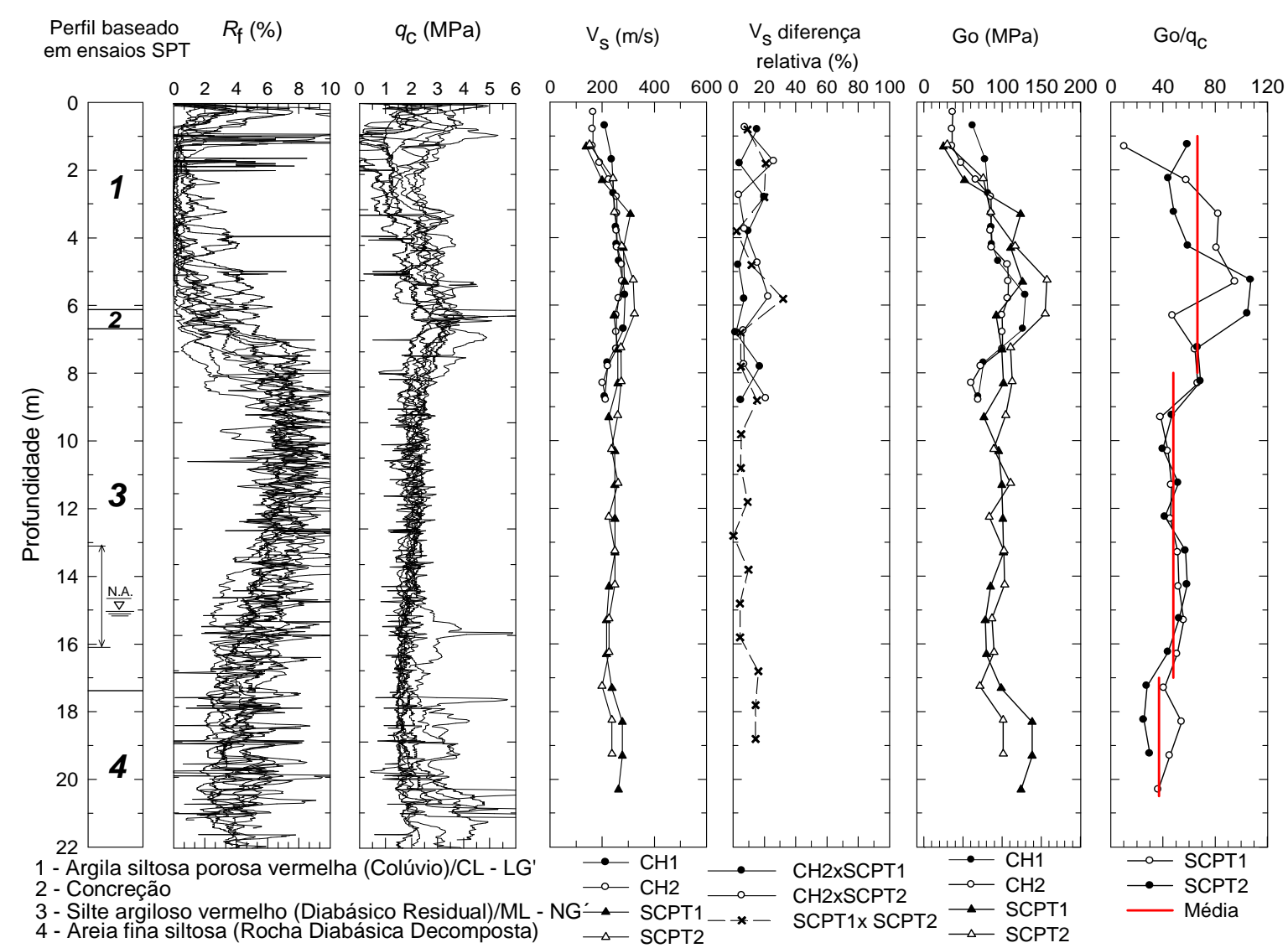

Figura 56: Ensaios sísmicos SCPT e Cross-hole executados no campo experimental da UNICAMP, Campinas Fonte: modificado de Giacheti, Peixoto e Marques (2003) e Giacheti e De Mio (2008)

A diferença média entre as velocidades de propagação de ondas $\mathrm{S}$ obtidas nos ensaios cross-hole e SCPT foi de aproximadamente $11 \%$. Como pode se ver na Figura 56, as maiores diferenças ocorrem em $2 \mathrm{~m}$ de profundidade e próximo à concreção. Na comparação entre os ensaios SCPT, a diferença média entre as velocidades obtidas foi de 10,7\%. Logo se verifica que as diferenças obtidas na comparação cross-hole e SCPT foram consistentes com as encontradas entre os ensaios SCPT. De Mio (2005) atribui essas diferenças a variabilidade do terreno, refletido por diferentes graus de alteração.

Similarmente a São Carlos e Bauru, a relação $\mathrm{G}_{0} / \mathrm{q}_{\mathrm{c}}$ é maior na espessura de solo laterítico do que em solo saprolítico. A Figura 56 mostra que até a profundidade de $8 \mathrm{~m}$, a relação $\mathrm{G}_{\mathrm{o}} / \mathrm{q}_{\mathrm{c}}$ apresenta um valor médio de 67 , entre 8 e $17 \mathrm{~m}$, o valor médio é de 48 e entre 17 e $21 \mathrm{~m}$, o valor é de 37. 


\section{RESULTADOS E ANÁLISE}

O capítulo de resultados e análise é dividido por área experimental e subdividido em três subtópicos. O primeiro subtópico irá tratar da determinação do perfil de velocidade da onda S através da realização dos ensaios S-SPT. No segundo, será abordado a relação entre o módulo de cisalhamento máximo $\left(\mathrm{G}_{\mathrm{o}}\right)$ e o índice de resistência a penetração normalizado para uma eficiência de $60 \%\left(\mathrm{~N}_{60}\right)$ determinados em ensaios sísmicos (cross-hole, down-hole e SCPT) e SPT já realizados. No terceiro, será apresentado a relação $\mathrm{G}_{0} / \mathrm{N}_{60}$ obtida dos resultados do ensaio S-SPT, para avaliar a aplicação e o desempenho do ensaio híbrido S-SPT e verificar as vantagens do uso integrado de ensaios sísmicos e de penetração na caracterização de solos tropicais, a partir da relação $\mathrm{G}_{\mathrm{o}} / \mathrm{N}$.

Para a determinação do módulo de cisalhamento máximo $\left(\mathrm{G}_{\mathrm{o}}\right)$ foi utilizada a equação 5 . Nessa equação os valores de massa específica do solo foram determinados a partir de amostras indeformadas retiradas de poços de inspeção, conforme apresentado por Giacheti (2001).

\subsection{Campo Experimental da FEB/UNESP, Bauru}

No campo experimental da UNESP de Bauru, o ensaio S-SPT foi realizado por Pedrini (2012), como validação do equipamento e metodologia desenvolvida. Um resumo desses resultados é apresentado a seguir.

\subsubsection{Determinação do perfil de velocidades de onda $S$ pelo ensaio S-SPT}

Pedrini (2012) realizou o total de quatro ensaios S-SPT no campo experimental da UNESP de Bauru, visando aperfeiçoar o hardware, software e a metodologia de execução. Para validação do equipamento foi realizado outro ensaio S-SPT (S-SPT3) até a profundidade de $21 \mathrm{~m}$, determinando-se o perfil de velocidade de onda S. Esses resultados foram comparados com resultados de outros ensaios sísmicos (DH e SCPT) anteriormente realizados no local. Na Figura 57 são apresentados os resultados do ensaio S-SPT 3, juntamente aos 
resultados obtidos em ensaios SCPT e de resultados obtidos pela técnica down-hole, estes últimos também realizados no campo da UNESP de Bauru, além do perfil do terreno obtido pelo ensaio SPT. Após a análise dos resultados obtidos, verificou-se que a técnica implementada por Pedrini (2012) é satisfatória, apresentando pouca discrepância entre os resultados dos ensaios S-SPT e os da técnica down-hole e SCPT na determinação do perfil de velocidades de onda S. Na comparação entre o S-SPT e a técnica down-hole houve um erro relativo de 6,3\% e, para o SCPT, houve um erro de $10,9 \%$.

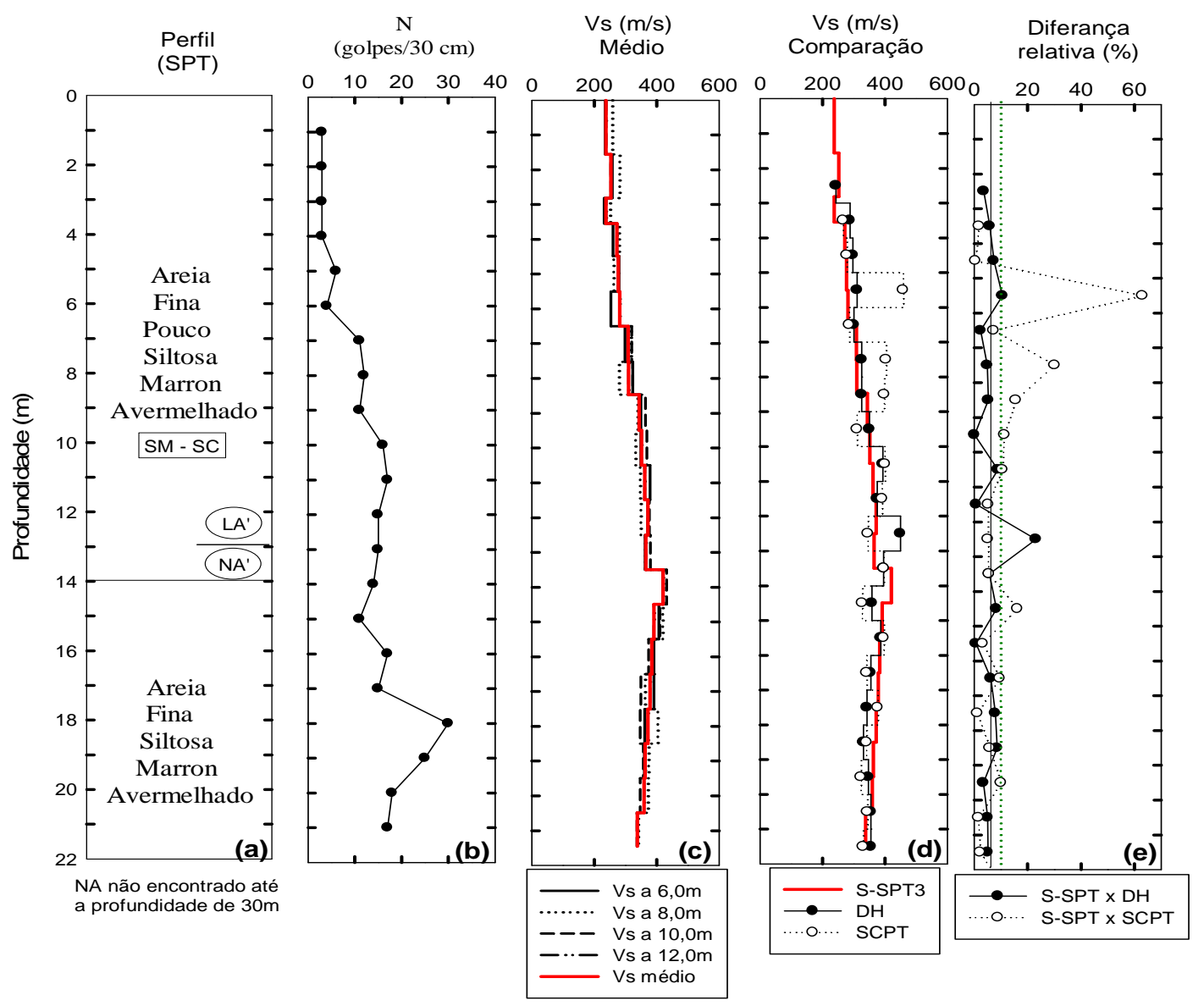

Figura 57: Comparação dos resultados dos ensaios S-SPT, SCPT e ponteira sísmica

Fonte: Pedrini, (2012)

\subsubsection{Relação $G_{0} / \mathbf{N}_{60}$ através de ensaios sísmicos e $S P T$ anteriormente realizados.}

No campo experimental da UNESP de Bauru, estão disponíveis resultados de dois ensaios down-hole, um ensaio cross-hole e dois ensaios SCPT, sendo estes três últimos descritos no item 4.1.1.2. Os ensaios down-hole foram executados por Vitali (2011), para o desenvolvimento de um sistema de realização de ensaios down-hole em conjunto ao ensaio CPT. Para a mesma área estão disponíveis resultados de dez sondagens SPT, como medida do 
$\mathrm{N}$ e determinação do perfil do subsolo. A Figura 58 apresenta uma síntese dos resultados dos ensaios SPT e sísmicos realizados no campo experimental da UNESP de Bauru. A Figura 58.a apresenta um perfil típico do campo estudado baseado em ensaios SPT, a Figura 58.b mostra os valores de $\mathrm{N}$ corrigidos para uma eficiência de 60\%. Na Figura 58.c são apresentados valores de velocidade de onda S determinados por ensaios cross-hole, down-hole e SCPT. Os valores de módulo de cisalhamento máximo são apresentados na Figura 58.d. A média dos valores de $\mathrm{G}_{0} / \mathrm{N}_{60}$ para cada metro de profundidade foi calculada, determinando $G_{o_{\text {med }}} /$ $N_{60}$ med $v e r s u s$ profundidade (Figura 58.e). O critério utilizado para o cálculo da relação $G_{o_{\text {med }}} / N_{60 \text { med }}$ foi a média de todos os valores de $\mathrm{G}_{\mathrm{o}}$ e $\mathrm{N}_{60}$ para cada metro de profundidade. Na Figura 59e observa-se que a relação $G_{o_{\text {med }}} / N_{60}$ med tende a diminuir com a profundidade, com um valor médio de 54 entre 1 e 4 m; 29, entre 4 e 11 m; 13, entre 11 e 16 m, e 8 abaixo de $16 \mathrm{~m}$ de profundidade. Estes resultados indicam valores maiores da relação $G_{o_{\text {med }}} / N_{60}$ med para camada de solo laterítico (1 a $13 \mathrm{~m})$ e tendem a diminuir em camadas de solo menos desenvolvido, como o solo saprolítico (14 a $21 \mathrm{~m})$.

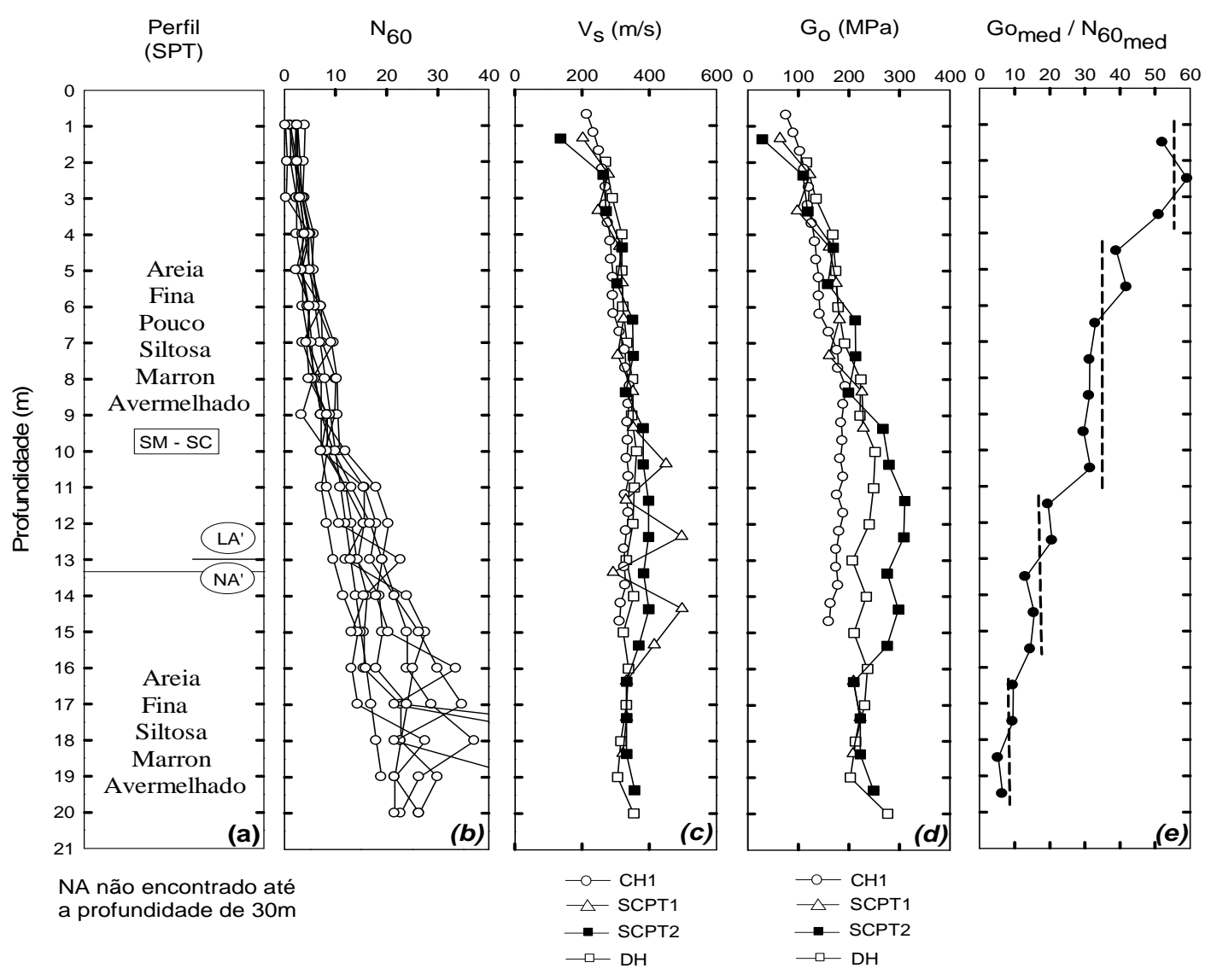

Figura 58: Ensaio SPT, ensaios sísmicos e relação $\mathrm{G}_{\mathrm{o}} / \mathrm{N}_{60}$ para o campo experimental da UNESP, Bauru 
A Figura 59 apresenta o gráfico de $\mathrm{G}_{0} / \mathrm{N}_{60}$ versus $\left(N_{1}\right)_{60}$ para avaliar presença de cimentação nos solos, conforme sugere Schnaid, Fahey e Lehane (2004). Observa-se nessa Figura que a maioria dos dados encontra-se próximo do limite superior para areia cimentadas, indicando que a estrutura dos solos arenosos tropicais levam a valores maiores de $\mathrm{G}_{0} / \mathrm{N}_{60}$ quando comparados àqueles medidos em solos sedimentares. Verifica-se, também, que os solos lateríticos apresentam maior cimentação que os solos saprolíticos. Estes resultados são similares aos encontrados por Giacheti e De Mio (2008), baseados na relação $\mathrm{G}_{\mathrm{o}} / \mathrm{q}_{\mathrm{c}}$, obtida através de ensaios SCPT (Figura 36).

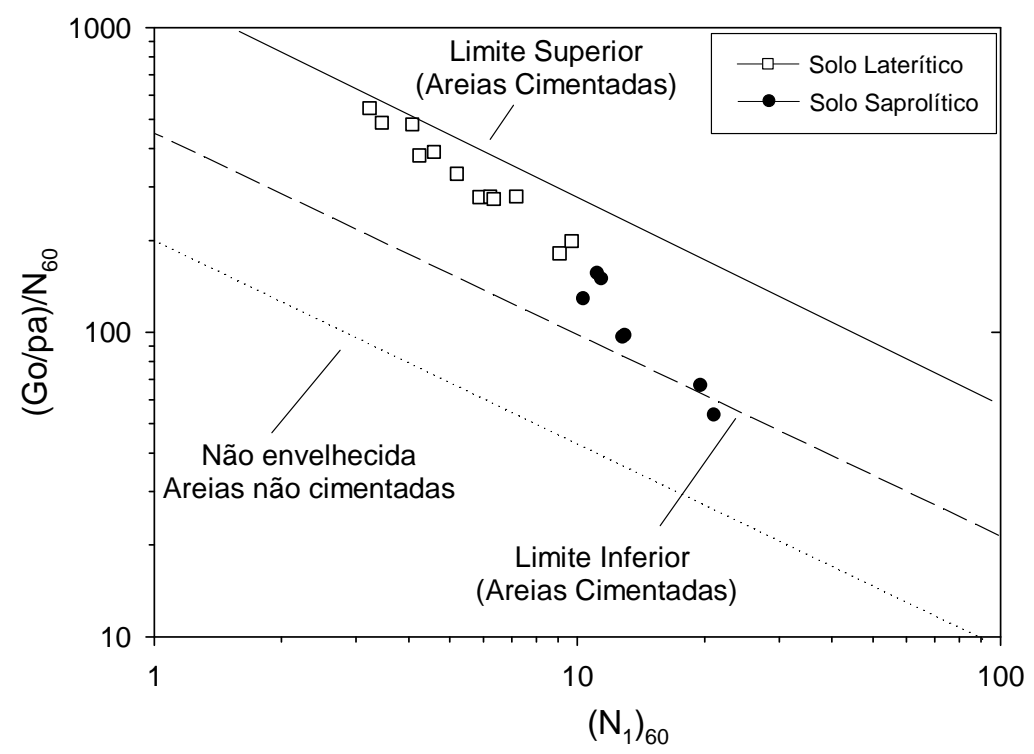

Figura 59: Relação entre $\mathrm{G}_{0}$ e $\mathrm{N}_{60}$ (ensaios anteriores) para o campo experimental da UNESP, Bauru

\subsubsection{Razão $G_{0} / N_{60}$ através do ensaio $S-S P T$}

A Figura 60 apresenta os resultados obtidos no ensaio S-SPT3 realizado por Pedrini (2012), juntamente com a determinação do módulo de cisalhamento máximo e da relação $\mathrm{G}_{\mathrm{o}} / \mathrm{N}_{60}$. Na Figura 60.c, verifica-se que os perfis de velocidades de onda $\mathrm{S}$ determinados pelos 4 últimos geofones não apresentam grande discrepância. A Figura 60.d, apresenta o perfil de $\mathrm{G}_{\mathrm{o}}$ com a profundidade e a Figura 60.e exibe os valores de $\mathrm{G}_{0} / \mathrm{N}_{60}$ com a profundidade. $\mathrm{O}$ perfil de $\mathrm{G}_{0} / \mathrm{N}_{60}$ obtido a partir do S-SPT apresenta resultados similares aos encontrados com a média dos ensaios sísmicos e SPT, onde a relação $\mathrm{G}_{0} / \mathrm{N}$ tende a diminuir com a profundidade, com um valor médio de 27 entre 1 e 7 m; 16, entre 7 e 18 m e 11 abaixo de 18 $\mathrm{m}$ de profundidade. 


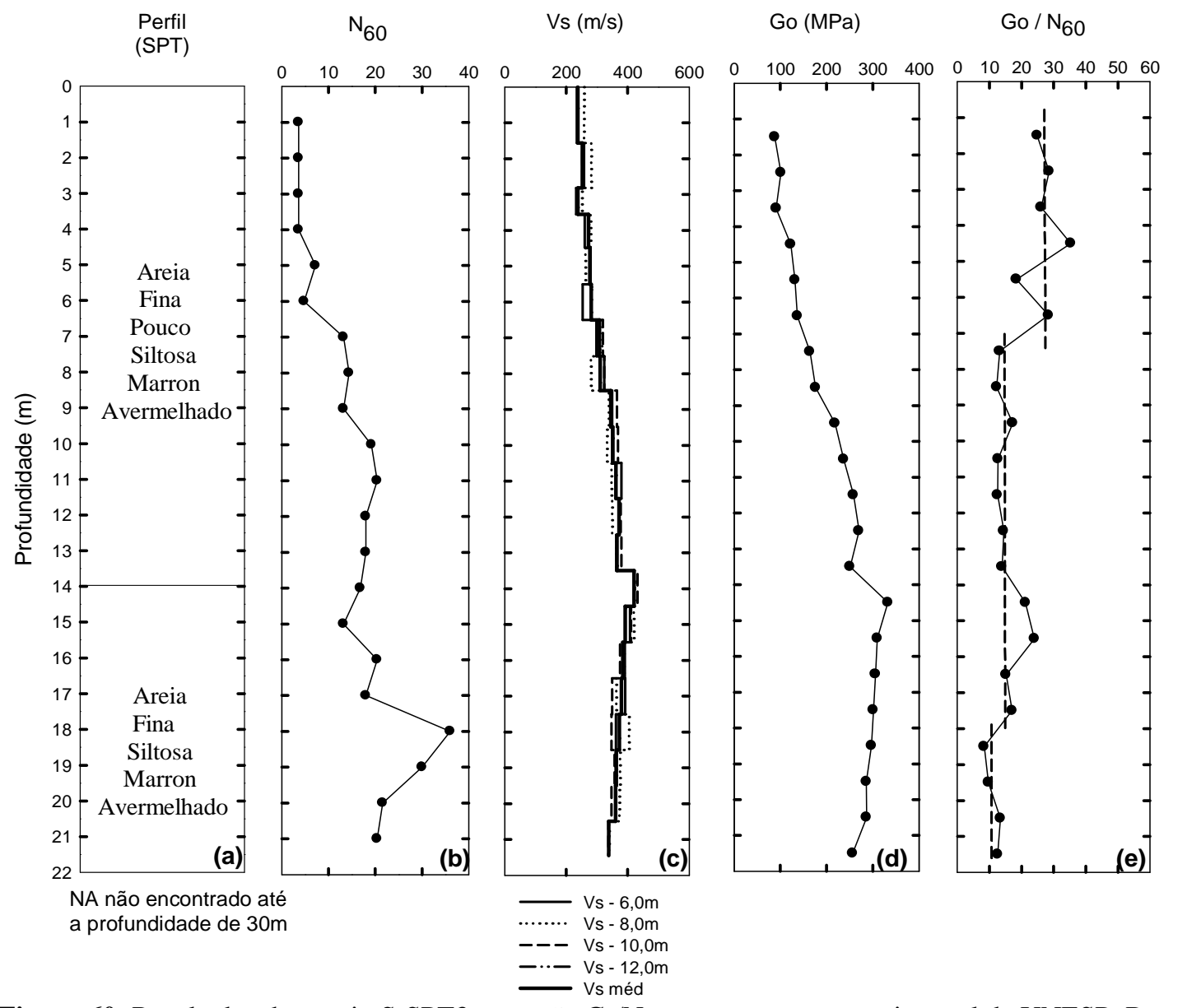

Figura 60: Resultados do ensaio S-SPT3 e a razão $\mathrm{G}_{0} / \mathrm{N}_{60}$ para o campo experimental da UNESP, Bauru Fonte: modificado de Pedrini, (2012)

Na Figura 61 têm-se os resultados do ensaio S-SPT3 plotados no gráfico de $\mathrm{G}_{\mathrm{o}} / \mathrm{N}_{60}$ versus $\left(N_{1}\right)_{60}$, bem como os limites que definem a faixa de areias cimentadas proposta por Schnaid, Fahey e Lehane (2004).

Verifica-se que todos os pontos estão no limite superior para areias cimentadas e que não há uma diferença nítida entre os solos lateríticos e saprolíticos. Somente a camada superior de solo laterítico reflete um maior grau de cimentação.

Este fato pode estar relacionado com a variabilidade observada nesse campo experimental, devido principalmente a processos morfológicos e pedogenéticos, como mencionado por Giacheti, Peixoto e Marques (2003) e Giacheti e De Mio (2008), bem como as características do ensaio S-SPT, cuja interpretação dos registros sísmicos para a determinação de $\mathrm{V}_{\mathrm{S}}$ pela técnica up-hole é mais difícil e menos precisa que em ensaios crosshole e down-hole. 


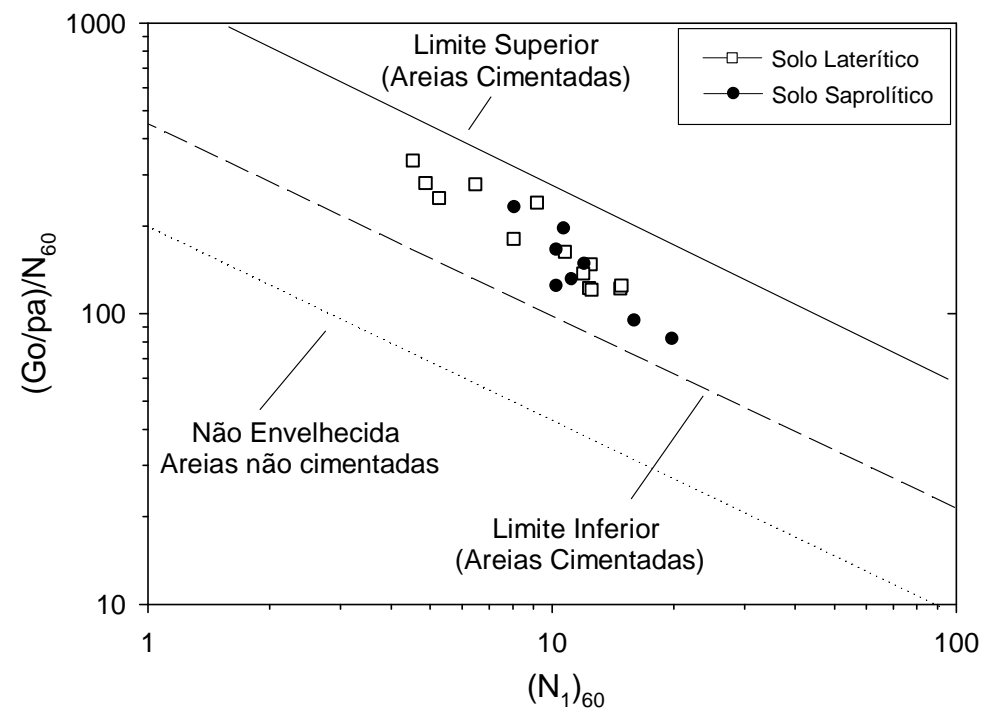

Figura 61: Relação entre $\mathrm{G}_{0}$ e $\mathrm{N}_{60}$ (ensaio S-SPT) para o campo experimental da UNESP, Bauru

\subsection{Campo Experimental da EESC/USP, São Carlos}

\subsubsection{Determinação do perfil de velocidades de onda $S$ pelo ensaio S-SPT}

No campo experimental da EESC/USP, São Carlos/SP, foi realizado uma campanha de ensaio S-SPT e determinação do perfil de velocidade de ondas cisalhantes $\left(\mathrm{V}_{\mathrm{S}}\right)$. Executouse um ensaio S-SPT (S-SPT1) até a profundidade de $21 \mathrm{~m}$. Além disso, existem nessa área resultados de outros seis ensaios sísmicos, sendo dois ensaios SCPT (SCPT1 e SCPT2), realizados também até $21 \mathrm{~m}$ de profundidade, dois ensaios cross-hole $(\mathrm{CH} 1$ e $\mathrm{CH} 2)$, até $8 \mathrm{~m}$ de profundidade, e dois ensaios down-hole (DH1 e DH2), até $20 \mathrm{~m}$ de profundidade. A Figura 62 apresenta a disposição na área de todos esses ensaios.

Os registros sísmicos do ensaio S-SPT1 foram analisados empregando a metodologia proposta por Pedrini (2012), apresentada no item 3 deste trabalho. Também foi verificado que os sinais captados pelos geofones horizontais apresentaram melhor caracterização da onda $S$. Já os sinais obtidos pelas caixas posicionadas a 2 e $4 \mathrm{~m}$ do furo de sondagem foram de baixa qualidade, dificultando a determinação da chegada das ondas. Os registros obtidos com essas caixas só puderam ser utilizados em pequenas profundidades, por isso não foram utilizadas para determinação do perfil de velocidade de ondas $\mathrm{S}$. 


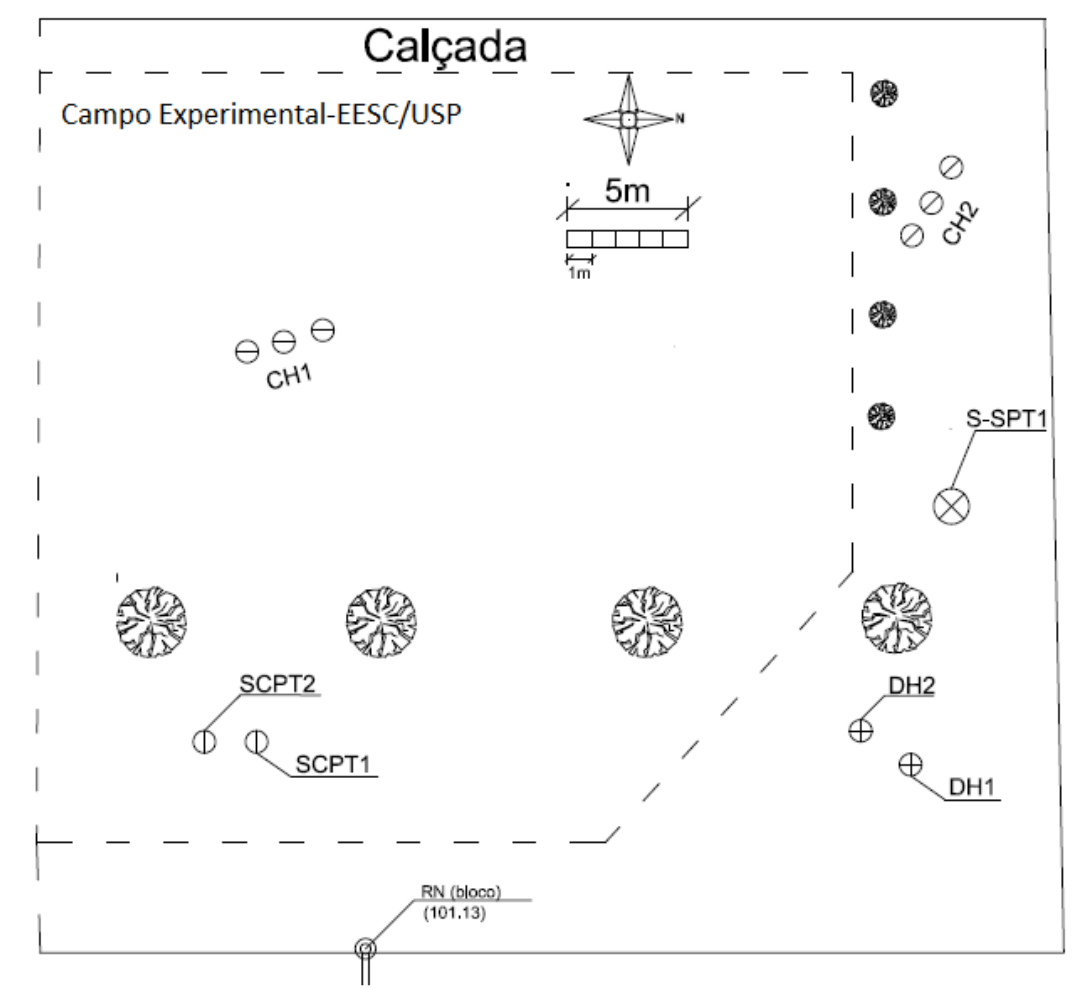

Figura 62: Posição dos ensaios sísmicos realizados no campo experimental EESC/USP, em São Carlos/SP

Os registros sísmicos obtidos das caixas posicionadas a 6, 8, 10 e $12 \mathrm{~m}$ do furo de sondagem puderam ser utilizados para a determinação das velocidades de onda $S$ até a profundidade final de ensaio. A Figura 63 apresenta o perfil de ondas registradas pelo geofone localizado a 10 m (Figura 63.a) e a 12 m (Figura 63.b) do furo de sondagem. Nota-se que não foi possível a identificação da onda $\mathrm{S}$ na profundidade de $10 \mathrm{~m}$, pelo geofone localizado a 10 $\mathrm{m}$ do furo de sondagem, sendo utilizado o recurso do software de cálculo, apresentado no item 3.1.4.2.1, item 3, a velocidade imposta como a média daquelas velocidades calculadas pelos outros três geofones.

Como apresentado no subitem 3.1.4.2.1 é necessário fornecer ao programa o tempo que será subtraído daquele encontrado pelo ponto de referência (ponto de mínimo), para assim determinar o tempo de chegada da onda S. Pedrini (2012) demonstra que esse tempo pode ser obtido indiretamente, pela frequência média predominante do pulso principal de onda $\mathrm{S}$. $\mathrm{Na}$ Figura 64 são apresentados três espectros de frequência de ondas em janela em diferentes profundidades, $2.57 \mathrm{~m}, 7.48 \mathrm{~m}$ e $15.48 \mathrm{~m}$, obtidos pelo gráfico 3 do programa de análise dos sinais. Na análise dos três espectros verifica-se uma frequência média de aproximadamente $72 \mathrm{~Hz}$, que representa um tempo de aproximadamente $3,47 \mathrm{~ms}$, que deve ser subtraído daquele encontrado a partir do ponto de referência ponto de referência do sinal. 

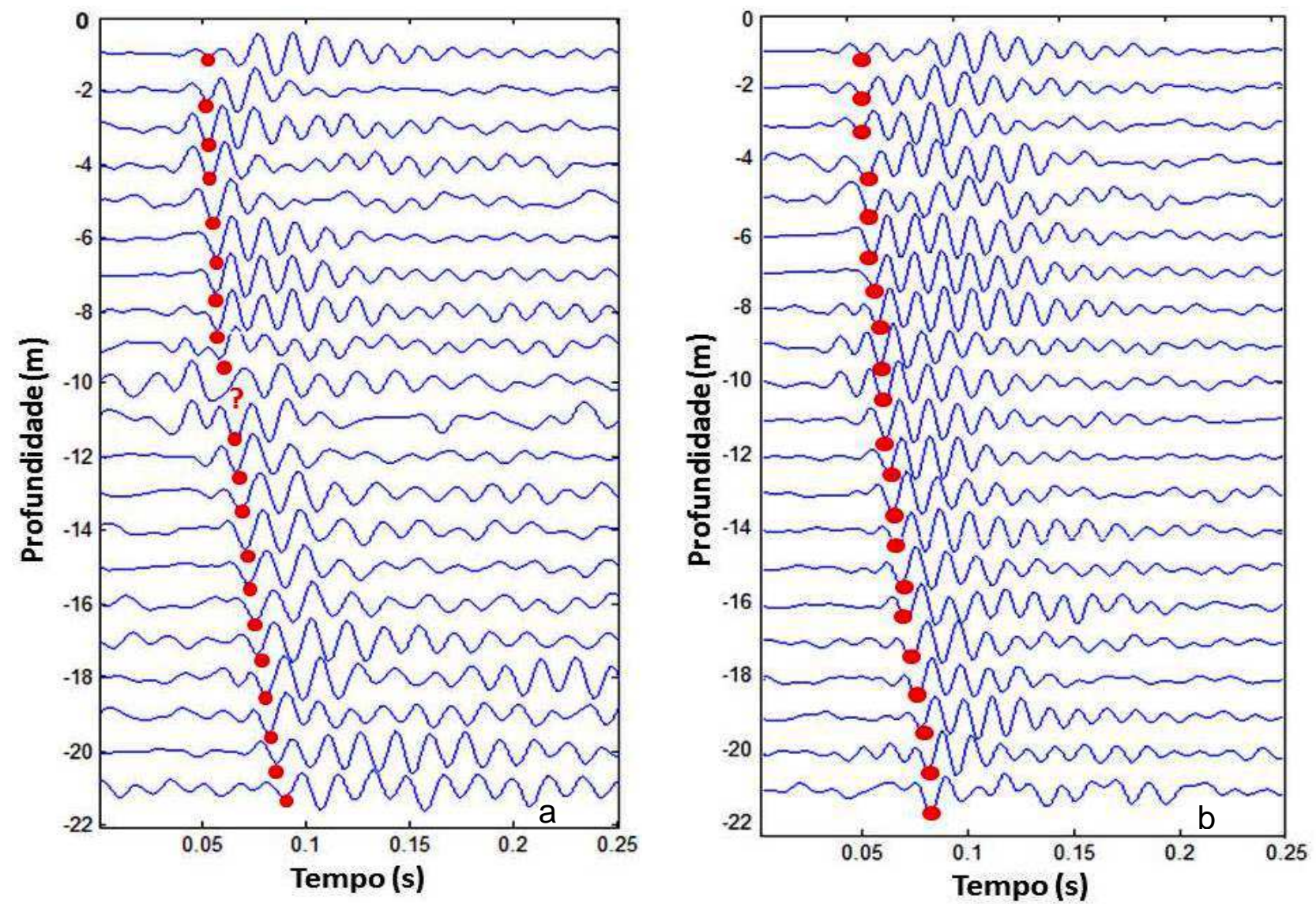

Figura 63: Registros dos geofones horizontais a 10m (a), a $12 \mathrm{~m}$ (b) do furo de sondagem para o campo experimental da EESC-USP, São Carlos

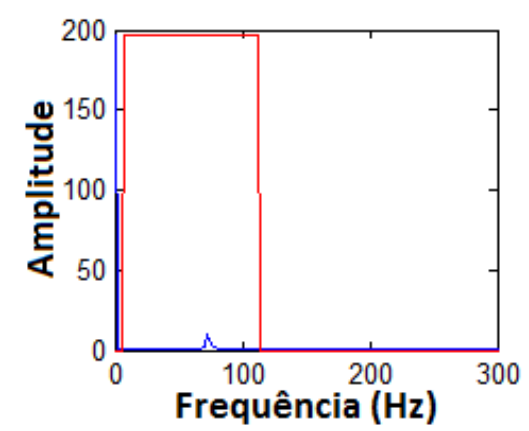

$2.57 \mathrm{~m}$

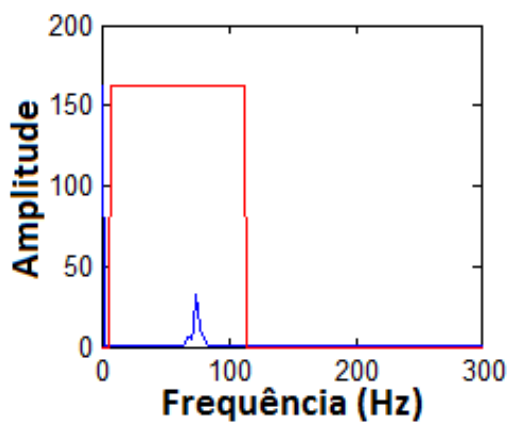

$7.48 \mathrm{~m}$

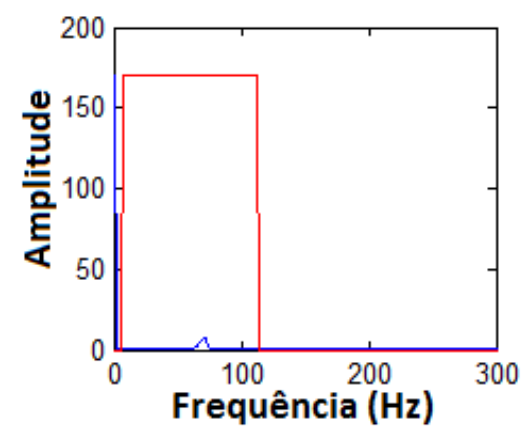

$15.48 \mathrm{~m}$

Figura 64: Espectros de frequências em diferentes profundidades do ensaio realizado no campo experimental da EESC/USP, São Carlos

A Figura 65 apresenta os resultados obtidos pelo ensaio S-SPT 1, sendo que (a) é apresentado o perfil típico, (b) tem os valores de $\mathrm{N}_{\mathrm{SPT}}$ e (c) às velocidades obtidas pelos geofones posicionados a 6, 8, 10 e $12 \mathrm{~m}$ do furo de sondagem, juntamente com o valor médio. Verifica-se que não ocorre grande diferença nos perfis de velocidades, exceto entre 9.5 e $10.5 \mathrm{~m}$ de profundidade, que corresponde à região de variação do nível d'água. Em função disso, nenhum perfil de velocidade foi descartado, como sugere Bang e Kim (2007). Na Figura 65.d é apresentado à comparação entre o perfil médio obtido no ensaio S-SPT1 e os 
perfis de velocidade obtidos nos ensaios SCPT, down-hole $(\mathrm{DH})$ e cross-hole $(\mathrm{CH})$ e (e) mostra as diferenças relativas das três comparações, incluindo as respectivas médias.
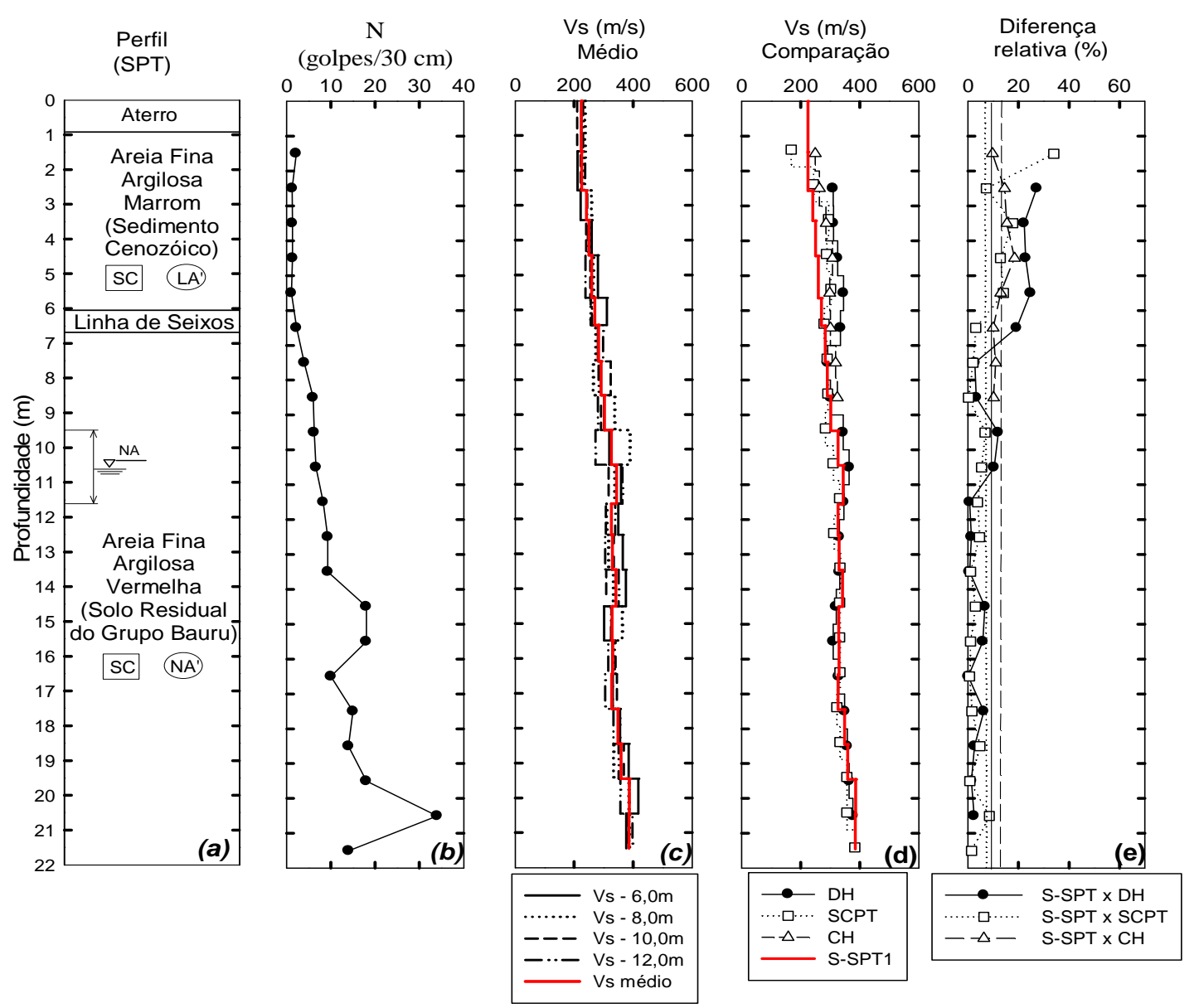

Figura 65: Resultados obtidos pelo ensaio S-SPT1 realizado no campo experimental da EESC/USP, São Carlos

$\mathrm{Na}$ comparação entre S-SPT1 e $\mathrm{CH}$, a diferença média foi de $12.8 \%$, valor bem próximo à diferença relativa dos ensaios cross-hole $(\mathrm{CH} 1$ e $\mathrm{CH} 2)$, que foi de $10.4 \%$. Isso demonstra que o ensaio S-SPT fornece resultados equivalentes. Essa diferença pode estar relacionada com a presença da linha de seixos, entre 6 e $7 \mathrm{~m}$, que pode afetar a propagação dos sinais captados pelos geofones. Também pode estar relacionada com a variação da sucção matricial, que afeta a rigidez e a velocidade de propagação de onda $S$, uma vez que estes ensaios foram realizados em épocas distintas, como informa Giacheti (1991) e Barros (1997).

A diferença relativa média entre S-SPT1 e a Ponteira sísmica (DH) foi de 9.1\%. Esta diferença é maior novamente na camada mais rasa (até $7 \mathrm{~m}$ ) do perfil, podendo estar relacionada com a variação da sucção matricial, uma vez que estes ensaios foram realizados em épocas distintas. Outro fato que pode justificar essa diferença é a posição da fonte sísmica geradora de ondas S nos ensaios down-hole, como discute Vitali (2011). Outra diferença 
significativa, aproximadamente $11.2 \%$, foi observado entre 9 e $11 \mathrm{~m}$ de, na região onde se observa a variação da posição do nível d'água.

$\mathrm{Na}$ comparação entre os valores de $\mathrm{V}_{\mathrm{S}}$ determinados nos ensaios S-SPT1 e SCPT, a diferença relativa média foi de $6.4 \%$. Novamente as maiores diferenças relativas encontram-se nas camadas superficiais do perfil (até $6 \mathrm{~m}$ ). Considerando que os ensaios foram realizados em épocas diferentes, a variação da sucção matricial pode ter influenciado os valores de velocidade de onda $S$, principalmente na camada mais superficial, que sofre maior variação na sucção matricial é maior. Observou-se que as diferenças relativas encontradas na região de variação do nível d'água ( 9 a 11m) foram pequenas, com valor médio de $6.1 \%$.

\subsubsection{Relação $G_{0} / N_{60}$ através de ensaios sísmicos e $S P T$ anteriormente realizados}

No campo experimental da EESC/USP de São Carlos estão disponíveis dois ensaios down-hole, dois ensaio cross-hole e dois ensaios SCPT. Também estão disponíveis resultados de treze sondagens SPT. A Figura 66 apresenta uma síntese dos resultados dos ensaios realizados no campo experimental da EESC/USP de São Carlos através de ensaios SPT e ensaios sísmicos. Na Figura 66.a tem-se o perfil típico do campo estudado baseado em ensaios SPT; na Figura 66.b os valores de N corrigidos para uma eficiência de 60\%; na Figura 66.c os valores de velocidade de onda $\mathrm{S}$ determinados por ensaios cross-hole, down-hole e SCPT; na Figura 66.d os valores de módulo de cisalhamento máximo e na Figura 66.e a média dos todos os valores de $\mathrm{G}_{\mathrm{o}}$ e $\mathrm{N}_{60}$ para cada metro de profundidade que foi calculada, determinando $G_{o_{\text {med }}} / N_{60}$ med $v$ versus profundidade.

Nessa Figura observa-se que a relação $G_{o_{\text {med }}} / N_{60}$ med tende a diminuir com a profundidade, com um valor médio de 50 entre 1 e $7 \mathrm{~m}$; 25, entre 7 e $14 \mathrm{~m}$ e 14 abaixo de 14 $\mathrm{m}$ de profundidade. Estes resultados indicam valores maiores da relação $G_{o_{\text {med }}} / N_{60}$ med para camada de solo laterítico (1 a $7 \mathrm{~m}$ ) e tendem a diminuir em camadas de solo menos desenvolvidos, como o solo saprolítico (7 a $21 \mathrm{~m}$ ).

Na Figura 67 é apresentado o gráfico de $\mathrm{G}_{0} / \mathrm{N}_{60}$ versus $\left(N_{1}\right)_{60}$. Observa-se nessa Figura que a maioria dos dados encontra-se próximo do limite superior para areias cimentadas, indicando que a estrutura desses solos levam a valores maiores $\mathrm{G}_{0} / \mathrm{N}_{60}$ do que em solos sedimentares. Nessa mesma Figura verifica-se que os solos lateríticos apresentam maior cimentação que os solos saprolíticos. Destaca-se que estes resultados são similares aos 
encontrados por Giacheti e De Mio (2008), baseados na relação $\mathrm{G}_{\mathrm{o}} / \mathrm{q}_{\mathrm{c}}$, determinado através de ensaios SCPT (Figura 36).

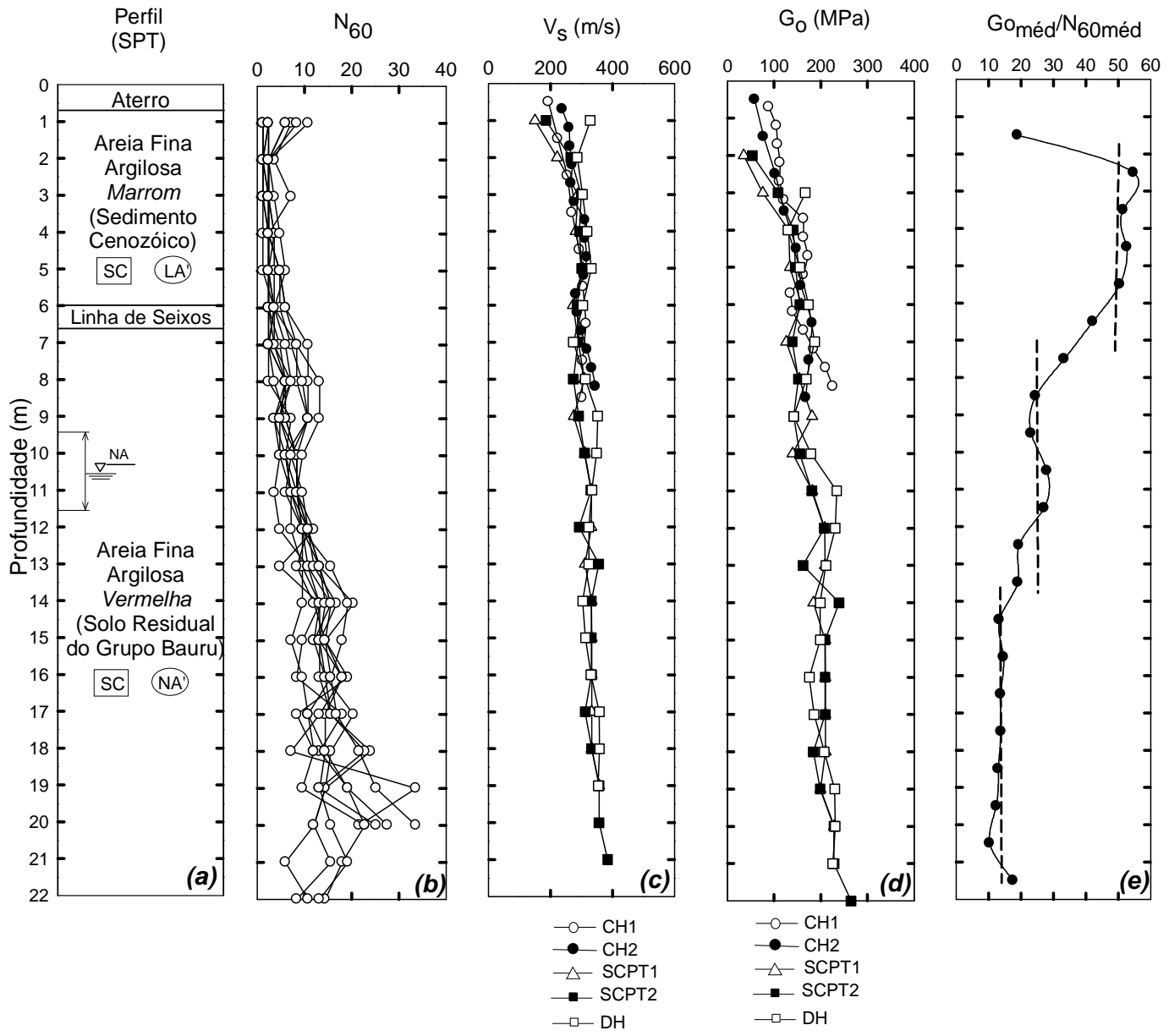

Figura 66: Ensaios SPT, sísmicos e relação $\mathrm{G}_{\mathrm{o}} / \mathrm{N}_{60}$ para o campo experimental da EESC/USP, São Carlos

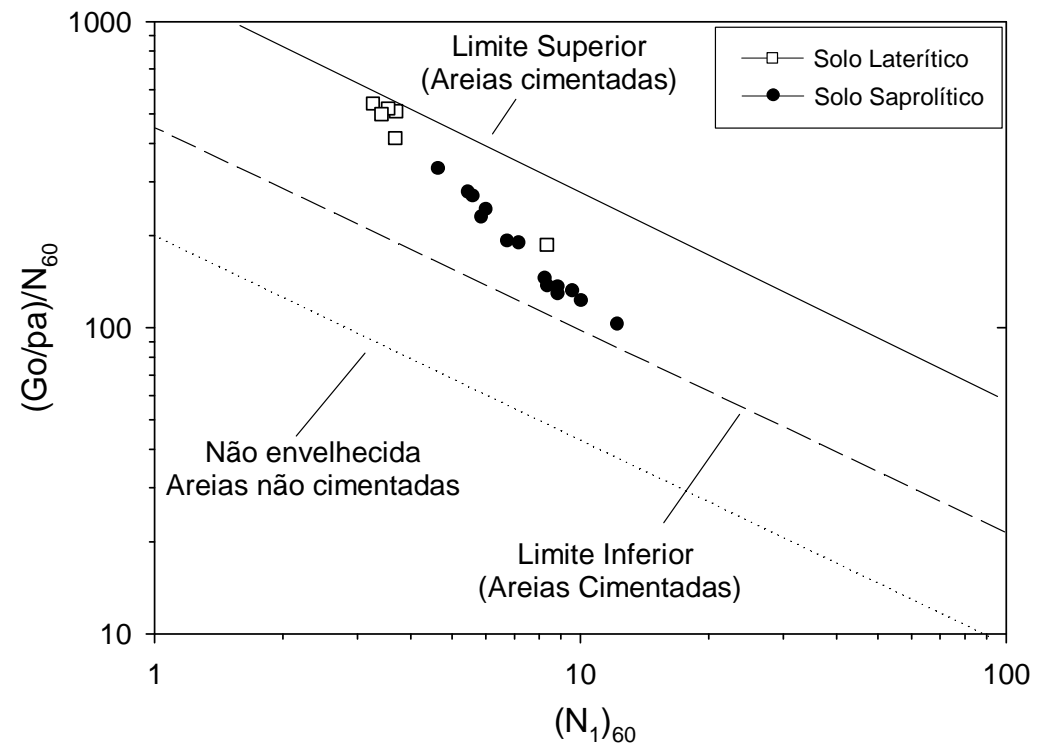

Figura 67: Relação entre $\mathrm{G}_{\mathrm{o}}$ e $\mathrm{N}_{60}$ (ensaios anteriores) para o campo experimental da EESC/USP, São Carlos 


\subsubsection{Relação $G_{0} / N_{60}$ através do ensaio $S-S P T$}

A Figura 68 apresenta os resultados do S-SPT1, bem como os perfis de módulo de cisalhamento máximo e da relação $\mathrm{G}_{0} / \mathrm{N}_{60}$. Na Figura 68.c verifica-se que os perfis de velocidades de onda $\mathrm{S}$ determinados pelos 4 últimos geofones não apresentam grande discrepância. A Figura 68.d apresenta o perfil de $\mathrm{G}_{\mathrm{o}}$ com a profundidade enquanto a Figura 68.e mostra os valores de $\mathrm{G}_{0} / \mathrm{N}_{60}$ com a profundidade, obtido a partir do S-SPT1. Observa-se que o perfil de $\mathrm{G}_{0} / \mathrm{N}_{60}$ é similar ao determinado com ensaios sísmicos e SPT (Figura 66). Na camada laterítica (1 a $7 \mathrm{~m}$ ) o valor médio de $\mathrm{G}_{\mathrm{o}} / \mathrm{N}_{60}$ foi de 63 . Na camada superior de solo saprolítico (7 a $14 \mathrm{~m}$ ) foi encontrado o valor médio de 20, e na inferior do mesmo (14 a $21 \mathrm{~m}$ ) foi encontrado o valor médio de 12. Esses resultados também foram plotados no gráfico de $\mathrm{G}_{0} / \mathrm{N}_{60}$ versus $\left(N_{1}\right)_{60}$ (Figura 69$)$.

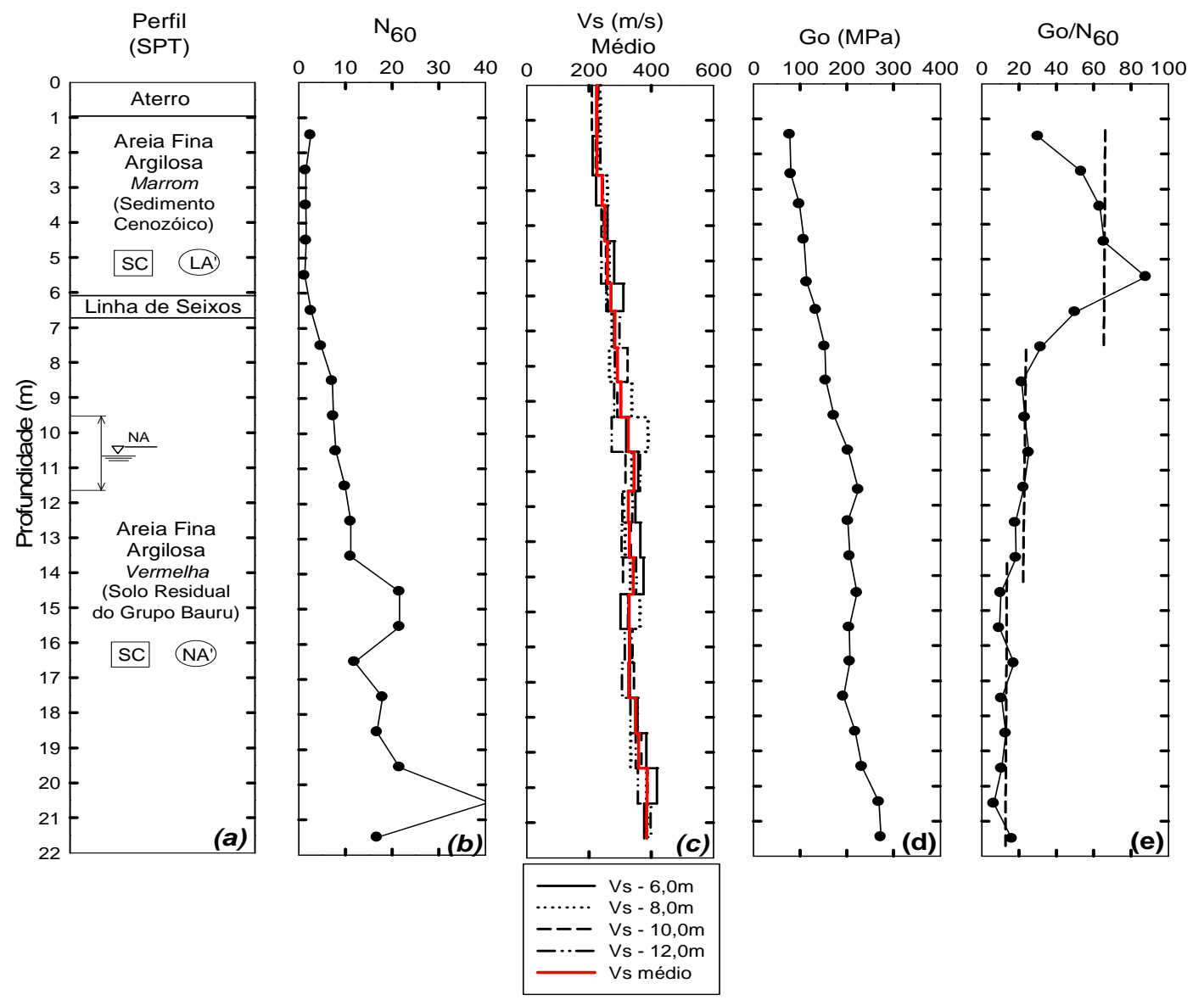

Figura 68: Resultados do ensaio S-SPT1 e a razão $\mathrm{G}_{\mathrm{o}} / \mathrm{N}_{60}$ para o campo experimental da EESC/USP, São Carlos

Verifica-se que a maioria dos pontos (solos lateríticos e saprolíticos) encontra-se acima do limite superior para areias cimentadas, proposto por Schnaid, Fahey e Lehane 
(2004). Nota-se ainda que a estrutura desses solos produza valores muito maiores de $\mathrm{G}_{0} / \mathrm{N}_{60}$ do que em solos sedimentares, também é possível observar que os solos lateríticos apresentam maior cimentação que os solos saprolíticos. Estes resultados são similares aos encontrados por Giacheti e De Mio (2008), baseados na relação $\mathrm{G}_{\mathrm{o}} / \mathrm{q}_{\mathrm{c}}$, obtida através de ensaios SCPT (Figura 36).

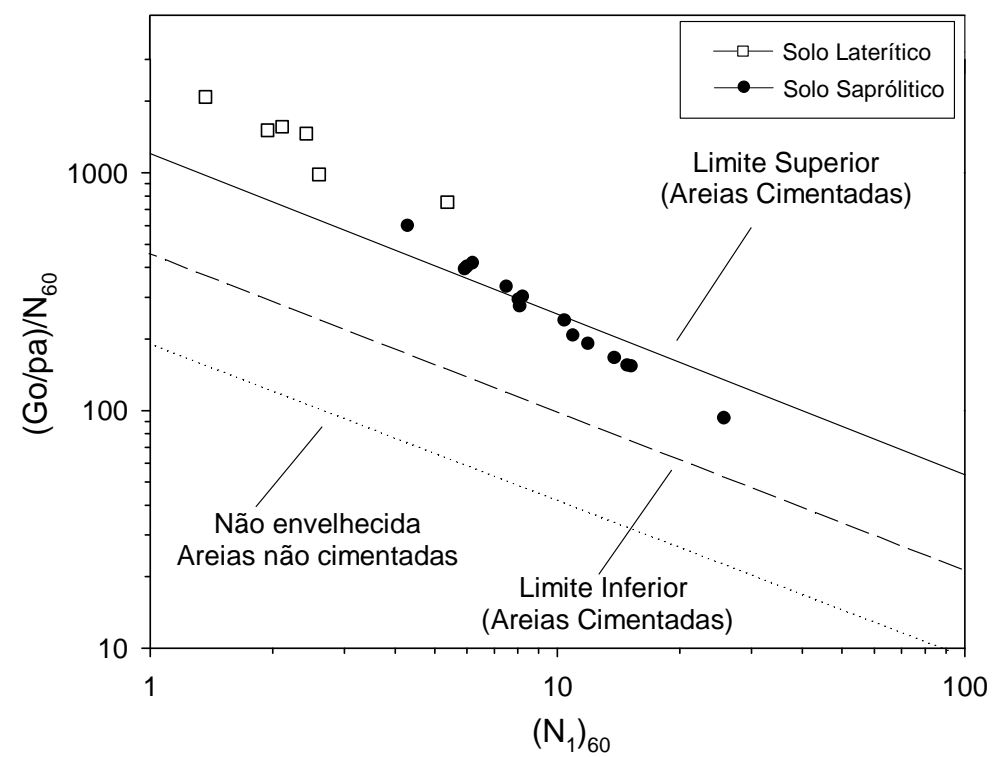

Figura 69: Relação entre $\mathrm{G}_{\mathrm{o}}$ e $\mathrm{N}_{60}$ (ensaio S-SPT) para o campo experimental da EESC/USP, São Carlos

\subsection{Campo Experimental da UNICAMP, Campinas}

\subsubsection{Determinação do perfil de velocidades de onda $S$ pelo ensaio S-SPT}

No campo experimental da UNICAMP foi executado um ensaio S-SPT até a profundidade de $21.45 \mathrm{~m}$. Estão disponíveis ainda resultados de outros cinco ensaios sísmicos, sendo dois ensaios SCPT (SCPT1 e SCPT2), realizados também até $21 \mathrm{~m}$, dois ensaios crosshole $(\mathrm{CH} 1$ e $\mathrm{CH} 2)$ e um ensaio down-hole (DH1). A Figura 70 apresenta a disposição desses ensaios na área.

Também se empregou a metodologia proposta por Pedrini (2012) para analisar os registros dos ensaios sísmicos realizados nesse campo experimental. Verificou-se novamente que os sinais captados pelos geofones horizontais permitiram uma melhor caracterização da onda $\mathrm{S}$ e que as caixas posicionadas a 2 e $4 \mathrm{~m}$ do furo de sondagem foram de baixa qualidade 
e, portanto, também não foram utilizadas para determinação do perfil de velocidades de onda S.

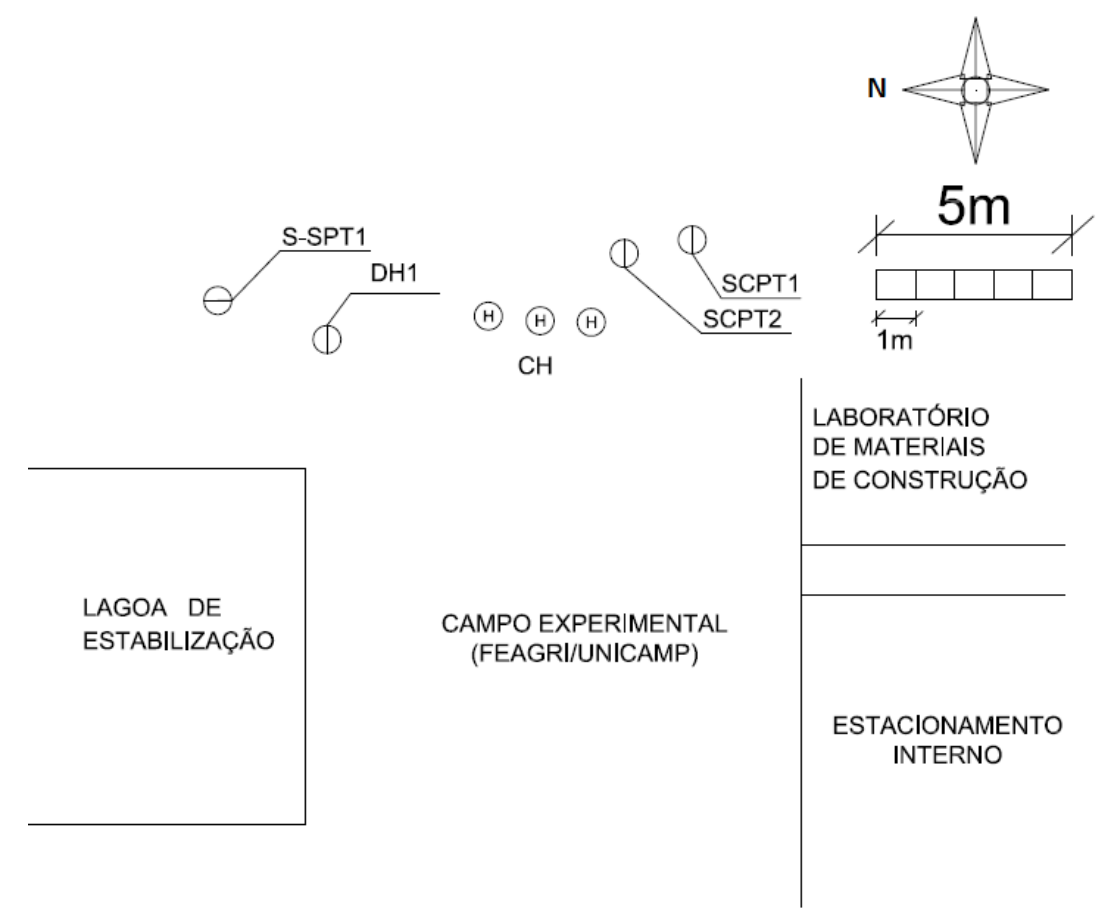

Figura 70: Posição dos ensaios sísmicos realizados no campo experimental da Unicamp, em Campinas

As caixas posicionadas a $6,8,10$ e $12 \mathrm{~m}$ do furo de sondagem foram utilizados para a determinação das velocidades de onda $\mathrm{S}$ até a profundidade final de ensaio. A Figura 71 apresenta o perfil de ondas registradas pelo geofone localizado a $10 \mathrm{~m}$ (Figura 71.a) e a $12 \mathrm{~m}$ (Figura 71.b) do furo de sondagem. Nota-se, também aqui, que é impossível identificar a onda $\mathrm{S}$ a $1 \mathrm{~m}$ de profundidade, pelo geofone a $12 \mathrm{~m}$ do furo de sondagem. Por isso, foi necessário utilizar o recurso de software de interpretação, descrito no item 3.1.4.2.1 deste trabalho.

Como já demonstrado para o campo experimental de São Carlos, foi determinado de modo indireto o tempo de chegada da onda $S$, através da frequência média predominante do pulso principal de onda S. Na Figura 72 são apresentados três espectros de frequência de ondas em janela em diferentes profundidades $6.45 \mathrm{~m}, 12.45 \mathrm{~m}$ e $15.45 \mathrm{~m}$, obtidos pelo gráfico 3 do programa de análise dos sinais para o campo experimental de Campinas. A partir da análise desses espectros verifica-se uma frequência média de aproximadamente $61 \mathrm{~Hz}$, que representa um tempo de aproximadamente $4.1 \mathrm{~ms}$, que deve ser subtraído daquele encontrado pelo ponto de referência. 

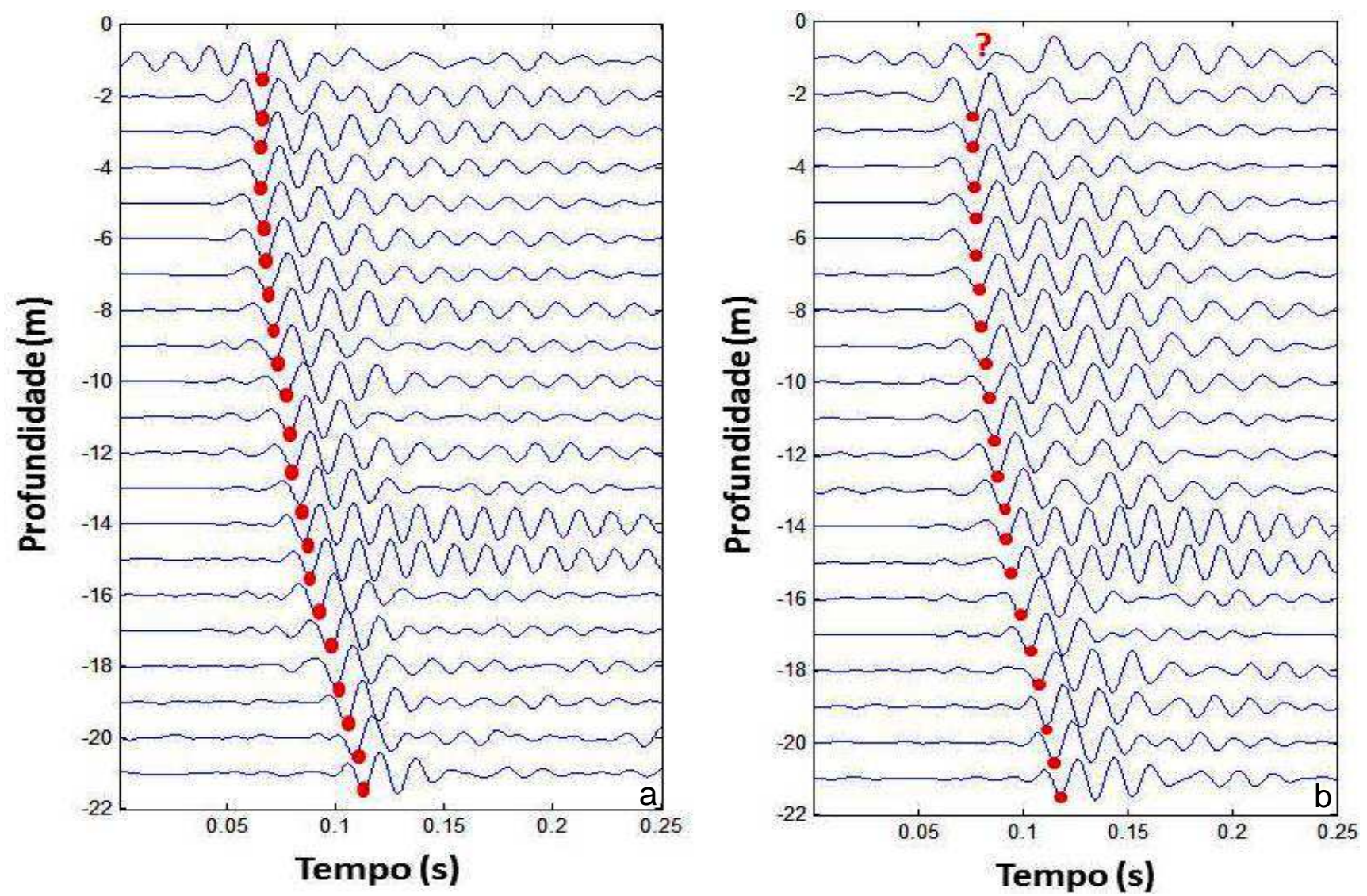

Figura 71: Registros obtidos pelo geofone horizontal a 10m (a), registro obtido pelo geofone horizontal a $12 \mathrm{~m}$ (b) do furo de sondagem
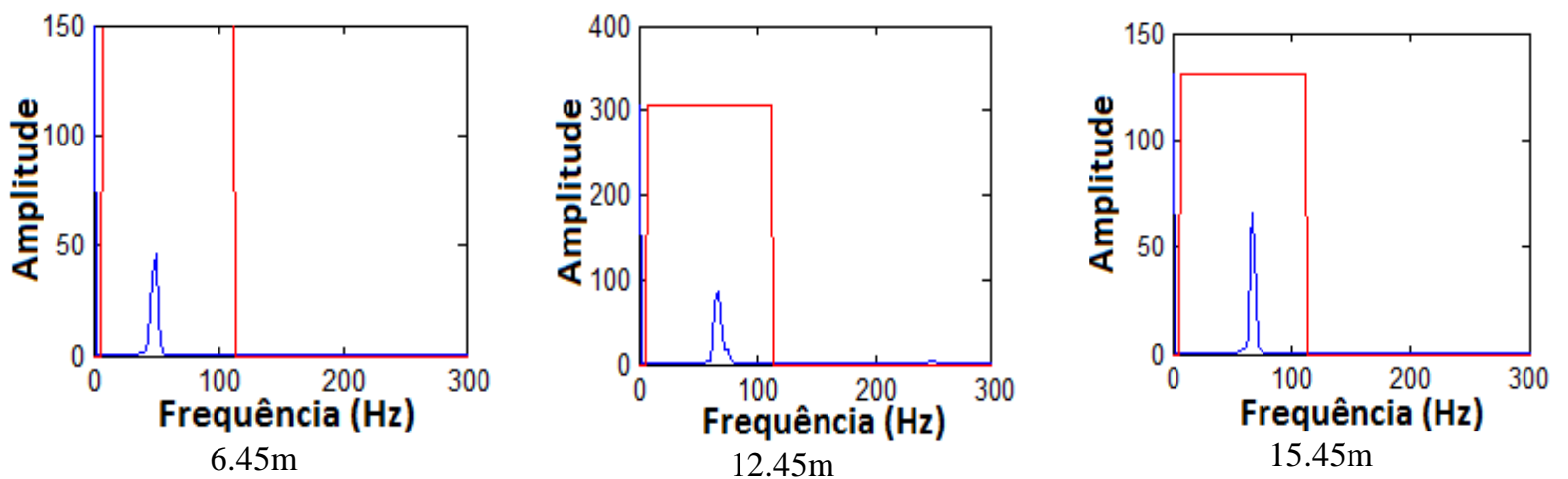

Figura 72: Espectros de frequências em diferentes profundidades do ensaio realizado no campo experimental da UNICAMP, Campinas

A Figura 73 sintetiza os resultados do ensaio S-SPT 1 realizado no campo experimental da UNICAMP-Campinas. Na Figura 73.a tem-se, na 73.b os valores de N do SPT, na 73.c têm-se os perfis de velocidades obtidas a partir dos geofones posicionados a 6, 8, 10 e $12 \mathrm{~m}$ do furo de sondagem, bem como o perfil médio. Verifica-se que não ocorre grande diferença nos perfis de velocidades, portanto todos foram utilizados para definir o perfil médio de $\mathrm{V}_{\mathrm{S}}$. A Figura 73.d compara o perfil médio de $\mathrm{V}_{\mathrm{S}}$ obtido no ensaio S-SPT1 com os perfis dos ensaios SCPT, down-hole $(\mathrm{DH})$ e cross-hole $(\mathrm{CH})$ e a Figura 73.e apresenta às diferenças relativas das três comparações, com as respectivas médias. 


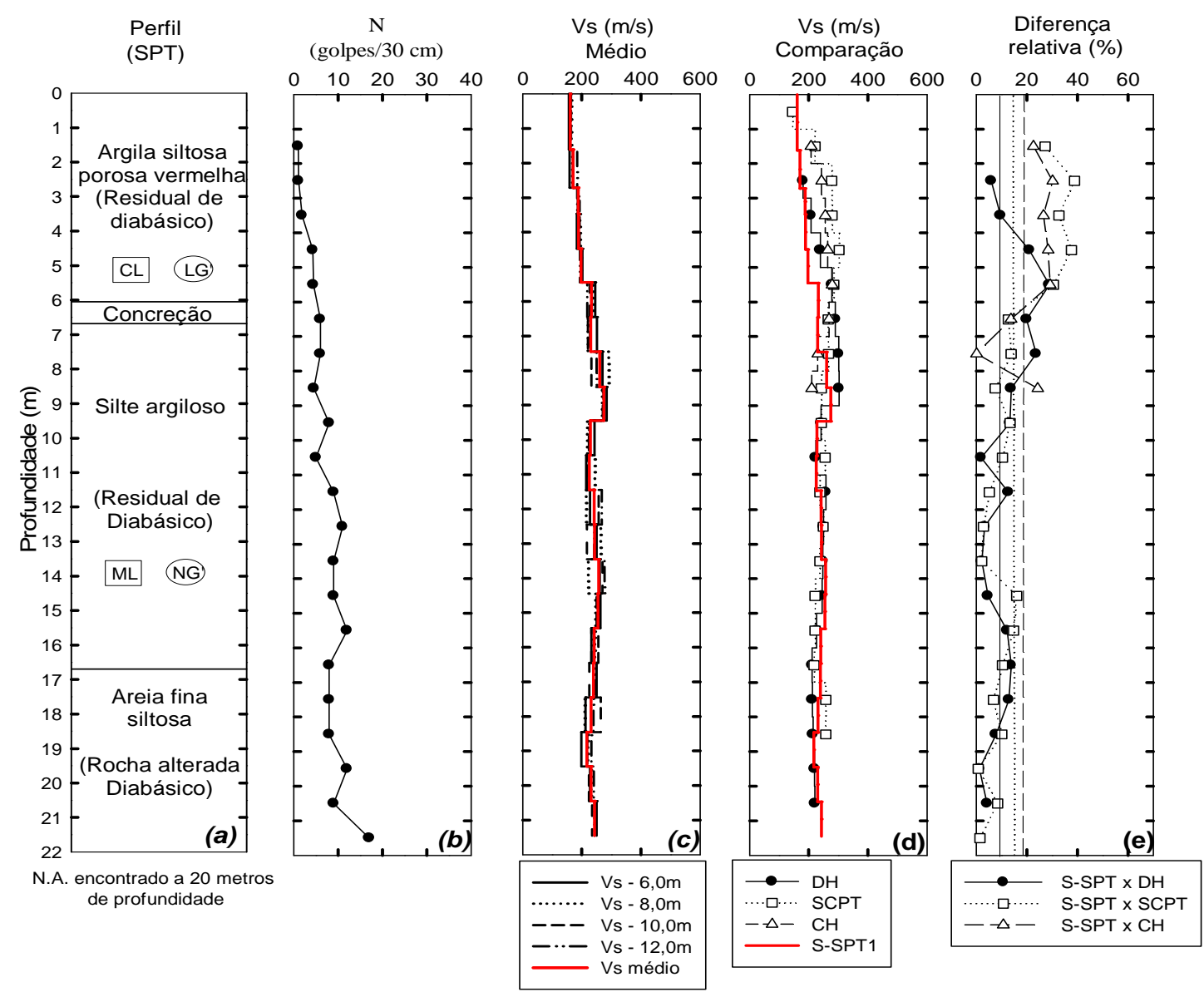

Figura 73: Resultados do ensaio S-SPT1 realizado no campo experimental da UNICAMP, Campinas

A diferença do valor médio de $\mathrm{V}_{\mathrm{S}}$ do ensaio $\mathrm{S}-\mathrm{SPT} 1 \mathrm{em}$ relação aos valores médios dos ensaios CH, SCPT e DH foram, respectivamente, $21,9 \%, 16,2 \%$ e 11,2\%. Verifica-se que as maiores diferenças encontram-se até a profundidade de $9 \mathrm{~m}$, onde Giacheti, Peixoto e De Mio (2007), demonstraram com ensaios CPT, a grande variabilidade nesse do local. Outro fator pode estar relacionado à presença da camada concrecionada, entre 6 e $7 \mathrm{~m}$ de profundidade, que pode ter afetado a propagação dos sinais captados pelos geofones. Outro aspecto que pode ter contribuído para essa maior diferença pode estar relacionada com a variação da sucção matricial, que afeta a rigidez e a velocidade de propagação de onda $\mathrm{S}$, uma vez que estes ensaios foram realizados em épocas distintas, como informa Giacheti (1991)e Barros (1997). Na camada de solo residual de diabásio (9 a 17 m) existe uma menor diferença entre os resultados, 9,4\% com os ensaios SCPT e 8,0\% para os DH. A menor variabilidade nesse trecho do perfil pode ser verificada também pela semelhança dos resultados de $\mathrm{q}_{\mathrm{c}}$ (Giacheti, Peixoto e De Mio, 2007), indicando maior homogeneidade das propriedades geotécnicas. Na camada de areia fina siltosa variegado (17 a $21 \mathrm{~m})$ verifica-se uma diminuição nas diferenças de $\mathrm{V}_{\mathrm{S}}$, sendo que a diferença média entre o ensaio S-SPT e os ensaios SCPT e DH foi, respectivamente de $8,5 \%$ e $6,6 \%$. 


\subsubsection{Relação $G_{0} / N_{60}$ através de ensaios sísmicos e $S P T$ anteriormente realizados}

No campo experimental da UNICAMP de Campinas, estão disponíveis resultados de um ensaio down-hole, dois ensaios cross-hole e dois ensaios SCPT. Além disso, existem resultados de treze sondagens SPT nessa mesma área. A Figura 74 apresenta uma síntese dos resultados dos ensaios SPT e ensaios sísmicos previamente realizados nesse campo experimental.
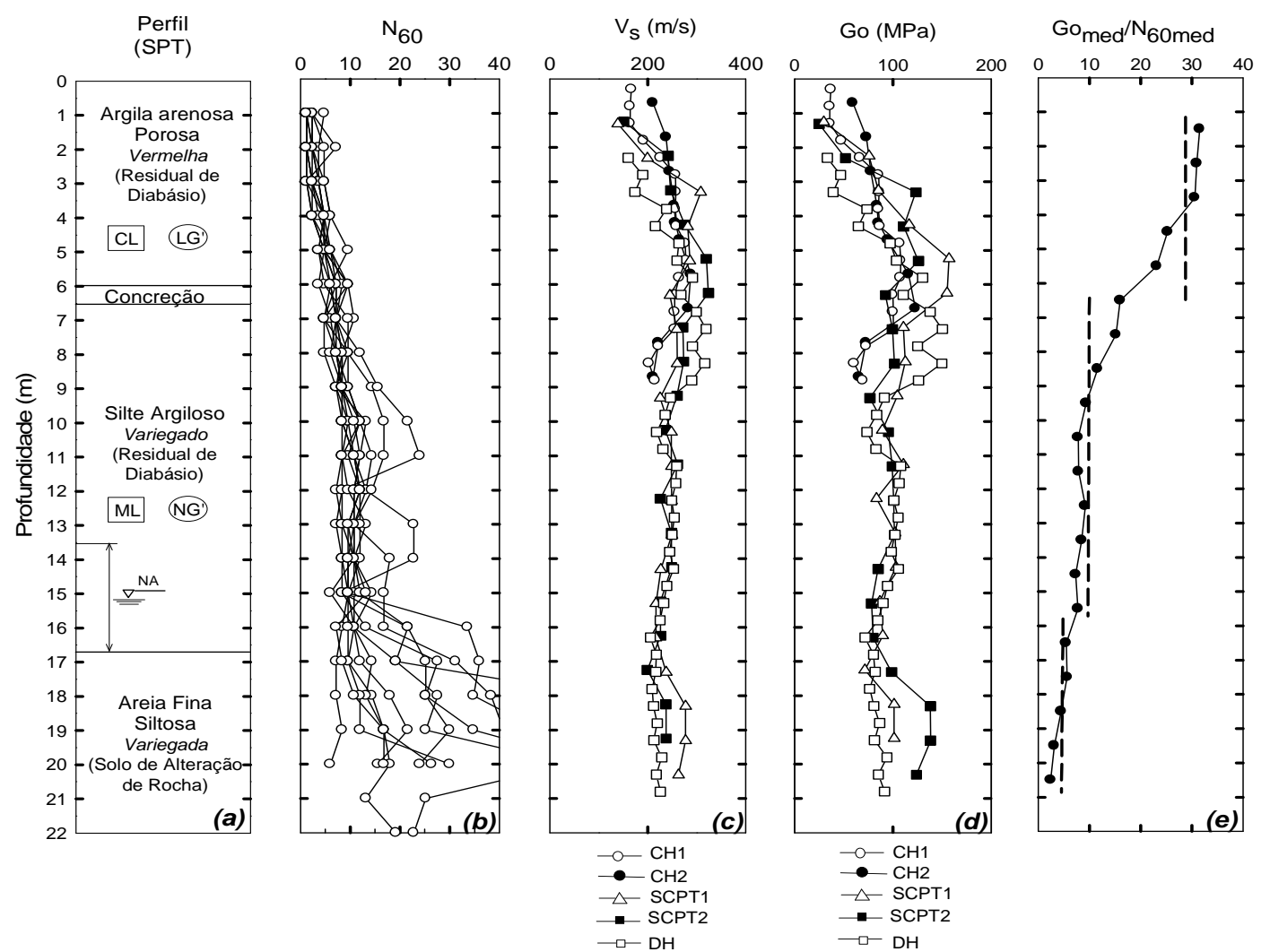

Figura 74: Resultados de ensaios SPT, sísmicos e relação $\mathrm{G}_{\mathrm{o}} / \mathrm{N}_{60}$ do campo experimental da UNICAMP, Campinas

A Figura 74.a apresenta um perfil típico dessa área, baseado nos ensaios SPT e a Figura 74.b mostra os valores de N corrigidos para uma eficiência de 60\%. Na Figura 74.c são apresentados valores de velocidade de onda $\mathrm{S}$ determinados por ensaios cross-hole, downhole e SCPT. A Figura 74.d apresenta os perfis de variação do módulo de cisalhamento máximo versus profundidade. A média dos valores de $\mathrm{G}_{0} / \mathrm{N}_{60}$ para cada metro de profundidade foi calculada, determinando $G_{o_{\text {med }}} / N_{60 \text { med }}$ versus profundidade (Figura 74.e). O critério utilizado para o cálculo da relação $G_{o_{m e d}} / N_{60}$ med foi a média de todos os valores de $\mathrm{G}_{\mathrm{o}}$ e $\mathrm{N}_{60}$ para cada metro. Na Figura 75 e observa-se que a relação $G_{o_{\text {med }}} / N_{60}$ med tende a 
diminuir com a profundidade, com um valor médio de 29 entre 1 e $6 \mathrm{~m}$; 14, entre 6 e $16 \mathrm{~m}$ e 4 abaixo de $16 \mathrm{~m}$ de profundidade. Estes resultados indicam valores maiores da relação $G_{o_{\text {med }}} / N_{60_{\text {med }}}$ para camada de solo laterítico ( 1 a $6 \mathrm{~m}$ ) e tendem a diminuir em camadas de solo menos desenvolvido, como o solo saprolítico (6 a $21 \mathrm{~m})$.

Do mesmo modo que nos campos experimentais da UNESP de Bauru e da EESC/USP de São Carlos, os resultados de ensaios sísmicos e de SPT foram plotados no gráfico de $\mathrm{G}_{\mathrm{o}} / \mathrm{N}_{60}$ versus $\left(N_{1}\right)_{60}$ (Figura 75$)$.

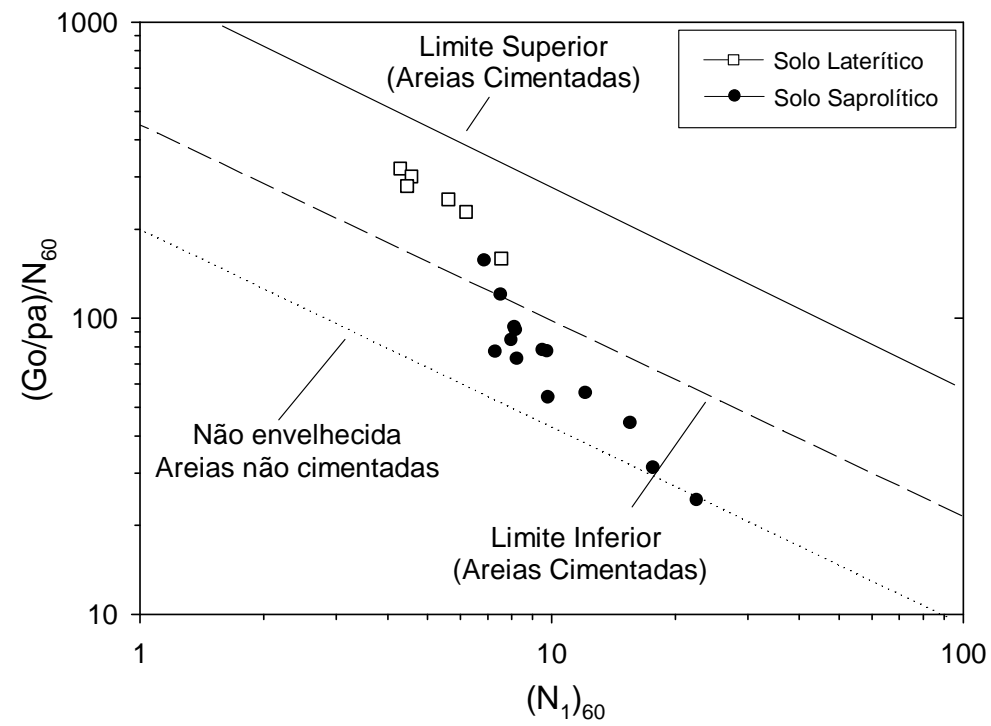

Figura 75: Relação entre $\mathrm{G}_{0}$ e $\mathrm{N}_{60}$ (ensaios anteriores) para o campo experimental da UNICAMP, Campinas

A maioria dos dados obtidos na camada de solo saprolítico encontra-se abaixo do limite inferior sugerido por Schnaid, Fahey e Lehane (2004) para areias cimentadas. Na mesma figura verifica-se que os dados obtidos na camada de solo laterítico encontram-se dentro da faixa do limite inferior para materiais cimentados, indicando maior cimentação nos solos lateríticos. Estes resultados são similares aos encontrados por Giacheti e De Mio (2008), baseados na relação $\mathrm{G}_{\mathrm{o}} / \mathrm{q}_{\mathrm{c}}$, obtida através de ensaios SCPT (Figura 36).

\subsubsection{Relação $\mathbf{G}_{0} / \mathbf{N}_{60}$ através do ensaio $S-S P T$}

A Figura 76 apresenta os resultados do ensaio S-SPT1, em conjunto com o perfil do módulo de cisalhamento máximo e da relação $\mathrm{G}_{\mathrm{o}} / \mathrm{N}_{60}$. A Figura 76.d apresenta o perfil de $\mathrm{G}_{\mathrm{o}}$ versus profundidade e a 76.e apresenta os valores de $\mathrm{G}_{0} / \mathrm{N}_{60}$ versus profundidade. $\mathrm{O}$ perfil de $\mathrm{G}_{\mathrm{o}} / \mathrm{N}_{60}$ obtido a partir do S-SPT também é similar aos encontrados com a média dos ensaios 
sísmicos e SPT para a camada laterítica superior (1 a $3 \mathrm{~m}$ ), com o valor médio igual a 35 . Na camada inferior de solo laterítico (3 a $6 \mathrm{~m}$ ) foi encontrado o valor médio de 15 . Este foi o mesmo valor encontrado para a camada superior $(6$ a $11 \mathrm{~m}$ ) de solo saprolítico. Na camada inferior de solo saprolítico o valor encontrado foi igual a 11 entre 11 e $19 \mathrm{~m}$ de profundidade e 8 a partir daí.

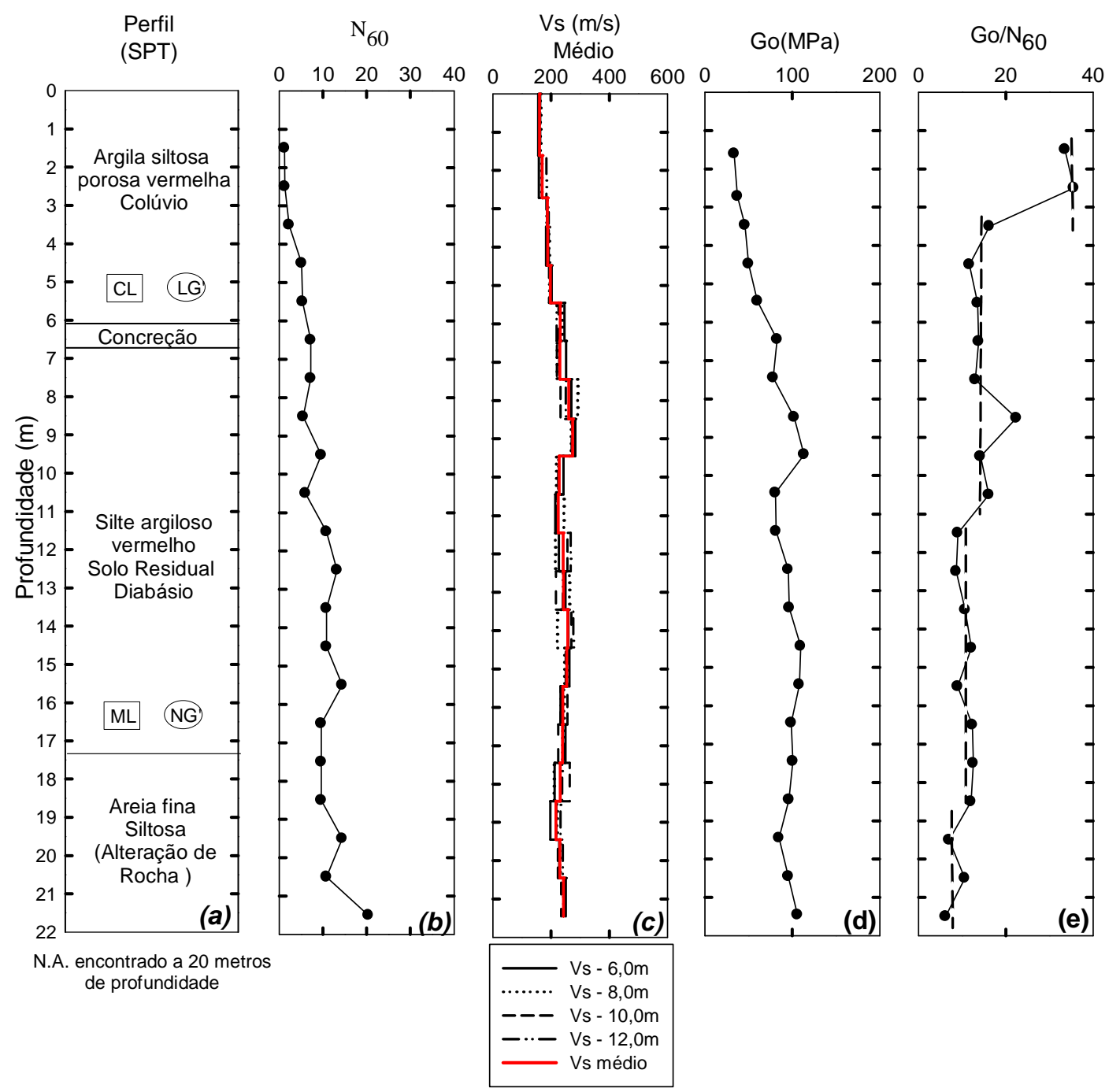

Figura 76: Resultados do ensaio $\mathrm{S}-\mathrm{SPT} 1$ e a razão $\mathrm{G}_{0} / \mathrm{N}_{60}$ para o campo experimental da UNICAMP, Campinas

Esses resultados também foram plotados no gráfico $\mathrm{G}_{0} / \mathrm{N}_{60}$ versus $\left(N_{1}\right)_{60}$ (Figura 77 ). Nesta figura verifica-se que a maioria dos pontos está dentro da faixa do limite inferior para areias cimentadas e que não há uma diferença nítida entre os solos lateríticos e saprolíticos. Constatou-se que somente a camada superior de solo laterítico (1 a $4 \mathrm{~m}$ de profundidade) reflete um maior grau de cimentação, com pontos na faixa superior dos materiais cimentados de Schnaid, Fahey e Lehane, 2004. 


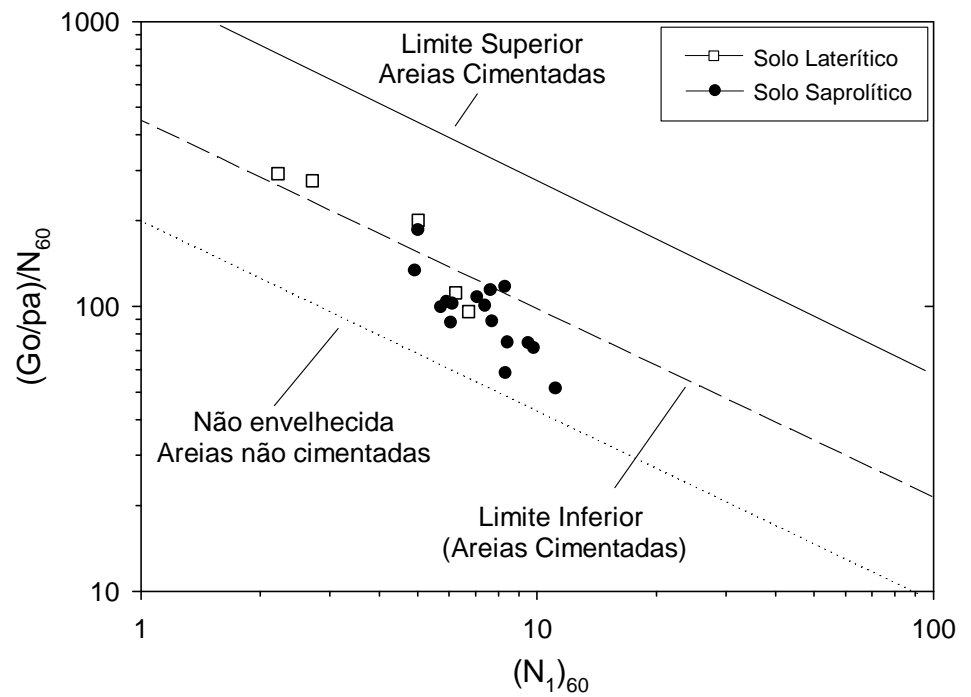

Figura 77: Relação entre $\mathrm{G}_{0}$ e $\mathrm{N}_{60}$ (ensaio S-SPT) para o campo experimental da UNICAMP, Campinas 


\section{Conclusão e sugestões para continuidade}

\subsection{Ensaio S-SPT}

Os perfis de velocidade de onda $\mathrm{S}$ determinados nos três campos experimentais com o ensaio S-SPT podem ser considerados equivalentes aos perfis de referência determinados nos ensaios cross-hole, down-hole e cone sísmico. Logo, o sistema e metodologia desenvolvida por Pedrini (2012) para realização da sísmica up-hole em conjunto ao ensaio SPT mostrou ser eficiente e de fácil execução.

Este método pode ser empregado para obter o perfil de $\mathrm{G}_{\mathrm{o}}$, em conjunto com o ensaio SPT, rapidamente e a um custo relativamente baixo. O S-SPT é indicado quando outras técnicas mais apropriadas, como o cross-hole e down-hole, não estão disponíveis para determinação do perfil de $\mathrm{V}_{\mathrm{S}}$.

\subsection{Relação $\mathrm{G}_{0} / \mathbf{N}_{60}$}

Visando uma melhor caracterização de solos tropicais, a partir da integração de ensaios geofísicos (Cross-hole, Down-hole e Up-hole) e ensaios geotécnicos de campo (sondagens SPT), foi determinado a relação $\mathrm{G}_{0} / \mathrm{N}_{60}$, que relaciona um parâmetro de rigidez elástica $\left(\mathrm{G}_{\mathrm{o}}\right)$ com um parâmetro de resistência última $(\mathrm{N})$. Considerando a proposta de Schnaid, Fahey e Lehane (2004) observou-se que a relação $\mathrm{G}_{0} / \mathrm{N}_{60}$ é maior na camada de solo laterítico do que na camada de solo saprolítico. Essa relação diminui quanto menos evoluído é o perfil do subsolo.

Com o mesmo objetivo, também foi determinada a relação $G_{0} / N_{60}$ a partir dos resultados dos ensaios S-SPT realizados nas três áreas estudadas. Observou-se também nesse caso a mesma tendência da camada de solo laterítico apresentar maiores valores de $\mathrm{G}_{\mathrm{o}} / \mathrm{N}_{60}$ maiores do que na camada de solo saprolítico, porém com menor nitidez. Este fato pode estar associado a diversos fatores, desde a maior dificuldade de interpretar os registros de ondas sísmicas pela técnica up-hole nos ensaios S-SPT, como pela variabilidade do perfil dos subsolos. 


\subsection{Sugestões para continuidade da pesquisa}

- Verificar a possibilidade de utilizar o ensaio S-SPT para a determinação de velocidade de propagação de ondas $\mathrm{P}$, e consequentemente determinar o módulo de elasticidade $\left(E_{\mathrm{o}}\right)$ e o coeficiente de Poisson dos solos.

- Avaliar a influência da sucção matricial nos valores de $V_{S}$, e consequentemente no valor de $\mathrm{G}_{\mathrm{o}}$, visando uma melhor caracterização de solos tropicais.

- Avaliar o potencial de utilização da razão $\mathrm{Go} / \mathrm{N}$ para caracterização de solos tropicais colapsíveis, levando em consideração a influência da sucção matricial no comportamento do solo. 


\section{REFERÊNCIAS BIBLIOGRÁFICAS}

ASSOCIAÇÃO BRASILEIRA DE NORMAS TÉCNICAS. NBR-12069: Solo - Ensaio de Penetração de Cone In Situ (CPT), Rio de Janeiro, 1991.

ASSOCIAÇÃO BRASILEIRA DE NORMAS TÉCNICAS. NBR 6484: Sondagens de Simples Reconhecimento com SPT - Método de Ensaio, Rio de Janeiro. 2001.

AMERICAN SOCIETY FOR TESTING AND MATERIALS. D 2845/ D 4428M: Standard Test Methods for Crosshole Seismic Testing, Annual Book of ASTM Standards, 1984, pp. 885-898.

AKIN, M., KRAMER, S.L. e TOPAL, T. Empirical correlations of shear wave velocity (Vs) and penetration resistance (SPT-N) for different soils in an earthquake-prone area (Erbaa-Turkey). Engineering Geology. v.119, Issues 1-2, p.1-17, 2011.

BANG, E. S. Evaluation of shear wave velocity profiles using downhole and up-hole tests 2001. Dissertation of Master of Science in Engineering, KAIST, Daejon, Korea, 2001.

BANG, E.S. e Kim, D.S. Evaluation of shear wave velocity profile using SPT based up-hole method, Soil Dynamics and Earthquake Engineering. v.27, Issue 7, p. 741-758, 2007.

BARROS, J. M. C. Módulo de cisalhamento dinâmico de solos tropicais. 1997. 437p. Tese (Doutorado em Geotecnia)-Escola Politécnica, Universidade de São Paulo, São Paulo, 1997.

BARROS, J. M. C.; GIACHETI, H. L. e MARTINS, M. C. R. (1991): Dynamic Properties of Some Brazilian Lateritic Soils. In: Pan-American Conference on Soil Mechanics and Foundation Engineering. Viña Del Mar, Chile. Proceedings... v.1, p. 15-27, 1991

BARROS, J. M. C. Parâmetros Dinâmicos de Alguns Solos Brasileiros Determinados em Ensaios de Coluna Ressonante. In: Congresso Brasileiro de Mecânica dos Solos e Engenharia de Fundações, 9, Salvador. Anais... v.2, p.475-484, 1990

BELINCANTA, A. Avaliação de fatores intervenientes no índice de resistência à penetração do SPT. 1998. 141 p. Tese (Doutorado em Geotecnia)-Escola de Engenharia de São Carlos, Universidade de São Paulo, São Carlos. 1998.

BUTCHER, A. P. et al. Seismic cone down-hole procedure to measure shear wave velocity a guideline. In: The International Society for Soil Mechanics and Geotechnical Engineering, Proceedings... Technical Committee n. 10, 2005

CAMPANELLA, R. G. et al. Seismic cone penetration testing in the Beaufort sea. In: $3^{\text {rd }}$ Canadian Conference on Marine Geotechnical Engineering Memorial University, St. John's. Newfoundland, Proceedings... $3^{\text {rd }}$ Canadian Conference on Marine Geotechnical Engineering Memorial University p.11-13,1986 
CAMPANELlA, R. G.; STEWART, W. P., Seismic cone analysis using digital signal processing for dynamic site characterization, Canadian Geotechnical Journal, vol. 29, n.3, p.477-486, 1992.

CAMPANELLA, R. G.; BAZIW, E. J.; SULLY, J. P., Interpretation of Seismic Cone Data Using Digital Filtering Techniques. In: International Conference on Soil Mechanics and Foundation, 12.,1989, Rio de Janeiro. Proceedings... International Conference on Soil Mechanics and Foundation, 1989.

CAVALCANTE, E.H. Investigação Teórico-Experimental sobre o SPT. 2002. 430 p. Tese (Doutorado em Engenharia Civil)-COPPE, Universidade Federal do Rio de Janeiro, Rio de Janeiro. 2002.

CHANG, M. F. In-situ testing of residual soils in Singapore. In: International Conference Geomechanics in Tropical Soils, 2., 1990, Singapore. Proceedings...v. 1, PP. 97-108.

Companhia Ambiental do Estado de São Paulo (CETESB), Projeto CETESB-GTZ atualizado 11/1999. 6200. 1. Métodos Geofísicos, Disponível em: $<$ www.cetesb.sp.Gov.br/solo/areas_contaminadas/anexos/.../6200.pdf $<$ Acesso dia 16 de janeiro de 2012.

COZZOLINO, V. M. N.; NOGAMI, J. S. Classificação Geotécnica MCT para Solos Tropicais. Solos e Rochas, São Paulo, V.16, n.2, p.77-91, 1993.

DA FONSECA, A. V.; COUTINHO, R. Q. Characterization of residual soils. In: Geotechnical and Geophysical Site Characterization: Proceedings...3rd International Conference on Site Characterization (ISC'3, Taipei, Taiwan, CD-ROM full papers. CRC Press, p. 195, 2008.

DE MIO, G. Condicionantes geológicos na interpretação de ensaios de piezocone para identificação estratigráfica na investigação geotécnica e geoambiental. 2005. 359p. Tese (Doutorado em Geotecnia) - Escola de Engenharia de São Carlos, Universidade de São Paulo, São Carlos, 2005

DAVIES, M. P.; CAMPANELLA, R. G. Piezocone technology: Down-hole geophysics for the geoenvironmental characterization of soil. In: Symposium on the Application of Geophysics to Engineering and Environmental Problems (SAGEEP),8, 1995, Orlando, United States. Proceedings... Orlando (Florida, USA), 11p, 1995.

DOURADO, J. C. A utilização da Sísmica na Determinação de Parâmetros Elásticos Dinâmicos de Maciços Rochosos e Terrosos In Situ. Publicações de Artigos Técnicos da ABGE n. 8, 12 p, 1984

FERREIRA, C. Implementação e Aplicação de Transdutores Piezoeléctricos na Determinação de Velocidades de Ondas Sísmicas em Provetes. Avaliação da Qualidade de Amostragem em Solos Residuais. 2003, Dissertação (Mestrado em Mecânica dos Solos e Engenharia Geotécnica)-Faculdade de Engenharia do Porto, FEUP, Porto, 2003 
FONTOURA, S. A. B.; LITTLE, A. L.; COLLINS, K. Shear Strength of Undisturbed Tropical Lateritic and Saprolitic Soils, Particularly as Related to their Structure and Mineral Components, In: Committee on Tropical Soils of the ISSMFE, Peculiarities of Geotechnical Behavior of Tropical Lateritic and Saprolitic Soils. 1985, São Paulo-SP Proceedings...pp.45-67

FRANCISCO, G. M. Ensaios de Piezocone Sísmico em Solos. 1997. 157p. Tese (Doutorado em Geotecnia)- Pontifícia Universidade Católica do Rio de Janeiro, Pontifícia Universidade Católica, Rio de Janeiro, 1997

FUTAI, M. M. Propriedades Geotécnicas De Solos Saprolíticos e Rochas Alteradas De Filito. In: IX Congresso Brasileiro de Geologia de Engenharia, 1999, São Pedro. Anais... IX Congresso Brasileiro de Geologia de engenharia. São Pedro, 1999

GEOLOGICAL SOCIETY Engineering Group Working Party Report: Tropical Residual Soils: The Quarterly Journal of Engineering Geology, v.1, n.1, 1990

GIACHETI, H. L. Estudo experimental de parâmetros dinâmicos de alguns solos tropicais do Estado de São Paulo. 1991. 232p. Tese (Doutorado em Geotecnia) Escola de Engenharia de São Carlos, Universidade de São Paulo, São Carlos, 1991.

GIACHETI, H. L. Ensaios In Situ para Determinação de Parâmetros Geotécnicos do subsolo, Relatório de Pesquisa no Exterior, Fapesp, Proc. No. 97-0859-7, 4 vol, 1999.

GIACHETI, H. L. Os ensaios de campo na investigação do subsolo: Estudo e considerações quanto à aplicação em solos tropicais. 2001. 327p. Livre- Docência, Faculdade de Engenharia, Universidade Estadual Paulista, Bauru, 2001.

GIACHETI, H. L.; PEIXOTO, A. S. P.; MARQUES, M. E. M. Cone Penetration Testing on Brazilian Tropical Soils. In: Panamerican Conference on Soil Mechanics and Geotechnical Engineering, 12., 2003, Cambridge/MA/USA. Proceedings... v. 1. p. 397-402, 2003

GIACHETI, H. L.; PEIXOTO, A. S. P.; MONDELLI, G. Comparação entre resultados de ensaios de penetração com os cones mecânico e elétrico em solos tropicais. Solos e Rochas, v.27, n.2, p.191-200, 2004.

GIACHETI, H. L. Implantação e desenvolvimento do ensaio de piezocone sísmico para investigação de solos tropicais. Relatório final de pesquisa. Processo nº3/05024-3. Fundação de Amparo à Pesquisa do Estado de São Paulo, 2005.

GIACHETI, H. L.; PEIXOTO, A. S. P.; DE MIO, G. Cross-hole and SCPT tests in a tropical soil from Campinas-SP, Brazil. In: XIII Panamerican Conference on Soil Mechanics amd Geotechnical Engineering, 13., 2007, Proceedings... CD-Rom. P. 1-6. ETI. Isla Margarita, Venezuela, 2007.

GIACHETI, H. L. et al. Ensaios de Campo na Investigação Geotécnica e Geoambiental (artigo de palestra convidada). In: XIII Congresso Brasileiro de Mecânica dos Solos e Engenharia Geotécnica, 13., 2006, Curitiba. Anais...Cobramseg' 2006, Palestra. p. 1$25,2006 a$ 
GIACHETI, H. L. et al. Comparação entre Resultados de Ensaios Sísmicos Down-hole e Cross-hole no Campo Experimental da UNESP de Bauru. Anais... XIII Congresso Brasileiro de Mecânica dos Solos e Engenharia Geotécnica, Curitiba. v. 2. P.669-674, $2006 b$

GIACHETI, H. L.; De MIO, G. Seismic cone penetration tests on tropical soils and the ratio Go/qc. In: The 3 International Conference on Site Characterization, 2008, Taipei Taiwain. Proceedings... The 3 International Conference on Site Characterization, ISC’3. Londres: Taylor e Francis Group, 2008. v. 1. p. 1289-1295.

GIACHETI, H. L.; ROHM, S. A. Efeito da Sucção Matricial no Módulo de Cisalhamento Máximo de Um Solo Laterítico. In: Congresso Brasileiro de Geologia de Engenharia, 8., 1996, Rio de Janeiro/RJ. Anais... Congresso Brasileiro de Geologia de Engenharia. Rio de Janeiro/RJ, 1996. v. 1. p. 252-262.

GIDIGASU. M. D. Geomechanics in Tropical Soils: General Report. In: International Conference Geomechanics in Tropical Soils, 2., 1990, Singapure. Proceedings... II Int. Conf. Geomechanics in Tropical Soils, v.1, pp. 495-505.

HARA, A.; NIWA, M.; TANAKA, S. e BANNO, T. Shear Modulus and Shear Strength of Cohesive Soils, Soils e Foundation, JSSMFE, v.14, n.3, p. 1-24, 1974

HARDIN, B. O. The Nature of Stress-Strain Behavior of Soils, Proceedings... ASCE, Specialty Conference on Earthquake Engineering and Soil Dynamics, Pasadena/California, V.1, p. 3-90, 1978.

HANUMANTHARAO, C e RAMANA, C.V. Dynamic soil properties for microzonation of Delhi, India, Journal of Earth System Science, Vol.117, S2, pp.719-730, 2008

KIM, D.S., BANG, E. S. e KIM, W.C. Evaluation of various down-hole data reduction methods for obtaining reliable VS profiles. Geotechnical Testing Journal, v. 27, n. 6, pp.585-597, 2004

KARL, L.; HAEGEMAN, W.; DEGRANDE,G. Determination of the material damping ratio and the shear wave velocity with the Seismic Cone Penetration Test. Soil Dynamics and Earthquake Engineering, v. 26, PP.1111-1126, 2006

KEAREY, P. Geofísica de exploração, Michael Brooks, Ian Hill. Tradução de Maria Cristina Moreira Coelho-São Paulo: Oficina de Textos, 2009

LUNA, R.; JADI, H. Determination of Dynamic Soil Properties Using Geophysical Methods. In: International Conference on the Application of Geophysical and NDT Methodologies to Transportation Facilities and Infrastructure, 1., 2000, St. Louis, MO, Proceedings...v.3, p.1-15, 2000.

LUnNe, T., ROBERTSON, P.K. e POWELL, J. Cone Penetration Test in Geotechnical Practice, London, Blackie Academic Professional. 311 p, 1997. 
MACHADO, F. G. Estudo do Comportamento de Fundações submetidas a Vibrações de Máquinas. 2010. 149p. Dissertação (Mestrado em Engenharia Civil)-COPPE, Universidade Federal do Rio de Janeiro, Rio de Janeiro. 2008.

MAYNE, P. W. Enhanced Geotechnical Site Characterization by Seismic Piezocone Penetration Tests. Invited Lecture. In: Fourth International Geotechnical Conference, 4., 2000, Cairo University. Proceedings... Fourth International Geotechnical Conference p. 95-120, 2000.

MAYNE, P. W.; RIX, J. G. G máx $^{-q_{c}}$ relationships for clays. Geotechnical Testing Journal. v.16, n.1, p.54-60, 1993.

MONDELLI, G. Investigação geoambiental em áreas de disposição de resíduos sólidos urbanos utilizando a tecnologia do piezocone. 2004. 391p. Dissertação (Mestrado em Engenharia Geotécnica). Escola Politécnica, Universidade de São Paulo, 2004.

NEVES, L. F. S. Metodologia para determinação da eficiência do ensaio SPT através de prova de carga estática sobre o amostrador padrão. 2004. 111p. Dissertação (Mestrado em Geotecnia) - Escola de Engenharia de São Carlos, Universidade de São Paulo, São Carlos, 2004

NOGAMI, J. S. et al. Peculiarities of Geotechnical Behavior of Tropical Lateritic and Saprolitic Soils. Progress Report. Committee on Tropical Soils of the ISSMFE. Theme 1, Topic 1.1. Preliminary Remarks. ABMS.

NOGAMI, J. S. e VILliBOR, D. F. Pavimentação de Baixo Custo em Solo Lateríticos, São Paulo: Villibor, 1995.

PEDRINI, R. A. A. Desenvolvimento de Sistema para Realização de Sísmica Up-hole em Conjunto com Sondagem SPT. 2012. 127p. Dissertação (Mestrado em Geotecnia) Faculdade de Engenharia de Bauru, Universidade Estadual Paulista, Bauru, 2012

PEIXOTO, A. S. P. Estudo do ensaio SPT-T e sua aplicação na prática de engenharia de fundações. 2001. 510p. Tese (Doutorado em Geotecnia)-Universidade Estadual de Campinas, Campinas, 2001

REYNOLDS, J.M. An Introduction to Applied and Environmental Geophysics, Wiley, New York, 1997.

PRESA, E. P. $7^{\circ}$ Sessão Técnica: Solos Tropicais, Especiais (Expansivos, Colapsíveis e Dispersivos) e Pavimentos. In: CONGRESSO BRASSILEIRO DE MECÂNICA DOS SOLOS E ENGENHARIA DE FUNDAÇÕES, 10., Foz do Iguaçu. Anais... v. PósCongresso, p. 231-243, 1994.

ROBERTSON, M. D. Principles and parameters for the design of a portable shear wave source. 1986. 81p. Thesis (Degree of Bachelor of applied Science), Faculty of Applied Science Geological Engineering, University of British Columbia, Vancouver, 1986. 
ROBERTSON, P. K. et.al. Use of piezometer cone data. In: IN-SITU' 86-Use of In-situ testing in Geotechnical Engineering. 1986, Virginia, United States. Proceedings... InSitu-86, ASCE Specialty Conference, p. 1263-1280.

ROBERTSON, P. K. et al. Estimation of Sand Compressibility from Seismic CPT. In: 48th Canadian Geotechnical Conference. Proceedings... 48th Canadian Geotechnical Conference, Vancouver, BC, Canada, p. 441-448, 1995

ROBERTSON, P. K.; CABAL, K. L. Guide to Cone Penetration Testing for Geotechnical Engineering. Rio de Janeiro, Gregg Drilling e Testing Inc., 2009.

SAMARA, V.; MARTINS, J. A. A. Comparação entre Resultados de Ensaios Dinâmicos de Campo e Laboratório. In: Congresso Brasileiro de Mecânica dos Solos e Engenharia de Fundações, 8.,1986, Porto Alegre. Anais... Porto Alegre: VIII COBRAMSEF, 1986, v.1, p. 223-229

SCHEFFER, L. Desenvolvimento e aplicação do cone sísmico. 2005. 107p. Dissertação (Mestrado em Geotecnia)-Universidade Federal do Rio Grande do Sul, Universidade Federal do Rio Grande do Sul, Porto Alegre, 2005

SCHNAID, F. Ensaios de campo e suas aplicações à engenharia de fundações. São Paulo, Oficina de textos, 2000

SCHNAID, F.; CONSOLI, N. C. e AVERBECK, J. H. Aspects of cone penetration in natural weakly-cemented deposits, In: Geotechnical Site Characterization, 1998, Atlanta, Proceedings...vol. 2. p. 1159-1163, 1998.

SCHNAID, F.; NACCI, D. C.; CONSOLI, N.C. e FIALHO, A.S.. Caracterização Geotécnica e Parâmetros de Projeto na Ampliação do Aeroporto Internacional Salgado Filho. Solos e Rochas, V.24, n.2, p.155-170. 2001

SCHNAID, F., FAHEY, M.; LEHANE, B. In situ test characterization of unusual geomaterial. Keynote Lecture. In: Geotechnical e Geophysical Site Characterization. 2004, Millpress, Rotterdam. Proceedings... Millpress, Rotterdam: Ed. A. Viana da Fonseca e P.W. Mayne. v. 1, pp. 49-74, 2004.

SEED, H. B.; IDRISS, I.M. Soil moduli and damping factors for dynamic response analyses. Report No. EERC 70 - 10, Earthquake Engineering Research Center, Univ. of California, Berkeley, California. 1970

SHARMA, P. V. (1997): Environmental and engineering geophysics. Cambrige, University Press. 775pgs

STOKOE, K. H.; HOAR, R. S. Variables affecting in situ seismic measurements.In: Earthquake Engineering and Soil Dynamics. 1978. Proceedings...Conference Earthquake Engineering and Soil Dynamics., ASCE, Pasadena, v.2, pp. 919-939, 1978.

VELLOSO, D. A.; LOPES, F.R. Fundações, critérios de projeto, investigação do subsolo, fundações superficiais. Rio de Janeiro, Setor de Reprografia da COPPE, 1996 
Universidade Presbiteriana Mackenzie- Curso de Engenharia Civil- Graduação, Notas de aula, Estradas 2- Noções de Solos, Disponível em: < http://meusite.mackenzie.com.br/rmfortes/estradas2/1_NOCOES_DE_SOLOS.pdf < Acesso dia 03 de fevereiro de 2012

VITALI, O. M. P. Um novo sistema para realização de ensaios sísmicos down-hole, Relatório de Pesquisa, Iniciação Científica, 2009, PIBIC - CNPq.

VITALI, O. M. P. Desenvolvimento de um sistema para realização de ensaios sísmicos down-hole em conjunto com o CPT. 2011. 114p. Dissertação (Mestrado em Geotecnia) - Escola de Engenharia de São Carlos, Universidade de São Paulo, São Carlos, 2011

WU, S. Capillary Effects on Dynamic Modulus of Fine-Grained Cohesionless Soils. 1983. 226p. Thesis (PhD Thesis)-University of Michigan, Michigan, 1983 